\title{
MAIRA REZENDE FORMENTON
}

Eletroterapia e laserterapia no controle da dor e inflamação no período pós-operatório em cães submetidos a cirurgia de osteotomia de nivelamento do platô da tíbia: estudo prospectivo

\section{São Paulo}




\section{MAIRA REZENDE FORMENTON}

Eletroterapia e laserterapia no controle da dor e inflamação no período pós-operatório em cães submetidos a cirurgia de osteotomia de nivelamento do platô da tíbia: estudo prospectivo

Dissertação apresentada ao Programa de Pós-Graduação em Clínica Cirúrgica Veterinária da Faculdade de Medicina Veterinária e Zootecnia da Universidade de São Paulo para obtenção do título de Mestre em Ciências

\section{Departamento:}

Cirurgia

Área de concentração:

Clínica Cirúrgica Veterinária

Orientador:

Profa. Dra. Denise Tabacchi Fantoni

São Paulo 
Autorizo a reprodução parcial ou total desta obra, para fins acadêmicos, desde que citada a fonte.

\section{DADOS INTERNACIONAIS DE CATALOGAÇÃO-NA-PUBLICAÇÃO}

(Biblioteca Virginie Buff D’Ápice da Faculdade de Medicina Veterinária e Zootecnia da Universidade de São Paulo)

Formenton, Maira Rezende

Eletroterapia e laserterapia no controle da dor e inflamação no período pós-operatório em cães submetidos a cirurgia de osteotomia de nivelamento do platô da tíbia: estudo prospectivo / Maira Rezende Formenton. -- 2015.

109 f. : il.

Dissertação (Mestrado) - Universidade de São Paulo. Faculdade de Medicina Veterinária e Zootecnia. Departamento de Cirurgia, São Paulo, 2015.

Programa de Pós-Graduação: Clínica Cirúrgica Veterinária.

Área de concentração: Clínica Cirúrgica Veterinária.

Orientador: Prof $^{\mathrm{a}}$. Dr ${ }^{\mathrm{a}}$. Denise Tabacchi Fantoni.

1. Dor aguda. 2. Fisioterapia. 3. TPLO. 4. Laser. 5. TENS. I. Título. 


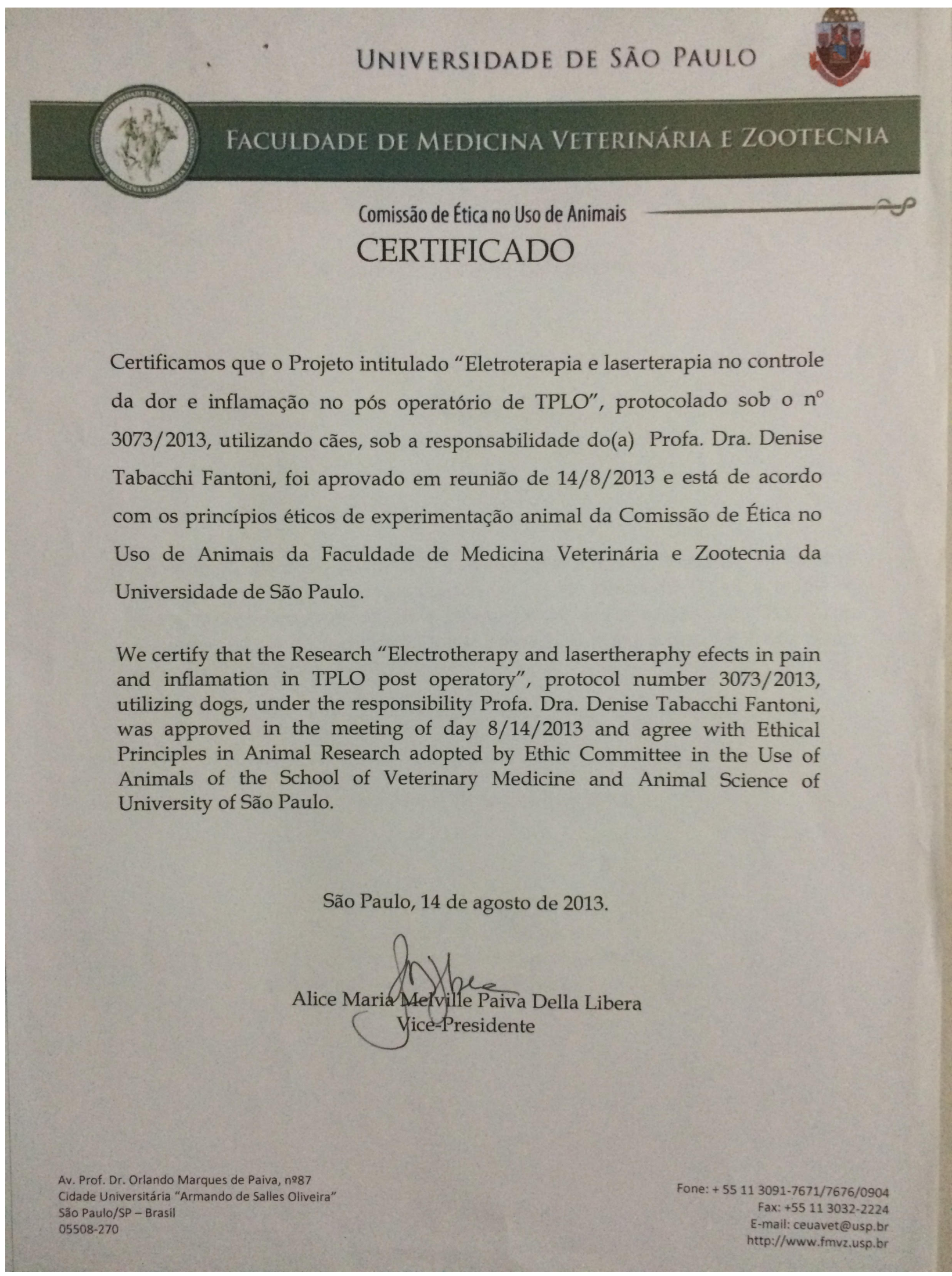




\section{FOLHA DE AVALIÇÃO}

Autor: FORMENTON, Maira Rezende

Título: Eletroterapia e laserterapia no controle da dor e inflamação no período pósoperatório em cães submetidos a cirurgia de osteotomia de nivelamento do platô da tíbia: estudo prospectivo

Dissertação apresentada ao Programa de Pós-Graduação em Clínica Cirúrgica Veterinária da Faculdade de Medicina Veterinária e Zootecnia da Universidade de São Paulo para obtenção do título de Mestre em Ciências

Data:

1

\section{Banca Examinadora}

Prof. Dr.:

Instituição: Julgamento:

Prof. Dr.:

Instituição: Julgamento:

Prof. Dr.:

Instituição: Julgamento: 


\section{Agradecimentos}

Agradeço imensamente à minha orientadora, Profa. Dra. Denise Tabacchi Fantoni, por abrir as portas para uma nova idéia, creditando-me tanta confiança durante o projeto, além do carinho, paciência, orientação e apoio em todos os momentos.

Ao Professor Dr. Cássio Ricardo Auada Ferrigno, por apoiar e possibilitar este projeto, além dos colegas membros do LOTC, Márcio, Renato, Fernanda, Viviane, Isis e Jaqueline, pelo suporte aos animais do projeto, além da ajuda do dia a dia o experimento.

Ao colega Alexandre Navarro de Sousa, por toda a orientação e por compartilhar sua experiência comigo.

Aos meus pais, por apoiarem-me e fornecerem-me o suporte para mais esta etapa de minha vida. Sem ajuda de vocês, tenham certeza, nunca seria possível esta grande realização, além de tantas outras mais. Amo vocês, sei que nosso caminho será eterno, é sempre um prazer e constante aprendizado estar ao lado de vocês.

Agradeço ao meu marido, pela sua compreensão nos momentos de ausência, e carinho nas dificuldades, por ser meu porto seguro nesta jornada.

Aos meus colegas da Fisioanimal, Camila, Wendel, Marina, Vanessa, Olinda, Carol, Bianca, Greysson, Carla, Teresinha Martins, e, ainda nossa colega do ADCP Roberta Figueiredo, agradeço por toda ajuda nestes dois anos.

À Katherine Palmina Colomba, eterna irmã, em quem sempre posso confiar. 
"Agradeço todas as dificuldades que enfrentei; não fosse por elas, eu não teria saído do lugar". Francisco Cândido Xavier 
Esta tese está de acordo com as seguintes normas, em vigor no momento desta publicação:

Referências: adaptado de International Committee of Medical Journals Editors (Vancouver).

Universidade de São Paulo. Faculdade de Medicina. Divisão de Biblioteca e Documentação. Guia de apresentação de dissertações, teses e monografias. Elaborado por Anneliese Carneiro da Cunha, Maria Julia de A. L. Freddi, Maria F. Crestana, Marinalva de Souza Aragão, Suely Campos Cardoso, Valéria Vilhena. $3^{a}$ ed. São Paulo: Divisão de Biblioteca e Documentação; 2011.

Diretrizes da Faculdade de Medicina Veterinária e Zootecnia da Universidade de São Paulo, 2013.

Abreviatura dos títulos dos periódicos de acordo com List of Journals Indexed in Index Medicus. 


\section{RESUMO}

FORMENTON, M. R. Eletroterapia e laserterapia no controle da dor e inflamação no período pós-operatório em cães submetidos a cirurgia de osteotomia de nivelamento do platô da tíbia: estudo prospectivo. [Electrotherapy and laser therapy on the control of pain and inflammation in the post operatory period after Tibial Plateau Leveling Osteotomy: a prospective study]. 2015. $109 \mathrm{f}$. Dissertação (Mestrado em Ciências) - Faculdade de Medicina, Universidade de São Paulo, São Paulo, 2015.

A fisioterapia é uma área medicina veterinária com um crescente interesse científico, da mesma forma que sua aplicação em pequenos animais. Em cães, entre as indicações da reabilitação está o pós-operatório ortopédico recente, em que os objetivos principais são o controle álgico e da inflamação, possibilitando um restabelecimento funcional precoce. Dentre as afecções ortopédicas, a ruptura de ligamento cruzado cranial é a mais comum na articulação fêmoro-tíbio-patelar em cães, sendo a técnica de nivelamento do platô tibial amplamente empregada. 0 presente estudo teve como objetivo a análise dos efeitos da eletroterapia e da laserterapia nos aspectos de dor e inflamação no pós-operatório recente da referida cirurgia ortopédica. Para esta avaliação, foi utilizada uma metodologia multimodal que incluiu escalas de dor unidimensional (ENV) e multidimensional (Glasgow), escalas de claudicação, análise cinética por baropodometria, análises perimétricas e termográficas da articulação. Vinte e quatro cães foram selecionados, sendo que efetivamente distribuídos e randomizados entre os grupos, 16. Dentre eles, 9 animais foram distribuídos no grupo Fisioterapia $(F)$ e 7 no grupo Placebo(P). Os animais do grupo fisioterapia foram submetidos a 6 sessões de eletroterapia associada à laserterapia, enquanto os animais do segundo grupo submetidos a 6 sessões placebo. Ambos os grupos foram avaliados antes da cirurgia, no pósoperatório previamente às sessões e ao término das 6 sessões. O grupo fisioterapia teve benefícios evidenciados nas análises seriadas das escalas de dor, com valores de $\mathrm{P}=0,0156$ e $\mathrm{P}=0,011$, nos quesitos de $E N V$ do avaliador e do cuidador respectivamente. Nas análises de dor através da escala de Glasgow, os valores de 
$\mathrm{P}=0.0272$ na análise seriada do grupo tratado, confirmando a melhora deste grupo em relação ao controle, onde $\mathrm{o}$ resultado de $P=0.4375$. Porém, não foram observadas diferenças nos quesitos de escalas de claudicação, avaliação de edema através de perimetria, e, inflamação através da termografia, em relação ao grupo placebo. Na avaliação cinética, houve diferença na análise dos parâmetros de impulso vertical, tendendo à melhora do grupo fisioterapia, porém na análise do pico de força vertical, que é mais sensível, não houve diferença entre os grupos. Houve também a necessidade de resgate analgésico em três animais do grupo placebo, sendo que nenhum animal do grupo Fisioterapia necessitou de resgate. Conclui-se que os animais submetidos às sessões de fisioterapia tiveram melhor evolução nos quesitos de dor, além de não necessitarem de resgate analgésico. Não houve influência da laserterapia no controle da inflamação e do edema através dos métodos avaliados. Evidencia-se a necessidade de mais estudos sobre os resultados das técnicas de fisioterapia quando aplicadas à rotina clínica veterinária, especialmente, com um maior número de amostras.

Palavras-chave: Dor aguda. Fisioterapia. TPLO. Laser. TENS. 


\begin{abstract}
FORMENTON, M. R. Electrotherapy and laser therapy on the control of pain and inflammation in the post operatory period after Tibial Plateau Leveling Osteotomy: a prospective study. [Eletroterapia e laserterapia no controle da dor e inflamação no período pós-operatório em cães submetidos a cirurgia de osteotomia de nivelamento do platô da tíbia: estudo prospectivo]. 2015. 109 f. Dissertação (Mestrado em Ciências) - Faculdade de Medicina, Universidade de São Paulo, São Paulo, 2015.
\end{abstract}

Physical therapy is a veterinary medicine area with a growing scientific interest, as its application in small animals. In dogs, among the physiotherapy indications is the recent orthopedic post operatory period, in order to control pain and inflammation to get an early functional recovery. Among the orthopedic diseases, the cranial cruciate ligament rupture is the most common disease in the femoral-tibio-patellar joint in dogs, and the tibial plateau leveling osteotomy, the to more common surgical approach. This study aimed to evidence the effects of electrotherapy and laser therapy on aspects of pain and inflammation in the post operatory of that recent surgery. For this evaluation were used multimodal methods that included unidirectional and multidirectional pain scales, lameness scales, kinetic analysis by baropodometry, perimeter and thermographic analysis. Twenty-four dogs were selected, which effectively distributed between the groups 16. Among them, 9 animals in physiotherapy group (F) 7 and the placebo group (P). Animals in the physical therapy group underwent 6 electrotherapy sessions associated with laser therapy, and the other group underwent 6 placebo sessions. Both groups were evaluated before surgery, in the post recent post operatory, before the treatment, and after 6 sessions. The physiotherapy group had benefits shown in the serial analysis of pain scales, with $P=0.0156$ and $P=0.011$ values for the treated group, for $E N V$ questions of the evaluator and the owner, respectively. The pain analysis by the Glasgow scale, the values of $P=0.0272$ in the serial analysis of the treated group, confirming the improvement of this group compared to the control group, which had the $P=0.4375$. Despite of these findings, no differences were observed in the categories of lameness scales, edema assessment through perimetry and thermography. In the kinetic evaluation, there were differences in the analysis of 
vertical impulse parameters, tending to improve of the physiotherapy group, but in the analysis of vertical peak force, which is more sensitive, there was no difference between groups. There was also the need for analgesic rescue medication in three animals of the placebo group. We conclude that animals subjected to actual physical therapy sessions had improvement in pain scores, and do not require analgesic rescue. There was no influence on the swelling or on the inflammation through the methods used in this study. Further studies are needed, especially with a larger number of animals.

Keywords: Acute Pain. Physical therapy. TPLO. Laser. TENS. 


\section{LISTA DE FIGURAS}

Figura 1 - Fluxograma simplificado do delineamento experimental......

Figura 2 - Demonstração do posicionamento da fita métrica para aferir o edema na articulação fêmoro-tibio-patelar.

Figura 3 - Mensuração do comprimento do passo para cálculo e controle da velocidade. $\mathrm{Na}$ parte de baixo da figura $\mathrm{O}$ controle do tempo de fase da parte superior da figura. Animal denominado M4 registrada, momento da avaliação pré-operatória no LAL, FMVZ/USP, São Paulo, 2015........

Figura 4 - Cão M4 durante a passagem sobre a plataforma de baropodometria Tekscan® no LAL, FMVZ/USP, São Paulo, 2014

Figura 5 - Análise do cão pela colocação de "caixas". Aa forças de reação ao solo são evidenciadas nos diferentes membros, sendo na figura, a caixa verde o MPE, vermelha MTE, roxa MPD e azul MTD. Observa-se a linha amarela a distância entre as pegadas do MPD do animal. Passagem registrada no LAL, FMVZ/USP, São Paulo, 2015.

Figura 6 - Registro e medidas do PFV, IV e TA em $\mathrm{N}$ do membro acometido, no caso do animal P4, em sua avaliação préoperatória. O membro acometido no caso desta representação é o gráfico roxo. Passagem registrada no Laboratório de Análise da Locomoção (LAL), FMVZ/USP, São Paulo, 2015.

Figura 7 - Foto termográfica com guias (horizontal, vertical e círculo) para análise feita do Software FLIR Tools (versão 2.1, Flyr Systems, 2014), coletada durante uma avaliação inicial do animal $F 1$, vista latero-lateral. Foto registrada no ADCP, FMVZ-USP, São Paulo, 2014.

Figura 8 - Foto termográfica com guias (horizontal, vertical e círculo) para análise feita do Software FLIR Tools (versão 2.1, Flyr 
Systems, 2014), coletada durante uma avaliação inicial do animal $F 1$, vista latero-lateral. Foto registrada no $A D C P$, FMVZ-USP, São Paulo, 2014

Figura 9 - Relatório emitido pelo Software FLIR Tools (versão 2.1, Flyr Systems, 2014) em que se obtém o dado do média de temperatura na região do círculo (Circle Average). No caso do animal F1, na vista médio lateral da avaliação inicial, a medida é de $37,8^{\circ} \mathrm{C}$

Figura 10 - Exemplo dos pontos de aplicação da laserterapia na articulação fêmoro-tíbio-patelar de um animal SRD na vista lateral. Evidencia-se a distância de um centímetro entre cada ponto. Em amarelo, estão destacados os pontos interarticulares, em vermelho, os pontos ao redor da patela. Em roxo, encontram-se os pontos no terço proximal da tíbia e, em verde, os pontos no terço distal do joelho. Foto registrada no ADCP, FMVZ-USP, São Paulo, 2015.

Figura 11 - Aplicação de eletroterapia com o aparelho Bioset ${ }^{\circledR}$ Physiotonus Four, São Paulo, Brasil. Nota-se a aplicação segmental de eletrodos na região lombar (bilateral) e aplicação local no joelho acometido. Imagem coletada durante a sessão do animal F9 no ADCP, FMVZ-USP, São Paulo, 2015

Figura 12 - Aplicação de eletroterapia com o aparelho Bioset $₫$ Physiotonus Four, São Paulo, Brasil. Detalhe da aplicação local no joelho acometido. Ressalta-se que a aplicação não deve ser feita na região do implante metálico, por isso, o uso nas proximidades do côndilos femorais. Imagem coletada durante a sessão do animal F9 no ADCP, FMVZUSP, São Paulo, 2015.

Figura 13 - Fluxograma detalhado do delineamento experimental. 


\section{LISTA DE TABELAS}

Tabela 1 - Média e desvio-padrão dos pesos dos animais $(n=16)$ nos diferentes grupos do estudo -FMVZ-USP-São Paulo2015

Tabela 2 - Proporção entre fêmeas e machos $(n=16)$ nos diferentes grupos do estudo - FMVZ-USP -São Paulo -2015

Tabela 3 - Raças dos animais incluídos no estudo e a incidência no estudo (\%)- FMVZ-USP -São Paulo - 2015

Tabela 4 - Necessidade de resgate analgésico entre os grupos $F$ e $P$ - FMVZ-USP -São Paulo - 2015.

Tabela 5- Médias e Desvios Padrão dos escores de ENV do cuidador e do avaliador nos momentos de T0 e TFFMVZ-USP -São Paulo -2015.

Tabela 6 - Tabela 10: Análise dos escores de claudicação das escalas 1 e 2 nos diferentes grupos e momentos do estudo - FMVZ-USP -São Paulo - 2015.

Tabela 7 - Média e desvio padrão dos valores de baropodometria de PFV(\%DA) nos diferentes grupos e momentos do estudo FMVZ-USP -São Paulo -2015

Tabela 8 - Valores obtidos pela baropodometria considerando o IV(\%PC*s) nos diferentes grupos e momentos do estudo FMVZ-USP -São Paulo - 2015 


\section{LISTA DE GRÁFICOS}

Gráfico 1 - Resultados dos escores de ENV do Avaliador e do Cuidador nas avaliações inicial e final - FMVZ-USP -São Paulo - 2015 .

Gráfico 2 - Resultados dos escores segundo a Escala de Glasgow aferidos pelo avaliador nos momentos T0 e TF - FMVZUSP -São Paulo - 2015.

Gráfico 3 - Valores de média e desvio padrão da medida de perimetria da articulação fêmoro-tibio-patelar nos momentos TPRE, TO e TF- FMVZ-USP -São Paulo 2015.

Gráfico 4 - Valores de baropodometria do parâmetro de PFV(\%DA) expressos em Newtons (N) - FMVZ-USP -São Paulo 2015

Gráfico 5 - Valores obtidos pela baropodometria considerando o IV(\%PC*s) expressos em N*s - FMVZ-USP -São Paulo 2015.

Gráfico 6 - Resultado das análises termográficas entre os grupos $\mathrm{Fe}$ $P$ nos momentos TPRE, T0 e TF- FMVZ-USP-São Paulo $-2015$ 


\section{LISTA DE SIGLAS E ABREVIATURAS}

$\begin{array}{ll}{ }^{\circ} \mathbf{C} & \text { Graus Celsius } \\ \text { \%PC } & \text { Porcentagem do peso corpóreo } \\ \text { ADCP } & \text { Ambulatório de Dor e Cuidados Paliativos } \\ \text { CPME } & \text { Corno posterior da medula dorsal } \\ \mathbf{c m} & \text { Centímetro } \\ \mathbf{c m}{ }^{2} & \text { Centímetro quadrado } \\ \text { ENV } & \text { Escala Numérica Verbal } \\ \text { EUA } & \text { Estados Unidos da América } \\ \text { F } & \text { Grupo Fisioterapia } \\ \text { FMVZ } & \text { Faculdade de Medicina Veterinária e Zootecnia } \\ \text { FRS } & \text { Forças de reação ao solo } \\ \text { FTP } & \text { Fêmoro-tibio-patelar } \\ \text { IV } & \text { Impulso Vertical } \\ \text { J } & \text { Joules } \\ \text { Kg } & \text { Quilogramas }\end{array}$

LASER Light Amplification by Stimulated Emission of Radiation

LAL Laboratório do Aparelho Locomotor

LOTC Laboratório de Ortopedia e Traumatologia Comparada

P $\quad$ Grupo Placebo 


\begin{tabular}{|c|c|}
\hline MA & Massachusetts \\
\hline $\mathbf{N}$ & Newtons \\
\hline $\mathbf{N}^{*} \mathbf{S}$ & Newton multiplicado por segundo \\
\hline nm & nanômetros \\
\hline mg & miligramas \\
\hline $\mathrm{mmHg}$ & milímetros de mercúrio \\
\hline MPE & Membro pélvico esquerdo \\
\hline MPD & Membro pélvico direito \\
\hline MTE & Membro torácico esquerdo \\
\hline MTD & Membro torácico direito \\
\hline PFV & Pico de Força Vertical \\
\hline RLCCr & Ruptura do ligamento cruzado cranial \\
\hline SNC & Sistema Nervoso Central \\
\hline TO & Avaliação inicial \\
\hline TENS & Trans Electrical Nerve Stimulation \\
\hline TF & Avaliação Final \\
\hline TPLO & Tibial Plateau Leveling Osteotomy \\
\hline TPRE & Avaliação pré-operatória \\
\hline vo & Via oral \\
\hline
\end{tabular}




\section{LISTA DE SÍMBOLOS}

$\begin{array}{ll}\% & \text { porcentagem } \\ * & \text { asterisco } \\ < & \text { menor } \\ > & \text { maior } \\ = & \text { igual } \\ \mathbf{I} & \text { mais ou menos } \\ \mathbf{0} & \text { graus }\end{array}$




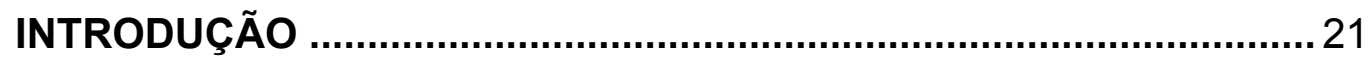

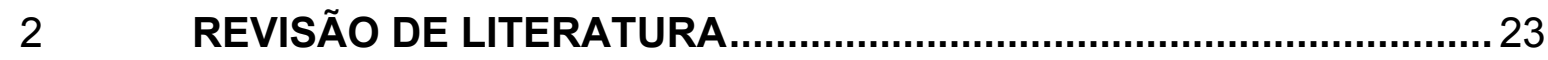

$2.1 \quad$ ELETROTERAPIA NO CONTROLE DA DOR ................................. 23

2.2 LASERTERAPIA NO CONTROLE DA DOR E INFLAMAÇÃO ...............25

2.3 DOR: CONCEITUAÇÃO E NOCICEPÇÃO MÚSCULO-ESQUELÉTICA .........27

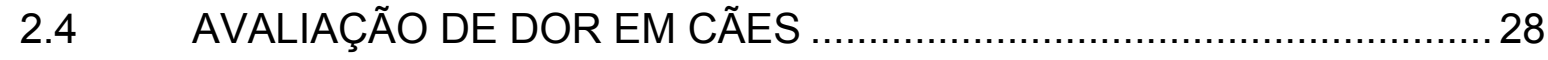

2.5 RUPTURA DE LIGAMENTO CRUZADO CRANIAL E OSTEOTOMIA DO NIVELAMENTO DO PLATÔ TIBIAL .............................................. 29

2.6 ANÁLISE CINÉTICA POR BAROPODOMETRIA................................... 31

2.7 TERMOGRAFIA NA AVALIAÇÃO DA DOR E DA INFLAMAÇÃO ..........32

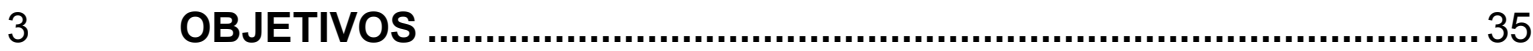

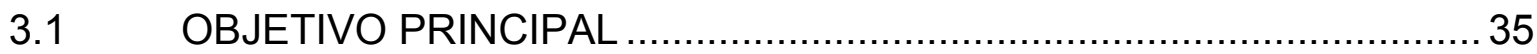

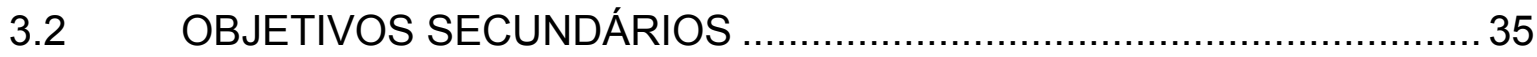

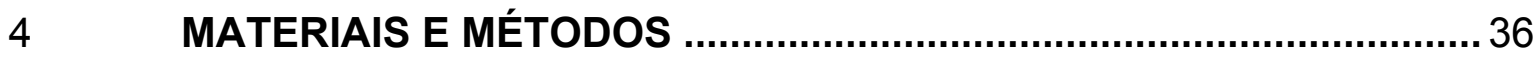

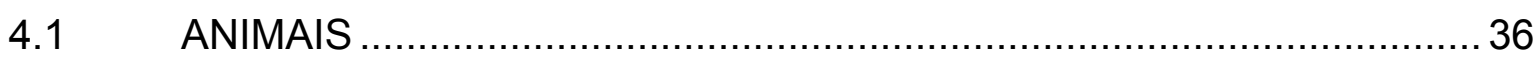

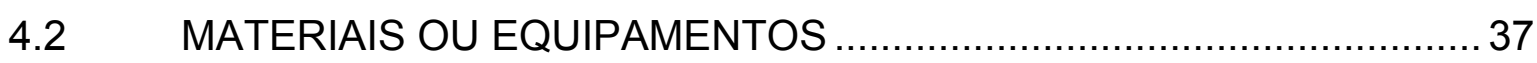

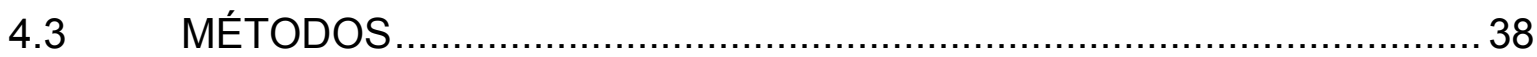

4.3.1 Delineamento experimental ............................................................. 38

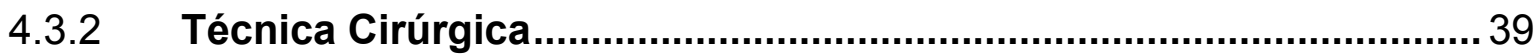

4.3.3 Técnica anestésica e analgesia pós operatória....................................39

4.3.4 Distribuição dos grupos e momentos da avaliação.......................... 40

4.3.5 Randomização e minimização dos animais ...................................... 40

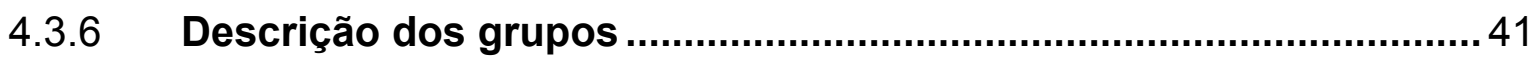

4.3.7 Métodos de Avaliação ........................................................................... 42

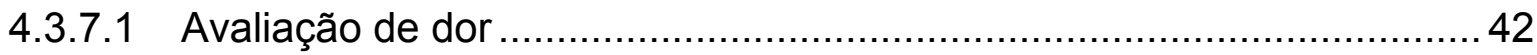

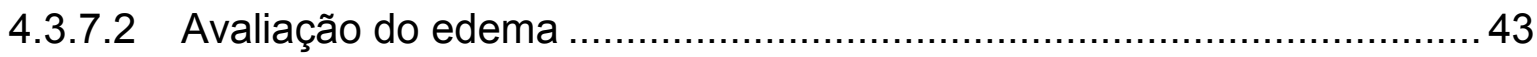

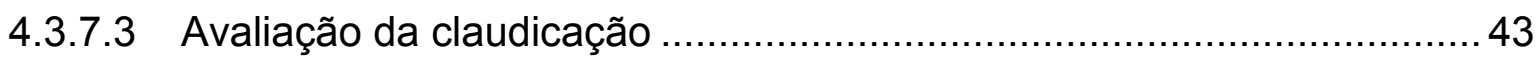

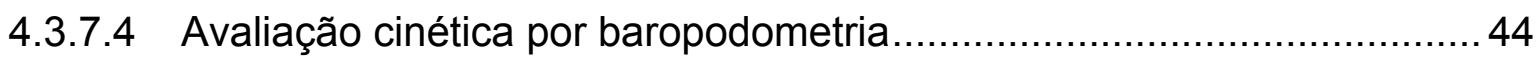

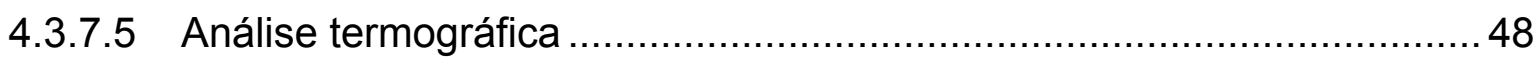

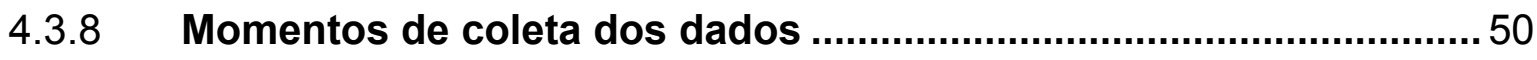

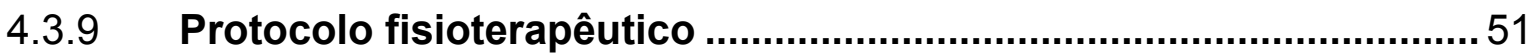




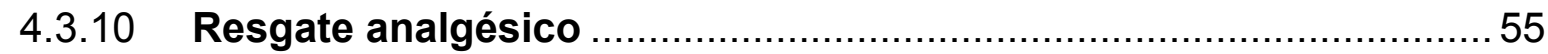

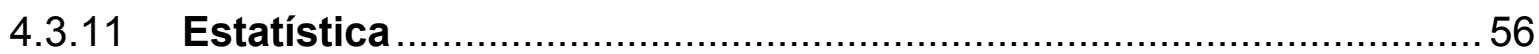

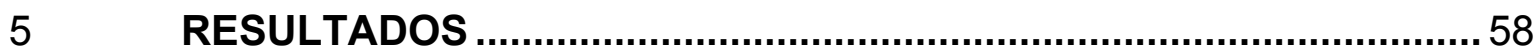

5.1 CARACTERÍSTICAS DEMOGRÁFICAS DOS ANIMAIS ....................... 58

5.2 NECESSIDADE DE RESGATE ANALGÉSICO .............................61

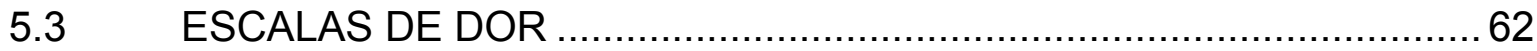

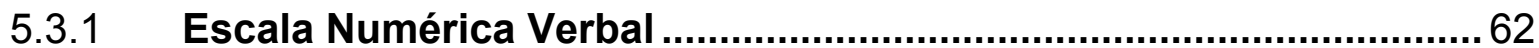

5.3.2 Escala de Dor Composta de Glasgow Modificada ............................. 64

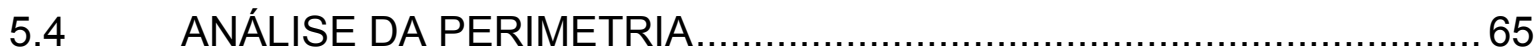

5.5 ESCALAS DE CLAUDICAÇÃO ................................................. 66

5.6 ANÁLISE CINÉTICA POR BAROPODOMETRIA ............................6 66

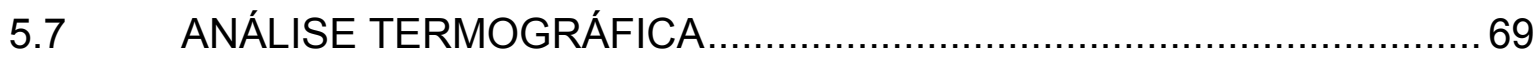

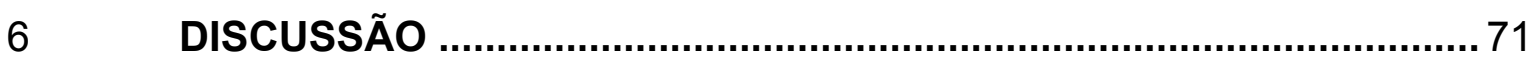

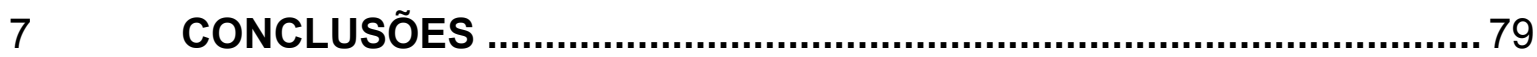

REFERÊNCIAS .............................................................................. 80

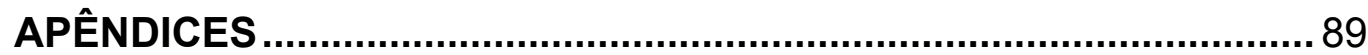

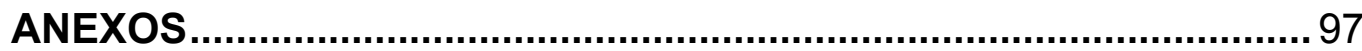




\section{INTRODUÇÃO}

A fisioterapia é uma área em ascensão dentro da medicina veterinária. Observa-se, nos últimos anos, um aumento significativo do número de profissionais que atuam especificamente com reabilitação, além do crescente volume de artigos científicos e pesquisas que ressaltam sua importância para os animais (MIKAIL, 2009; MILLIS; CIUPERCA, 2015).

Em cães, a fisioterapia tem como uma das indicações principais o auxílio na recuperação de cirurgias ortopédicas, melhorando o restabelecimento funcional dos pacientes após a intervenção cirúrgica (MILLIS, 2004). Esse restabelecimento é influenciado diretamente pelo grau de dor e inflamação (MILLIS, 2004), sendo que, a utilização da eletroterapia na forma de TENS (Estimulação Elétrica Nervosa Transcutânea) e da laserterapia têm destaque, apresentando fortes evidências cientificas na analgesia pós operatória (HENDERSON; LATIMER; MILLIS, 2015).

Considerando que a avaliação de dor em cães é complexa e dependente de um observador humano, para uma adequada quantificação e qualificação da dor deve-se utilizar a associação de mais de um método, considerada desta forma, uma avaliação multimodal (HELLYER et al., 2007; HAWKER et al., 2011). O cuidador do animal também desempenha um papel fundamental nesta avaliação, tornando-se um avaliador eficiente pela convivência com o paciente, e sua avaliação não deve ser negligenciada (BUFALARI et al., 2007). A partir destas considerações, a análise da dor, atualmente, é feita pela associação de escalas unidimensionais, como a Escala Numérica Verbal, e multidirecionais, como as de Glasgow e do Colorado (HELLYER; ROBERSON; FAILS, 2007; MICH; HELLYER; 2008; HAWKER et al., 2011). Essas escalas devem ser associadas a métodos complementares como a termografia (RING; AMMER, 2012) e a análise cinética (MOREAU et al., 2014), além de histórico clínico e exames de diagnóstico complementar (GAYNOR, 2008).

Abrangendo as análises complementares da dor, a análise cinética por

meio da baropodomentria mostra-se como padrão ouro para a avaliação da claudicação em cães após cirurgias ortopédicas (GILLETTE; ANGLE, 2008), e, com uma direta correlação à presença de dor (MOREAU et al., 2014). A análise baropodométrica confere indiretamente uma avaliação quantitativa da claudicação e possível correlação com dor em um membro onde há menor descarga de peso pelo 
animal (MOREAU et al., 2014; SOUZA; TATARUNAS; MATERA, 2014).

A termografia é outra técnica complementar à avaliação de dor que tem destaque na área médica (MEIRA et al., 2014). Consiste na captura de imagens térmicas do local acometido, apresentando alta sensibilidade ao aumento de temperatura e correlacionado por consequente à presença de inflamação e dor (DIAKIDES, 2002). É considerada um método de diagnóstico seguro e não invasivo, com a possibilidade de ser aplicada facilmente na medicina veterinária (MARINO; LOUGHIN, 2010).

A ruptura do ligamento cruzado cranial em cães é a afecção com maior incidência na articulação fêmoro-tíbio-patelar, causando dor, claudicação, diminuição da massa muscular e do uso do membro acometido (JOHNSON; JOHNSON, 1993). Dentre as técnicas cirúrgicas indicadas para o tratamento da afecção, a TPLO (Tibial Plateau Leveling Oeteotomy) é a mais utilizada atualmente, segundo Bergh et al. (2014). A técnica é descrita como uma osteotomia circular da tíbia proximal seguida da fixação com placa e parafuso, resultando na estabilização dinâmica do joelho do cão (SLOCUM; SLOCUM, 1993). No pós-operatório é indicado o controle da dor e restrição de atividade até a consolidação óssea (HOLZLER et al., 2005), além da fisioterapia (HENDERSON; LATIMER; MILLIS, 2015).

Tendo-se em vista que os estudos na medicina veterinária que analisaram o impacto da laserterapia e do TENS na recuperação pós-operatória de cães são raros, o presente estudo teve como objetivo avaliar de forma multimodal os efeitos destas modalidades da fisioterapia nos quesitos dor e inflamação, quando aplicados no pós-operatório recente de cães submetidos à TPLO. 


\section{REVISÃO DE LITERATURA}

\subsection{ELETROTERAPIA NO CONTROLE DA DOR}

A eletroterapia é a aplicação de uma corrente elétrica através da pele como forma de tratamento. Quando aplicada por meio da Estimulação Elétrica Nervosa Transcutânea (TENS), objetiva o controle da dor, sendo considerada uma terapia não invasiva e de fácil utilização, indicada para o controle ou alívio de dores com características agudas e/ou crônicas (SLUKA; WALSH, 2003).

Os mecanismos de analgesia da eletroterapia por TENS não estão totalmente elucidados, porém sugere-se que tenha ação por dois mecanismos: pelo bloqueio da passagem da dor no corno posterior da medula dorsal, através da teoria das comportas, e pela liberação de opióides endógenos. Quando embasamos a ação do TENS pela teoria das comportas proposta por Melzack e Wall (1985), o TENS causaria a estimulação das fibras grossas A-beta, provocando uma inibição da passagem do estímulo doloroso vindo das fibras finas A-delta e C, além da ativação de neurônios inibitórios na medula espinhal (JETTE, 1986; HOMSI et al., 2007). Já os opióides endógenos, como por exemplo as beta-endorfinas, seriam liberados pelo sistema nervoso central e responsáveis por parte dos efeitos de analgesia e pela sedação, relatada por pacientes durante a terapia (HOMSI et al., 2007).

O efeito causado no organismo pela aplicação da eletroterapia pode variar conforme a forma de aplicação e modulação da corrente aplicada (REZENDE et al., 2006). Para a aplicação da eletroterapia na forma de TENS, são utilizados os parâmetros de frequência (medidos em Hertz, Hz), intensidade (medidos em miliamperes, $\mathrm{mA}$ ) e duração de pulso (medidos em microssegundos, $\mu s$ ). Esses parâmetros referem-se à configuração do pulso elétrico emitido pelo aparelho, e devem ser configurados de acordo com a sensibilidade do paciente à corrente e do tipo de dor que apresenta (crônica ou aguda) (HOMSI et al., 2007).

Para a configuração dos parâmetros anteriormente citados, são utilizadas diversas modulações. Na abordagem do parâmetro de frequência dos pulsos, as frequências internacionalmente reconhecidas são: altas frequências (maior que 50 
$\mathrm{Hz}$ ), baixas frequências (menor que $10 \mathrm{~Hz}$ ) e "burst", que é a modulação de pulsos com alta frequência (50 a $160 \mathrm{~Hz}$ ) aplicados em "trens de pulsos" com baixa frequência (2 - 10 Hz) (JETTE, 1986; SLUKA; WALSH, 2003).

Agne (2013) recomenda que o ajuste destes parâmetros deve ser realizado a partir das características da dor apresentada pelo paciente. Para o caso de dores agudas, quando o paciente tem uma dor em que a movimentação é insuportável, recomenda-se o uso de frequências altas e baixos comprimentos de onda. Para pacientes com as características de dor crônica, na qual a movimentação é possível, porém a dor é presente e constante, devem-se utilizar frequências baixas e comprimentos de onda mais altos, se possível em modulação "burst" para a diminuição da impedância da pele e gerando um maior conforto e eficácia da terapia.

A regulagem da intensidade (amperagem) pode ser realizada de duas formas. A primeira é baseada na resposta sensorial (nível sensitivo ou sensório) do paciente, respeitando a tolerância do indivíduo, que deve sentir um leve formigamento confortável em altas frequências e tremores sem contração muscular em baixas frequências. A segunda forma de regular a intensidade é baseada na atividade motora (nível motor): a intensidade é aumentada a fim de produzir uma contração muscular visível (JETTE, 1986; SLUKA; WALSH, 2003).

Os mesmos parâmetros anteriormente descritos podem ainda ser configurados entre TENS convencional High (alta frequência, aplicada em baixa intensidade com sensação de intenso formigamento) e TENS Low (baixa frequência, aplicada em alta intensidade com contração muscular). Quanto à duração de pulso, pode ser classificado de 50 a $100 \mu$ s, quando aplicado TENS de alta frequência, e 100 a 400 s, em TENS de baixa frequência (JETTE, 1986; SLUKA; WALSH, 2003).

A melhor abordagem descrita para a aplicação do TENS é iniciar o tratamento na região da coluna que a inerva região acometida, ou seja, através dos dermátomos. No caso de hipergesia local, o uso dos dermátomos é imprescindível para o sucesso da aplicação da corrente. Se houver melhora do quadro, pode-se aplicar o TENS em região acima e abaixo do local acometido, sendo que, somente após a diminuição da dor, deve-se aplicar o TENS diretamente no local. Respeitando-se esta forma de aplicação, a exacerbação da dor pode ser evitada. Se esta exacerbação ocorrer, mesmo com o uso da aplicação em dermátomos, outro método de alívio da dor deve ser utilizado. Caso seja possível e não haja um grande aumento na sensibilidade, a aplicação pode ser realizada diretamente no local 
lesado desde o início, ou associado com a aplicação em dermátomos como anteriormente descrita (BERGER, 1999; AGNE, 2009; AGNE, 2013).

\subsection{LASERTERAPIA NO CONTROLE DA DOR E INFLAMAÇÃO}

Os aparelhos de emissão de LASER (Light Amplification by Stimulated Emission of Radiation - Amplificação da Luz por Emissão Estimulada de Radiação) são geradores de uma radiação eletromagnética, ou seja, uma fonte de luz ou de radiação de energia, com características específicas descritas inicialmente por Theodore Maiman em 1960. Estas características referem-se à monocromaticidade da energia luminosa gerada composta por um único comprimento de onda, à colimação e à coerência do feixe de energia luminoso emitido. O LASER foi classificado como sendo de alta potência, quando tinha potencial destrutivo e de baixa potência, sem potencial destrutivo (VINCK et al., 2003).

A laserterapia refere-se ao uso de lasers de baixa potência (Low Level Laser Therapy -LLLT) que desencadeia processos fisiológicos, como o aumento de metabolismo, imunomodulação local e microvasodilatação, sem elevar a temperatura tecidual (FARIVAR; MALEKSHAHABI; SHIARI, 2014). Por meio da laserterapia são descritos efeitos de redução da dor e do edema, modulação de processos inflamatórios, além da promoção da regeneração tecidual e nervosa, podendo ser indicado para afecções agudas ou de evolução crônica (ABERGEL, 1987; FARIVAR; MALEKSHAHABI; SHIARI, 2014). Para o emprego terapêutico, o laser, comumente utilizado, é o de baixa potência, dentre eles o infravermelho arseneto de gálio (Ga-As 904nm) ou gálio-alumínio-arsênio (Ga-Al-As 830nm) (VENANCIO et al., 2002; ROLA; DOROSZKO; DERKACZ, 2014).

O mecanismo de alívio da dor pela laserterapia ainda não está totalmente elucidado, porém sabe-se que a aplicação do LASER nos tecidos vivos diminui a velocidade de condução do nervo sensorial, tem ação anti-inflamatória local, influencia sobre a inervação autônoma e estimula respostas neurohumorais (serotonina, norepinefrina) do trato descendente de inibição. Além disso, estimula direta ou indiretamente a liberação de endorfinas, diminui a síntese de prostaglandinas e a potencialização das bradicininas, evita a redução do limiar de 
excitabilidade dos receptores da dor, levando ao equilíbrio da condução nervosa (CHENG, 1987; BJORDAL et al., 2006b; PRYOR; MILLIS, 2015). Além destes fatores, a ação analgésica esperada pela laserterapia também é promovida pela redução da inflamação local, com consequente reabsorção de exsudatos e eliminação de catabólitos, que sensibilizariam os receptores dolorosos (SILVA et al., 1998).

O laser também interfere na condução elétrica durante a transmissão do estímulo da dor mantendo o gradiente iônico, ou seja, o potencial de membrana e evitando que a mesma se despolarize (BRADLEY, 1996; SILVA et al., 1998). Artigos mostram que as velocidades de condução nervosa são cerca de $1 \%$ mais lentas com aplicação de um laser de He-Ne e 1\% mais rápidas com a luz branca (KRAMER; SANDRIN, 1993).

Em nível celular, o laser tem efeitos bioquímicos, bioelétricos e bioenergéticos, ocasionando um incremento no metabolismo, acelerando a proliferação e a maturação celular além da diminuição de mediadores inflamatórios, acelerando, desta forma, o processo de cicatrização como um todo (BOURGUIGNON et al., 2005; SILVA et al., 2007). A estimulação de fotorreceptores intracelulares pelos fótons emitidos na laserterapia causa incremento da produção de adenosina trifosfato, aumento da síntese de colágeno e de fatores de crescimento, que levam à aceleração do metabolismo celular anteriormente citado e do mecanismo de mitose (KREISLER et al., 2003; POSTEN et al., 2005). Já ações antiedematosas ocorrem devido à ativação da microcirculação e microvasodilatação, que altera a pressão hidrostática capilar e promove a reabsorção do linfa que está acumulada no interstício celular. Isso auxilia a eliminar o acúmulo de metabólitos, influenciando também no processo de resolução da inflamação (CAMELO, 2007).

$\mathrm{Na}$ literatura científica, não há um consenso sobre a dosificação da laserterapia para diferentes patologias. Diversos trabalhos têm o intuito de se alcançar um consenso acerca da intensidade, tempo de exposição e local de aplicação do laser, porém muitos não seguem padrões científicos aceitos para pesquisas clínicas (VENANCIO et al., 2002; PRYOR; MILLIS, 2015).

A dose recomendada em laserterapia para promover aumento no número de fibroblastos e consequentemente de fibras colágenas, incremento vascular e repitelização deve situar-se entre 1 e $5 \mathrm{~J} / \mathrm{cm}^{2}$ (ANNEROTH, 1988). Para o controle da dor em cães, recomenda-se uma dose de 2 a $6 \mathrm{~J} / \mathrm{cm}^{2}$ no caso de dor 
aguda, e de 4 a $8 \mathrm{~J} / \mathrm{cm}^{2}$, para o controle da dor crônica. Para a obtenção do efeito anti-inflamatório, recomenda-se em cães o uso de 1 a $6 \mathrm{~J} / \mathrm{cm}^{2} \mathrm{em}$ processos agudos e 4 a $8 \mathrm{~J} / \mathrm{cm}^{2}$ em processos crônicos (MILLIS; SAUNDERS, 2014).

\subsection{DOR: CONCEITUAÇÃO E NOCICEPÇÃO MÚSCULO-ESQUELÉTICA}

Segundo a Associação Internacional para o Estudo da Dor (IASP), "A dor é uma experiência sensorial e emocional desagradável que é associada ou descrita em termos de lesões teciduais" (TEIXEIRA; FIGUEIRÓ, 2001).

A fisiopatologia da dor ainda é estudada, porém sabe-se que a dor musculoesquelética é causada pela ativação dos receptores periféricos, que, em consequência, leva à despolarização de fibras nervosas do tipo Aठ e tipo $C$, gerando um impulso nervoso na via aferente. Estes estímulos recebidos no sistema nervoso periférico são conduzidos à substância cinzenta no corno posterior da medula espinhal (CPME) onde sofrem modulação por inibição ou facilitação na condução nervosa. (BOWSHER, 1957; WALL; GUTNICK, 1974; MENSE, 1994; MENSE, 1997; TEIXEIRA, 1999).

Fibras de projeção cranial transferem as informações do CPME ao sistema nervoso central (SNC) onde são interpretadas e decodificadas. Na dor aguda, há ativação do cortéx sensitivo-motor bilateralmente, resultando em uma alteração cognitiva motora de maior intensidade que uma experiência emocional. Já a dor crônica ativa predominantemente o córtex cerebral e cíngulo direito, independentemente do local de origem da lesão, levando a um consequente componente emocional na interpretação da dor crônica (YAKSH; AIMONE, 1989; TEIXEIRA, 1999; TEIXEIRA, 2001).

Os nociceptores e as terminações nervosas das fibras dos grupos III (A delta) e IV (fibras C) estão presentes nos tendões, fáscias, cápsulas e aponeuroses do sistema musculoesquelético, além da musculatura. Estes nociceptores são ativados por diversos estímulos químicos, térmicos e/ou mecânicos. (ZIMMERMANN, 1988). 
Aproximadamente $40 \%$ das unidades sensitivas musculares são ligadas à nocicepção, e apenas $20 \%$ reativas à atividade de contração muscular. Outros 30\% destas fibras recebem impulsos de receptores mecânicos de baixo limiar e envolvem-se com a sensação de pressão, sendo que $10 \%$ estão ligadas à termorregulação, reagindo à estimulação térmica. Nos tendões os nociceptores aparentam estar localizados juntamente à inserção muscular, e a densidade de nociceptores em ligamentos é relativamente pequena, quando comparado ao número presente em musculatura e cápsulas articulares (MENSE; SCHMIDT, 1977; TEIXEIRA, 1999).

Os nociceptores articulares são estimulados por pressão e por movimentação articular. Aqueles receptores que apresentam um elevado limiar são ativados apenas por estímulos nociceptivos, ou movimentos que excedem a capacidade de movimentação articular, além de unidades reativas à pressão intensa. Outros receptores reagem apenas ao movimentos normais articulares, sendo classificados como receptores silenciosos (MENSE; SCHMIDT, 1977; TEIXEIRA, 1999).

\subsection{AVALIAÇÃO DA DOR EM CÃES}

A avaliação da dor nos animais depende de um observador humano, consequente dos animais não poderem verbalizar a sensação dolorosa (HELLYER; ROBERSON; FAILS, 2007). Essa avaliação é subjetiva, e considerando que as escalas de avaliação de dor, usualmente utilizadas pela medicina humana, não são eficazes quando transpostas diretamente para diferentes espécies, a avaliação de dor torna-se um desafio na veterinária (HELLYER; ROBERSON; FAILS, 2007; ALMEIDA et al., 2010).

Mesmo com profissionais experientes e treinados na avaliação de dor, esta mensuração pode ser imprecisa, devido ao fato do comportamento do animal ser alterado no hospital ou clínica, fora de seu ambiente habitual. O cuidador do animal assume, desta forma, um papel importante na avaliação da dor, antes e durante o tratamento estabelecido (BUFALARI et al., 2007).

Devido à complexidade da dor e à dificuldade de avaliação nos animais, a 
associação de métodos deve ser realizada (GAYNOR, 2008). Sistemas simples e unidimensionais, como as escalas numéricas verbais, não são ideais, e devem estar associados a sistemas multidimensionais, como as escalas compostas, na tentativa de quantificar a dor percebida e minimizar as limitações e subjetividade da avaliação (HELLYER et al., 2007; HAWKER et al., 2011). Dentre as escalas unidimensionais mais utilizadas destacam-se a Escala Descritiva Simples, Escala de Avaliação Numérica, Escala Numérica Verbal e Escala Análoga Visual. Dentre as multidimensionais ou compostas, as mais utilizadas são a Escala de dor da Universidade de Melbourne, Escala Composta de Glasgow e a Escala de dor aguda canina da Universidade do Estado do Colorado (HELLYER et al., 2007; HELLYER; ROBERSON; FAILS, 2007; MICH; HELLYER, 2008).

Para que uma escala de avaliação seja considerada adequada, deve ser de fácil entendimento, a qual até mesmo pessoas leigas ou com pouca experiência na avaliação da dor possam utilizar. Em um estudo realizado por Barletta et al. (2015), comparou-se a avaliação de dois grupos de avaliadores em duas escalas de dor, uma Escala Análoga Visual e uma forma reduzida adaptada da Escala Composta de Glasgow. Neste estudo comparou-se a avaliação de graduandos dos primeiro e segundo anos da faculdade de medicina veterinária, com a avaliação de anestesistas de animais dentro da unidade de terapia intensiva do hospital. Os resultados mostraram que os estudantes obtiveram pontuações diferentes dos anestesistas, provavelmente pela falta de experiência na área, porém, ainda assim, foram capazes de utilizar as escalas facilmente.

\subsection{RUPTURA DE LIGAMENTO CRUZADO CRANIAL (RLCCR) E OSTEOTOMIA DE NIVELAMENTO DO PLATÔ DA TÍBIA (TPLO)}

A ruptura do ligamento cruzado cranial é umas das afecções de maior incidência na articulação fêmoro-tibio-patelar (FTP) dos cães, e, consequentemente, considerada uma das principais causas para doença articular degenerativa neste local (JOHNSON; JOHNSON, 1993). 
Esta lesão do ligamento ocorre quando forças articulares internas ou externas excedem a força de tensão do ligamento íntegro ou enfraquecido por doença articular prévia. O diagnóstico desta afecção é baseado em testes de instabilidade articular, como o de compressão tibial e de gaveta. Porém, exames complementares, como raios-X e ressonância magnética, podem ser considerados principalmente para avaliação do grau de degeneração articular. Preconiza-se para a RLCCr o tratamento cirúrgico, com a descrição de diversas técnicas, dentre as quais técnicas intra-articulares como técnicas de reparação do ligamento, extra articulares como a sutura fabelo-tibial e, recentemente, as osteotomias corretivas como o avanço da tuberosidade da tíbia (TTA) e a osteotomia de nivelamento do platô da tíbia (TPLO) (VASSEUR, 2003; PIERMATTEl et al., 2006; COMERFORD et al., 2011).

As técnicas de osteotomia corretiva, como a TPLO, foram desenvolvidas a partir estudos de biomecânica do joelho do cão. Estas técnicas visam a estabilizar o joelho, neutralizando a força de translação tibial cranial (thrust tibial cranial), ao invés de restringir o movimento da tíbia (SLOCUM; SLOCUM, 1993; WARZEE et al., 2001). A técnica de TPLO consiste em uma osteotomia circular da tíbia proximal, com rotação caudal e distal do platô tibial e posterior fixação com placa e parafuso (SLOCUM; SLOCUM, 1993). Por meio desta técnica, há a estabilização dinâmica da articulação, neutralizando o anteriormente referido thrust tibial e tornando o teste de compressão tibial negativo. Em contrapartida, o teste de gaveta permanecerá positivo, considerando que não houve a estabilização estática da articulação (PIERMATTEl et al., 2006). No pós-operatório os cuidados envolvem o controle da dor e restrição de atividade até a consolidação óssea, considerando-se que o apoio precoce do membro operado é um dos benefícios da técnica (HOLZLER et al., 2005).

A fisioterapia pode auxiliar no controle da dor e na recuperação muscular em cães após a TPLO. Um estudo realizado por Monk et al. (2006), comparou dois grupos no pós-operatório de TPLO: um foi submetido a três sessões semanais de fisioterapia e o outro apenas a exercícios domiciliares. Os animais do grupo fisioterapia apresentaram uma perimetria muscular aproximada entre os membros (operado e contralateral) quando avaliados após três semanas do procedimento cirúrgico, e, consistentemente, maior do que o grupo que realizou apenas exercícios em casa. A amplitude de movimento dos animais do grupo fisioterapia também foi 
significativamente maior que o grupo controle, tanto as 3 quanto as 6 semanas de pós-operatório. Não houve diferença entre os grupos na questão de claudicação e descarga de peso.

Na veterinária, não há estudos sobre o impacto da dor no pós-operatório de TPLO, porém em humanos, Vasconcelos et al. (2011) fez um estudo avaliando a presença de dor na região anterior do joelho, em pacientes submetidos a técnicas reconstrutivas de ligamento cruzado anterior. Em avaliação, após dois anos da intervenção cirúrgica, detectou-se dor em $28 \%$ dos pacientes em uma intensidade média de 2,8/10 e, quando presente, ocasionava um efeito deletério nos escores funcionais avaliados. Neste estudo, evidenciou-se que a dor, mesmo quando em mínima intensidade, prejudica no resultado da reconstrução do ligamento cruzado anterior e tem impacto negativo na funcionalidade do membro mesmo após dois anos da intervenção.

Outro aspecto deletério da presença de dor no pós-operatório de reconstrução de ligamento cruzado é o retardo do início ou execução de exercícios de fortalecimento. Brown et al. (1997) avaliaram pacientes humanos no pósoperatório de reconstrução de ligamento cruzado anterior via artroscopia nos cinco primeiros dias. O pico de intensidade de dor foi descrito no segundo dia, sendo que ao final dos cinco dias, os pacientes que apresentaram uma maior pontuação nos escores referentes à dor tinham maior dificuldade em elevação ativa do membro. Sugeriu-se que a dor inibe a função de elevação ativa e pode, portanto, retardar uma reabilitação precoce e o retorno funcional adequado.

\subsection{ANÁLISE CINÉTICA POR BAROPODOMETRIA : PICO DE FORÇA VERTICAL E IMPULSO VERTICAL}

A avaliação subjetiva do passo através da inspeção é o método mais frequentemente empregado na rotina clínica. Porém, esta análise, baseada em aspectos visuais do ciclo do passo, pode ser difícil e pouco sensível, às vezes até mesmo para estudiosos do tema. Isso ocorre pelo fato da habilidade humana em perceber detalhes do passo é limitada, percebendo poucos aspectos do ciclo do passo ao mesmo tempo. Detalhes minúsculos, como a rotação do joelho em alguma 
fase do passo, podem passar despercebidas. Consequentemente, observamos que o humano tem a capacidade de observar o animal em movimento, mas não consegue captar as forças envolvidas no passo ou até mesmo identificar uma atividade neuromuscular específica envolvida no movimento do membro (GILLETTE; ANGLE, 2008).

Em decorrência da necessidade de métodos acurados para análise biomecânica do movimento, a análise cinética do passo foi desenvolvida e, atualmente, é empregada em cães, cavalos e outras espécies (DECAMP, 1997). Com o objetivo de avaliar a claudicação através de parâmetros precisos como o Pico de Força Vertical (PFV) e o Impulso Vertical (IV), a análise cinética pode ser feita por meio de plataformas de pressão de alta sensibilidade, também chamadas de plataformas de baropodometria (FANCHON; GRANDJEAN, 2007; SOUZA et al., 2014, 2015).

Os parâmetros supra citados têm sido usados para avaliar os resultados de intervenções ortopédicas em cães. Um estudo Au et al. (2010) avaliou cães com RLCCr submetidos à TPLO ou à técnica de sutura fabelo-tibial. Neste estudo, foi realizada a padronização da fisioterapia pós operatória, e, como método de avaliação, foi utilizada a plataforma de baropodomentria, além de outros parâmetros. Neste estudo, a análise cinética mostrou que os animais submetidos à TPLO tiveram melhores resultados aos 6 meses e após 2 anos pós-operatório, porém, estatisticamente, não diferiram do grupo que foi submetido à sutura fabelo-tibial.

$\mathrm{Na}$ área de reabilitação, a análise cinética mostra ser importante método para avaliação complementar dos pacientes, e utilizada com frequência associada a outros métodos como as escalas de dor e a perimetria (MARSOLAIS; DVORAK; CONZEMIUS, 2002). Além disso, a mensuração das forças de reação ao solo tem mostrado uma correlação válida com a presença de dor e diminuição do apoio do membro, tornando-se um medida objetiva para a avaliação indireta da dor (MOREAU et al., 2014).

\subsection{TERMOGRAFIA NA AVALIAÇÃO DA DOR E INFLAMAÇÃO}

A termografia surgiu durante a II Guerra Mundial, como um instrumento 
para formar imagens térmicas abaixo do espectro visível, com alta sensibilidade. Em 1957, após o término da guerra, o médico canadense Ray Lawson utilizou uma câmera infravermelha em uma paciente com tumor mamário, observando-se um aumento de temperatura na pele correspondente ao local do tumor (CHRISTANSEN; GEROW, 1990). Em 1959, a imagem ainda era precária e, frequentemente, utilizavam-se aparelhos de uso militar nos experimentos, porém, rapidamente, houve a ampliação da tecnologia para diversas áreas de interesse, principalmente para a medicina. Conferências médicas nos Estados Unidos em 1964 e na Alemanha em 1966 consolidaram o uso da termografia como um método diagnóstico complementar (RING, 1998).

A partir do desenvolvimento da termografia, houve a necessidade de criar um índice que correlacionasse a temperatura e a inflamação. Ring et al. em 1988, baseados em um processamento matemático, desenvolveram este índice por meio do uso de áreas isotérmicas em intervalos de $0,5{ }^{\circ} \mathrm{C}$ divididas pela área analisada (RING, 1998; DIAKIDES, 2002). Seguindo-se pela década de 90, houve o incremento tecnológico com o surgimento de novas câmeras, com maior resolução e precisão, possibilitando também filmagens e a fácil reprodução das imagens coletadas (ANBAR, 1998).

A termografia, quando utilizada na área médica, mostra ser um método não invasivo de diagnóstico, confortável ao paciente e sem a emissão de qualquer radiação, possibilitando seu uso como um complemento aos demais exames, inclusive em cães (MARINO; LOUGHIN, 2010). O infravermelho captado pela câmeras utilizadas na área médica estão nas faixas entre $7 \mu \mathrm{m}$ e $12 \mu \mathrm{m}$, sendo que a pele humana emite um intervalo de 9,4 $\mu \mathrm{m}$ (CHRISTIANSEN; GEROW, 1990).

As alterações nas imagens térmicas mostram disfunções vasomotoras, podendo, assim, serem aplicados para avaliar alterações em músculos, tendões, ligamentos, cápsulas articulares, articulações, pele e tecido subcutâneo, além de órgãos (FARRIS, 1990). Na ortopedia humana, doenças associadas à inflamação nas articulações como artrite reumatóide, osteoartrite e bursite, além de alterações em ossos e tecidos moles podem ser caracterizadas por hipertermia local (RING, 1998; RUSCH et al., 2000). A análise de diferenças entre temperaturas confere à termografia a capacidade de distinguir quadros inflamatórios agudos ou crônicos (VARJÚ et al., 2004). Ainda na área médica, a termografia é o exame mais indicado para diagnóstico da Síndrome de Dor Complexa Regional. Alterações e mudanças 
de temperatura na extremidade afetada podem ser atribuídas a alterações na intensidade da dor por respostas do sistema nervoso simpático (WEISS, 1994; HARWAY, 1997). 


\section{OBJETIVOS}

\subsection{OBJETIVO PRINCIPAL}

O objetivo do presente estudo foi avaliar os efeitos da eletroterapia por meio do emprego de TENS, associada à laserterapia, no controle da dor e da inflamação durante o período pós-operatório recente da cirurgia de osteotomia de nivelamento do platô da tíbia (TPLO).

\subsection{OBJETIVOS SECUNDÁRIOS}

Avaliar a precisão da análise termográfica na detecção da inflamação no pós-operatório de cirurgias ortopédicas.

Avaliar os efeitos da laserterapia como um tratamento adjuvante do edema e inflamação secundários à uma intervenção cirúrgica. 


\section{MATERIAIS E MÉTODOS}

\subsection{ANIMAIS}

Foram selecionados animais encaminhados ao Laboratório de Ortopedia e Traumatologia Comparada (LOTC), do Departamento de Cirurgia da Faculdade de Medicina Veterinária e Zootecnia da Universidade de São Paulo (FMVZ-USP). Foram recrutados cães de ambos os sexos e com histórico de ruptura de ligamento cruzado cranial, candidatos à técnica de TPLO (Osteotomia de Nivelamento do Platô da Tíbia).

\subsubsection{Critérios de Inclusão}

Os animais foram selecionados a partir dos seguintes critérios de inclusão:

1. Cães, candidatos à cirurgia para ruptura de ligamento cruzado cranial, preferencialmente unilateral, em que se utilizaria a técnica de TPLO.

2. Animais entre 15 e $60 \mathrm{~kg}$.

3. Proprietários que consentiram e assinaram o Termo de Consentimento Livre e Esclarecido (Anexo A).

\subsubsection{Critérios de exclusão}

Os termos de exclusão dos animais foram considerados:

1. Histórico ou suspeita de neoplasia em qualquer parte do corpo (CSP, 1991);

2. Animais com idade inferior a 1 ano, quando de raças pequenas, e médias e $1 \frac{1}{2}$ ano em raças grandes e gigantes (OLIVEIRA et al., 2012);

3. Animais com doenças ou síndromes clínicas graves (ex. cardiopatias graves, 
hepatopatias, doença renal aguda ou crônica descompensada, afecções de pele descontroladas);

4. Animais obesos com índice de condição corpórea 8, 9 ou 10 (considerando uma escala de 0 a 10, onde "0" seria o animal caquético e "10" o animal obeso);

5. Animais agressivos;

6. Animais cujo cuidador não poderia trazer o animal nas sessões e retornos;

7. Animais com falhas pós operatórias nos implantes, complicações pósoperatórias tais como: mal posicionamento dos implantes, traumas pós-operatórios que afetassem a cirurgia, desenvolvimento de doenças que impedissem o animal de receber as medicações ou comparecer às sessões, animais com indícios de contaminação cirúrgica ou infecção no local dos implantes;

8. Animais com doenças neurológicas (ex. neuropatias periféricas, déficit proprioceptivo ou sensorial, convulsões), ou outros problemas ortopédicos associados no membro (ex. luxação patelar, luxação coxofemoral, artrites imunomediadas ou infecciosas).

\subsection{MATERIAIS OU EQUIPAMENTOS}

Foram empregados os seguintes equipamentos:

1. Aparelho de eletroterapia (Bioset $®$ Physiotonus Four, São Paulo, Brasil disponível no Anexo B ), Certificado de Calibração disponível no anexo C;

2. Aparelho de laserterapia de baixa potência (Bioset $\circledast$, caneta de $830 \mathrm{~nm}$, modo contínuo, potência $40 \mathrm{mV}$, Arseneto de Gálio Alumínio, São Paulo, Brasil - disponível no Anexo D), Certificado de Calibração disponível no anexo $\mathrm{E}$;

3. Termógrafo (Flir Systems $®$, modelo Thermacam $T 400 \AA$ com sensitividade térmica de 0,05 graus Celsius);

4. Plataforma de baropodometria (7100 QL Virtual Sensor 3 Mat System, Tekscan Inc. South Boston, MA, EUA);

5. Fita métrica plástica de 30 centímetros. 


\subsection{MÉTOdOS}

\subsubsection{Delineamento Experimental}

Após a seleção, os animais do estudo foram submetidos à avaliação pré operatória (APRE), a ser descrita no item "Parâmetros avaliados". Em seguida foram encaminhados para a cirurgia de estabilização da articulação fêmoro-tíbio-patelar, onde realizou-se a anestesia e o procedimento cirúrgico de TPLO, seguindo com o pós-operatório recomendado pelo cirurgião.

Após a cirurgia, os animais foram randomizados e reavaliados em uma avaliação inicial (T0). Em seguida, encaminhados a realização de sessões em dois grupos : um foi submetido à sessões de fisioterapia real e outro a sessões placebo. Ao término de 6 sessões, realizadas em um período de duas semanas, os animais foram avaliados em uma avaliação final (TF). Os procedimentos do presente estudo estão resumidos no fluxograma da figura 1 :

Figura 1 - Fluxograma simplificado do delineamento experimental

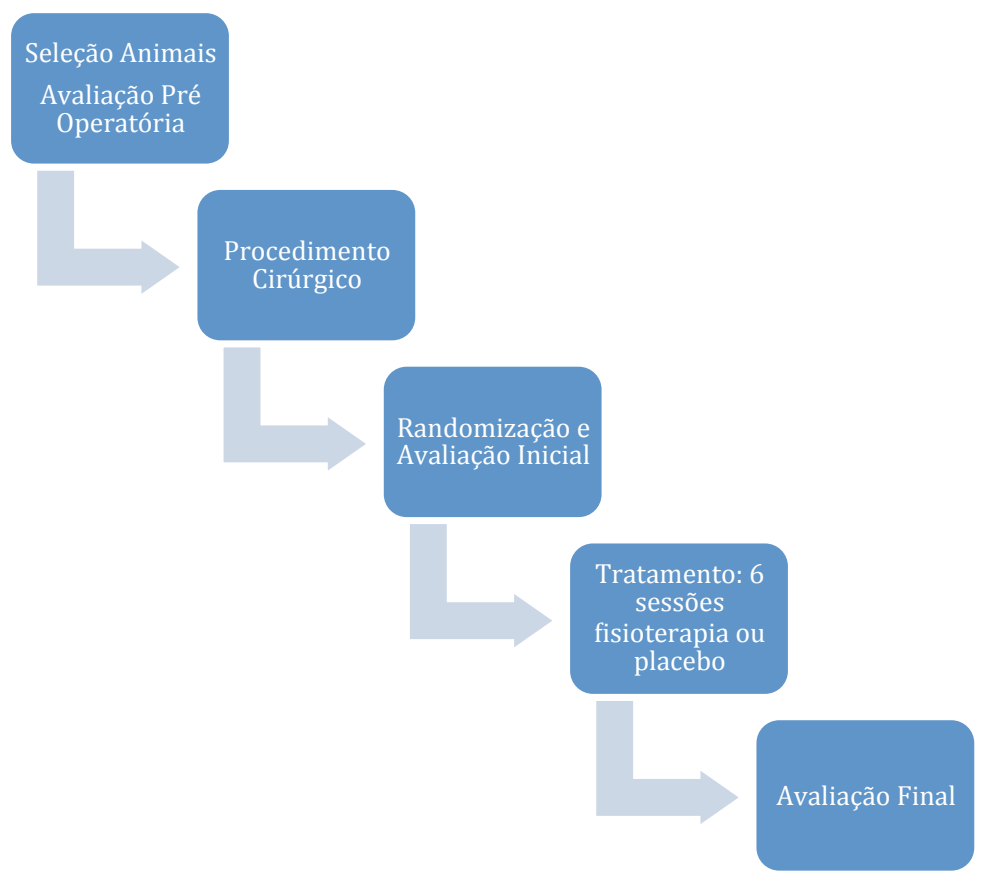

Fonte: Formenton, M. R. (2015). 


\subsubsection{Técnica cirúrgica}

Os animais foram submetidos à avaliação ortopédica no LOTC, na qual foi diagnosticada a ruptura do ligamento cruzado cranial. Em seguida foi realizada a análise radiográfica constituídas de 2 ou mais radiografias, nas projeções láterolateral e crânio-caudal, a fim de aferir o ângulo do platô tibial e evidenciar outras condições que poderiam afetar a articulação, como a luxação patelar e o grau de artrose.

A cirurgia de TPLO foi realizada sempre pelo mesmo cirurgião. Ademais, foi realizada a artrotomia exploratória do joelho e, se necessária, a meniscotomia ou liberação do menisco, de acordo com a avaliação do cirurgião, sendo anotado na ficha de cada animal.

\subsubsection{Técnica anestésica e analgesia pós-operatória}

O protocolo anestésico utilizado foi aquele proposto pelo Serviço de Anestesia do Departamento de Cirurgia da Faculdade de Medicina Veterinária e Zootecnia da Universidade de São Paulo. A medicação pré-anestésica foi realizada pela administração de cloridrato de tramadol $4 \mathrm{mg} / \mathrm{kg}$, por via intramuscular. Após 30 minutos, a indução anestésica foi realizada com propofol por via intravenosa, até que se alcançasse o efeito desejado de perda do reflexo laringotraqueal (dose de 5$8 \mathrm{mg} / \mathrm{kg}$ ). A manutenção foi realizada com isofluorano em $100 \%$ de oxigênio, em circuito circular de anestesia e sob ventilação mecânica controlada por pressão (8$\left.10 \mathrm{cmH}_{2} \mathrm{O}\right)$, e frequência respiratória controlada para manter a normocapnia $\left(\mathrm{ETCO} \mathrm{O}_{2}\right.$ de $35-45 \mathrm{mmHg}$ ). Os animais foram posicionados em decúbito esternal e foi realizada anestesia epidural com bupivacaina 0,5\% sem vasoconstritor $(1 \mathrm{mg} / \mathrm{kg})$, associada à morfina $10 \mathrm{mg} / \mathrm{ml}(0,1 \mathrm{mg} / \mathrm{kg})$ entre o segmento L7-S1, diluídos para um volume total de 0,26 ml/kg em solução fisiológica.

No pós-operatório foi prescrito cloridrato de tramadol, $2 \mathrm{mg} / \mathrm{kg}$, por via oral (VO) por 7 dias, sendo a administração iniciada decorridas 12 horas da administração da morfina epidural. Como anti-inflamatório, foi estabelecida a 
prescrição do carprofeno, na dose de 2,2mg/kg, VO, a cada 12 horas por 7 dias; e dipirona, na dose de $25 \mathrm{mg} / \mathrm{kg}$, VO, a cada 8 horas por 7 dias. Foi prescrito de forma complementar como antibióticoterapia, a cefalexina $25 \mathrm{mg} / \mathrm{kg}$, VO, a cada 8 horas por 7 dias, e indicado o confinamento ou restrição de espaço em que o animal vive até o término do estudo.

Logo após o procedimento cirúrgico, os animais receberam uma bandagem do tipo Robert-Jones, permanecendo por 24 horas. Decorridas as 24 horas, os mesmos retornavam para uma consulta com o cirurgião, para avaliação pós operatória. Foi restringido o uso de gelo, pela presença da bandagem nas primeiras 24 horas e para não interferir nos dados a serem coletados no estudo da termografia.

\subsubsection{Distribuição dos grupos e momentos de avaliação}

Os animais foram distribuídos em dois grupos, sendo o primeiro denominado Fisioterapia (F) e o segundo grupo Placebo $(P)$. Sobre os momentos de avaliação, estes foram divididos em três, a serem dispostos:

-Avaliação pré-operatória (TPRE): esta foi realizada no dia da cirurgia, porém antes de qualquer intervenção;

- Avaliação Inicial (T0): realizada 3 a 5 dias após o procedimento cirúrgico, no período de pós-operatório recente;

- Avaliação Final (TF): realizada 17 a 20 dias após o procedimento cirúrgico.

As fichas utilizadas na avaliação inicial e final estão dispostas nos anexos $\mathrm{F}$ e G.

\subsubsection{Randomização e minimização dos animais}

A distribuição dos animais nos grupos foi realizada a partir de envelopes lacrados, abertos após a cirurgia, porém, antes da obtenção do T0. O pesquisador não teve acesso à confecção e ao fechamento dos envelopes sendo este processo 
realizado por um segundo indivíduo.

Os animais recrutados com lesão unilateral do ligamento cruzado foram randomizados conforme o descrito anteriormente por meio dos envelopes. Já os animais com lesão bilateral foram minimizados entre os grupos, sendo que, o primeiro animal que aparecesse com lesão bilateral seria randomizado, o seguinte seria minimizado, e assim por diante, mantendo a maior uniformidade possível entre os grupos.

\subsubsection{Descrição dos grupos}

\section{a) Grupo Placebo (P)}

Após a avaliação inicial (T0), os animais designados para este grupo foram encaminhados para sessões placebo de fisioterapia. Os equipamentos foram posicionados de forma idêntica aos do grupo fisioterapia, porém, no caso do aparelho de laserterapia, a probe foi bloqueada à passagem do LASER. No caso da eletroterapia foi instituída intensidade de $1 \%$, a qual não tem efeito terapêutico algum. Estas sessões tiveram a duração média de 40 minutos, realizadas três vezes por semana por 2 semanas, totalizando 6 sessões.

Por questões éticas, após a realização da avaliação final (TF), era evidenciado ao cuidador se o animal havia sido designado ao grupo placebo, e em seguida, oferecia-se mais 6 sessões reais de fisioterapia ao seu animal.

\section{b) Grupo Fisioterapia (F)}

Os animais designados para este grupo, após a avaliação inicial (T0), foram encaminhados para realização de sessões de laserterapia associadas a eletroterapia. Estas sessões tiveram a duração média de 40 minutos, sendo realizadas três vezes na semana, por 2 semanas, totalizando 6 sessões. Os parâmetros estipulados para estas sessões serão descritos no item "Protocolo Fisioterapêutico". 


\subsubsection{Métodos de avaliação}

\subsubsection{Avaliação da dor}

Para a avaliação e quantificação do grau de dor do animal, foram empregadas três metodologias:

a) Primeiramente foi empregada a ESCALA NUMÉRICA VISUAL (ENV) para a quantificação de dor percebida pelo cuidador e pela palpação do avaliador. Nesta, consideramos como "0" a ausência de dor e "10" uma dor insuportável. O proprietário e o avaliador marcavam suas avaliações de forma independente.

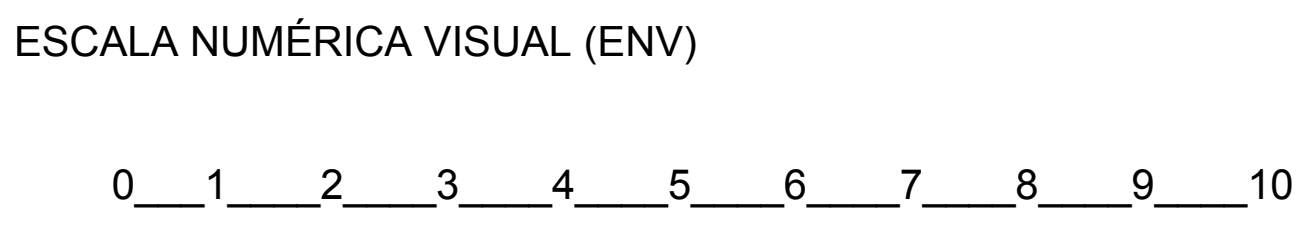

b) Após o emprego da ENV acima, foi realizada pelo avaliador, a mensuração através do uso da Escala de Medida Composta de Dor de Glasgow (Glasgow Composite Measure Pain Scale). Nesta avaliação, foram observados os sinais a distância de postura do animal e de comportamento, além da sensibilidade ao toque. As respostas sem seguida foram convertidas em números (escalonamento) e somados, gerando uma quantificação definida por peso e importância do parâmetro observado, ao qual o máximo grau de dor e desconforto era descrito como a nota 10 (MORTON et al., 2005). A escala utilizada encontra-se no anexo $\mathrm{H}$.

c) Grau de decaimento da dor:

Para interpretação dos dados de ENV, ademais foi calculado o grau de decaimento da dor, que significa, em porcentagem, o quanto o animal melhorou dado sua condição inicial. Para este cálculo foi utilizada a fórmula [(ENVinicial ENVfinal)/ENV inicial]x100. 


\subsubsection{Avaliação do edema}

A avaliação do edema foi feita pelo método de aferir a circunferência da articulação estudada, denominado perimetria. Para tanto, foi utilizada a aferição com fita métrica plástica de $30 \mathrm{~cm}$, a qual foi posicionada ao redor da articulação fêmorotibio-patelar com o animal em estação, sobre a linha interarticular entre o fêmur e a tíbia (Figura 2). Foram realizadas três aferições seguidas, sendo a média simples entre elas considerado o valor final. Foram realizadas aferições antes do procedimento cirúrgico, ao T0 e ao TF.

Figura 2 - Demonstração do posicionamento da fita métrica para aferir o edema na articulação fêmoro-tíbio-patelar

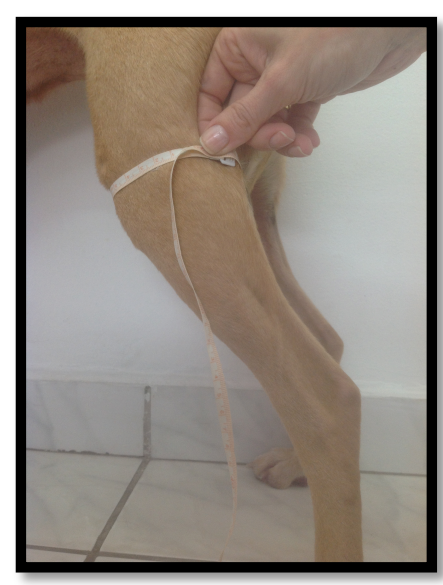

Fonte: Formenton, M. R. (2015)

\subsubsection{Avaliação da claudicação}

Para avaliação da claudicação foram utilizadas duas escalas distintas (Anexo I), sendo uma proposta por Monk et al. (2006) e outra por Hudson et al. (2004). A primeira escala estabelece uma graduação de 0 a 5, a qual "0" é considerado o animal sem claudicação e " 5 " a ausência de apoio do membro. A segunda escala apresenta uma graduação de 0 a 4 , sendo "0" considerado como a ausência de claudicação e "4" como uma claudicação intensa. 


\subsubsection{Análise cinética por Baropodometria}

Como complemento à avaliação de claudicação, os animais foram submetidos à análise cinética por meio de uma plataforma de baropodometria (7100 QL Virtual Sensor 3 Mat System, Tekscan Inc. South Boston, MA, EUA) na avaliação pré-operatório (TPRE), e ao término das sessões de fisioterapia, no momento TF.

O sistema de baropodometria Tekscan $®$ é composto por uma plataforma de 3 placas alinhadas em série totalizando uma dimensão de 1,5mX0,5mX0,005m. Este sistema integra 6864 unidades sensitivas de pressão que geram 50 quadros por segundo, gravados em formato de filme em um computador (Pentium V) para posterior análise. Esta análise foi feita por meio do software I-scan 5.231 (Tekscan Inc., South Boston, MA, USA) pela mensuração das forças verticais de reação ao solo (FRS), tempo de fase do passo e trajeto durante a passagem.

O animal foi submetido à um máximo de 20 passagens, e destas selecionadas 5 válidas para análise. Esta validação foi padronizada pela aceleração de $\pm 0,1 \mathrm{~m} / \mathrm{s}^{2}$, e pelo tempo de fase do passo de 1,3 e 1,6 m/s. Para o cálculo da razão do comprimento do passo pelo tempo de sua respectiva fase, manteve-se a velocidade constante. A Velocidade foi calculada por meio dos parâmetros de aceleração, dados pela diferença entre as velocidades finais e iniciais, divididas pela média do tempo de fase, considerando a mensuração nos membros anteriores e posteriores (Figuras 3 e 4). 
Figura 3 - Na parte superior da figura, encontra-se a mensuração do comprimento do passo para cálculo e controle da velocidadade. Complementarmente na parte de baixo o controle do tempo de fase da parte superior da figura. Animal denominado M4 registrada, momento da avaliação pré-operatória no LAL, FMVZ/USP - São Paulo - 2015

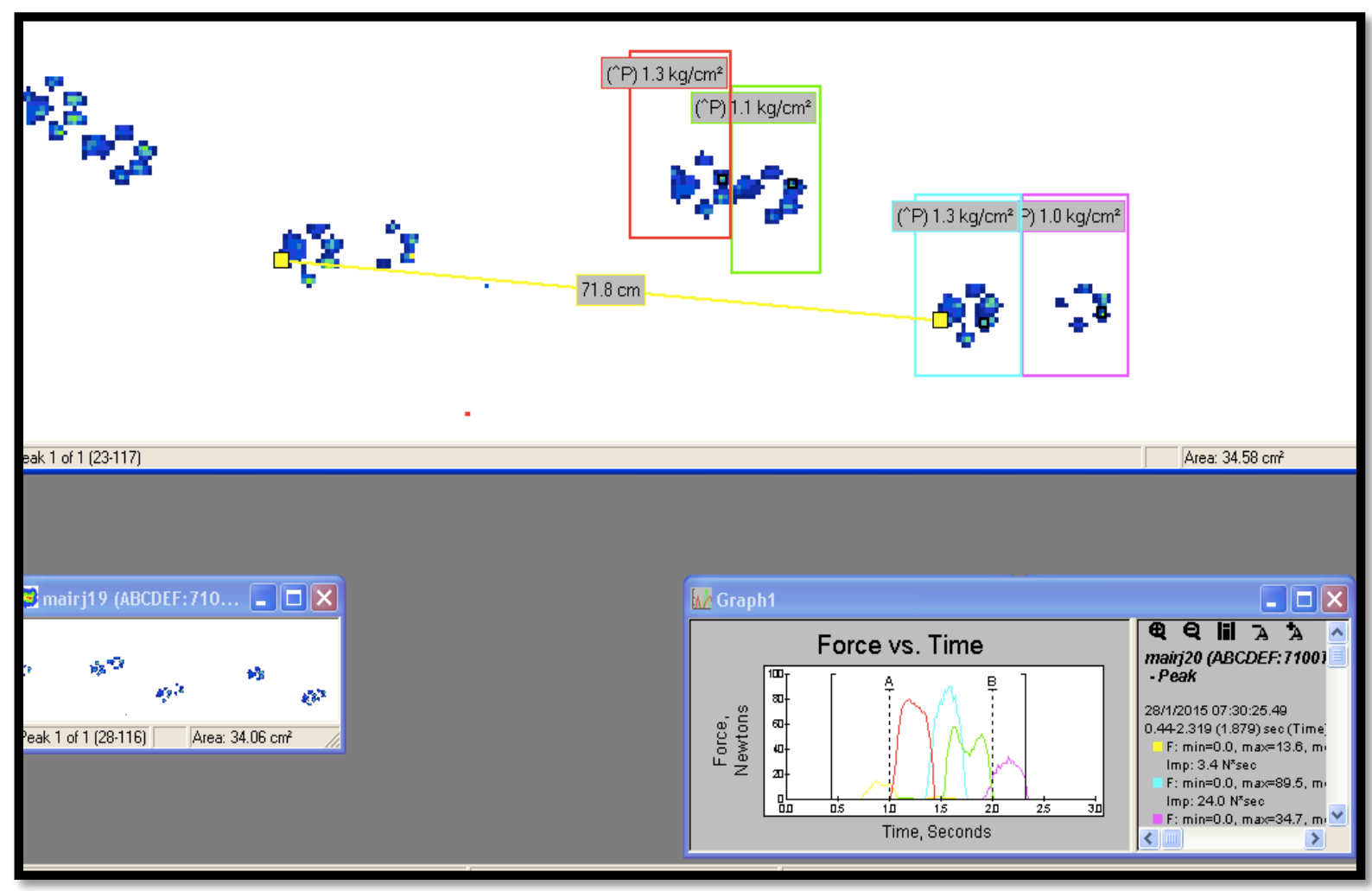

Fonte: Formenton, M. R. (2015)

Os cães foram conduzidos pelo cuidador do animal, ao lado esquerdo do mesmo. Foi estabelecido o trajeto retilíneo, não permitindo o desvio da cabeça durante a passagem. Passagens nas quais houve a alteração e desvio da cabeça ou o animal pisou fora da plataforma (total ou parcialmente) foram descartadas. $O$ exemplo da condução ideal da passagem é mostrado na figura 4. 
Figura 4 - Cão M4 durante a passagem sobre a plataforma de baropodometria Tekscan® no LAL, FMVZ/USP - São Paulo - 2014

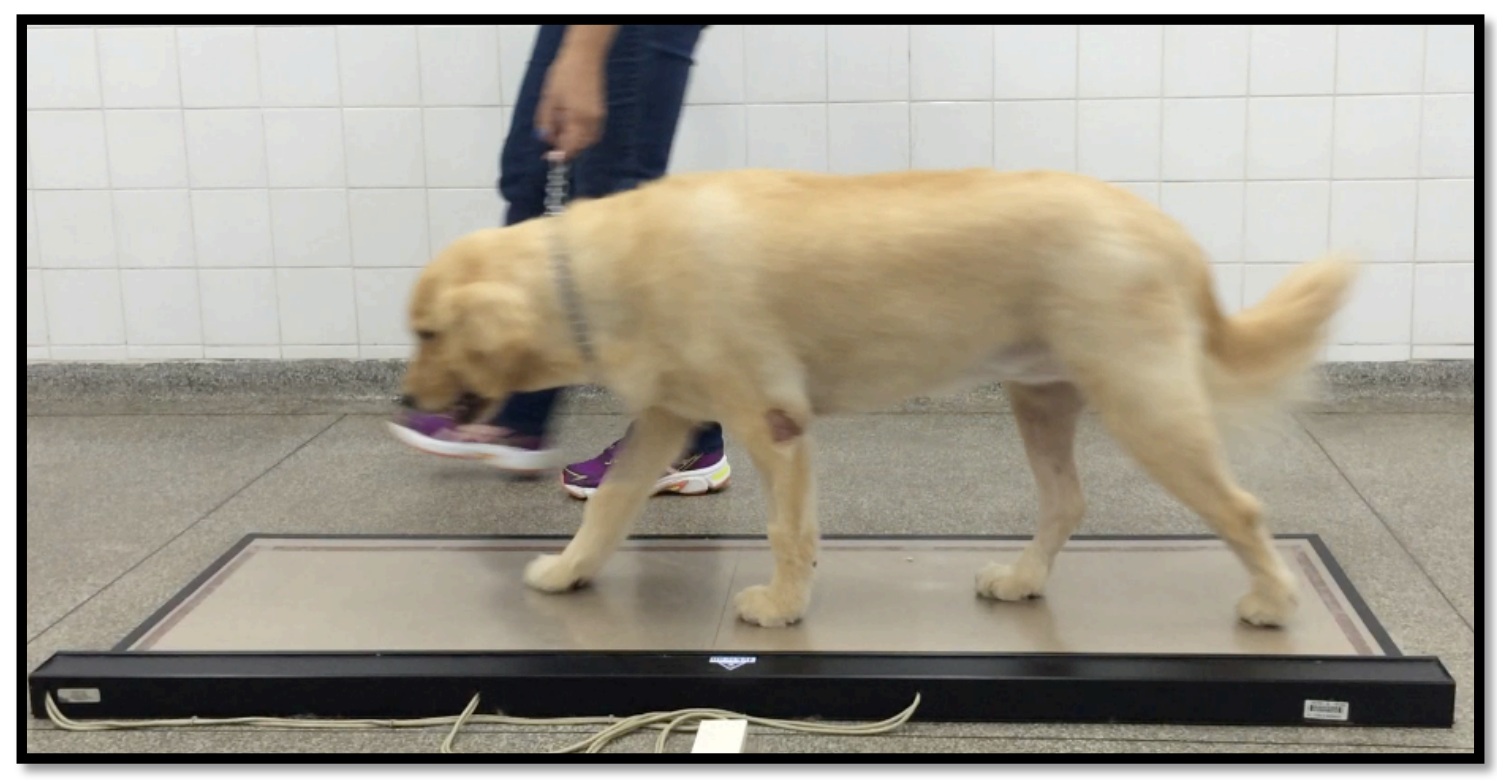

Fonte: Formenton, M. R. (2015)

A avaliação dos gráficos (Figuras 5 e 6 ) fornece os parâmetros de pico de força máxima vertical (PFV) em Newtons (N), impulso vertical (IV) expressos em $N^{*}$ s, o tempo de fase, de balanço e tempo de apoio (TA) em segundos, de todos os membros do animal. Para este estudo foram analisados e comparados os valores de PFV e IV apenas do membro acometido. 
Figura 5 - Análise do cão pela colocação de "caixas". As forças de reação ao solo são evidenciadas nos diferentes membros, sendo na figura a caixa verde o MPE, vermelha MTE, roxa MPD e azul MTD. Observa-se a linha amarela a distância entre as pegadas do MPD do animal. Passagem registrada no LAL, FMVZ/USP - São Paulo - 2015

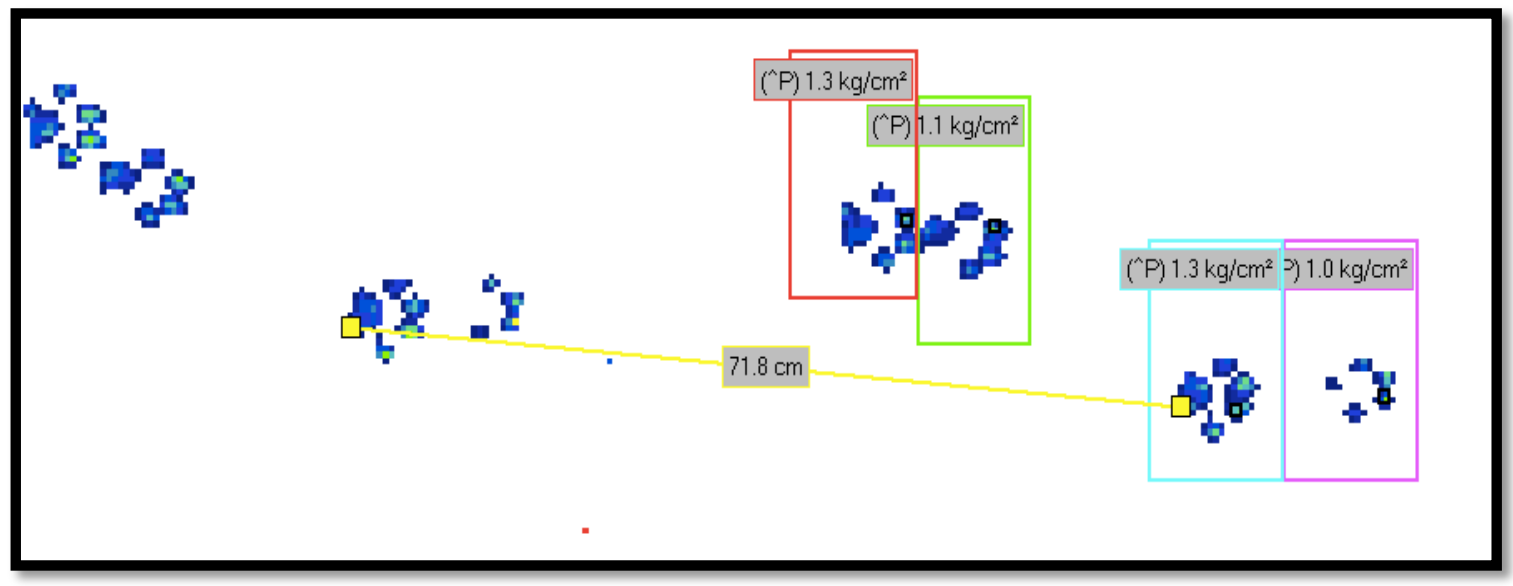

Fonte: Formenton, M. R. (2015)

Figura 6 - Registro e medidas do PFV, IV e TA em N do membro acometido, no caso do animal P4, em sua avaliação pré-operatória. O membro acometido, no caso desta representação, é o gráfico roxo. Passagem registrada no Laboratório de Análise da Locomoção (LAL), FMVZ/USP - São Paulo - 2015

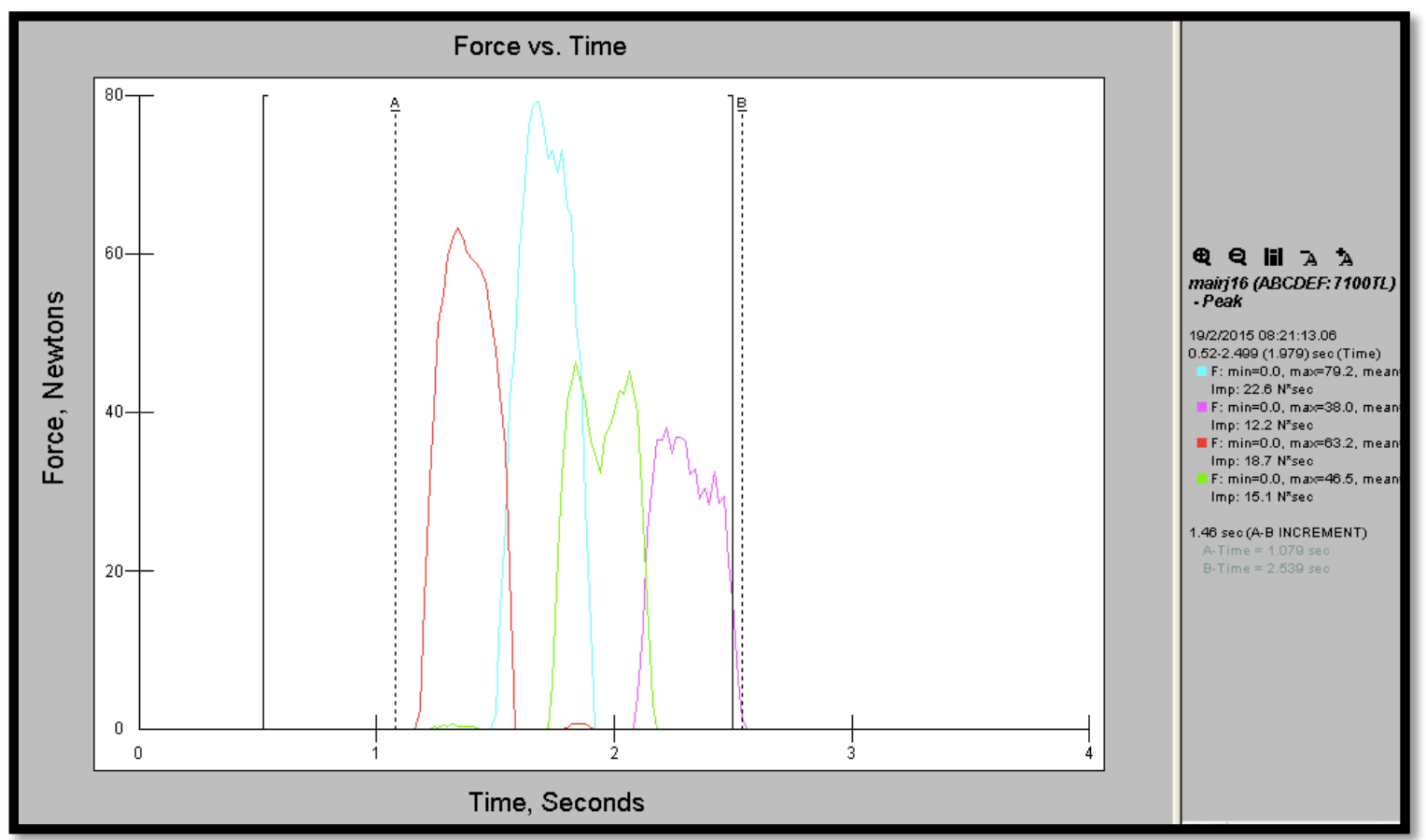

Fonte: Formenton, M. R. (2015) 
Para a normalização dos parâmetros obtidos em relação ao peso total de cada animal, o peso em estação foi estabelecido como a massa $(\mathrm{kg})$ multiplicado pela aceleração da gravidade. Em seguida foram aplicadas as fórmulas a seguir, para normalizar os parâmetros de PFV e IV pelo peso total, e gerar um o valor final em porcentagem de peso corpóreo (\%PC) e \%PC*s respectivamente.

$$
\begin{aligned}
& \text { PFV\%PC }=(100 * P F V) / \text { massa*10 } \\
& \text { IV\%PC }=(100 * I V) / \text { massa*10 }
\end{aligned}
$$

\subsubsection{Análise termográfica}

Para a coleta da imagem termográfica, utilizou-se o aparelho de termografia Flir Systems $®$, modelo Thermacam T400®. A articulação fêmoro-tíbiopatelar afetada foi fotografada, na porção do terço distal do fêmur ao terço proximal da tíbia, em posicionamento látero-lateral e médio-lateral, à uma distância de 30 centímetros do membro (Figuras 7 e 8).

Vale salientar que os pelos do membro afetado foram removidos anteriormente, com um mínimo de 30 minutos de intervalo entre a remoção dos pelos e a coleta da imagem. O animal foi mantido na sala onde foi coletada a termografia por 20 minutos antes da coleta, para que ele se adaptasse à temperatura da mesma. A sala utilizada para a coleta foi sempre a mesma, sendo os animais dispostos na mesma posição, em estação.

Para análise da foto termográfica foi utilizado o software FLIR Tools (versão 2.1, Flyr Systems, 2014). A partir da importação da foto no software, foram traçadas duas linhas-guia, uma horizontal, outra vertical, na topografia do joelho do animal. Foi delimitado um círculo, com o centro deste na intersecção das duas linhas, como mostra as figuras 7 e 8 . Em sequência, foi emitido um relatório (Figura 9) no qual todas as informações sobre as áreas e medições das linhas-guia são evidenciadas. A partir deste relatório, utilizou-se a medida de média de temperatura na região do círculo (Circle Average), em graus Celcius $\left({ }^{0} \mathrm{C}\right)$ como medida para a termografia da articulação. 
Figura 7 - Foto termográfica com linhas para análise horizontal, vertical e círculo feitas no Software FLIR Tools (versão 2.1, Flyr Systems, 2014), coletada durante uma avaliação inicial do animal F1, vista médio-lateral. Foto registrada no ADCP, FMVZ-USP - São Paulo - 2015

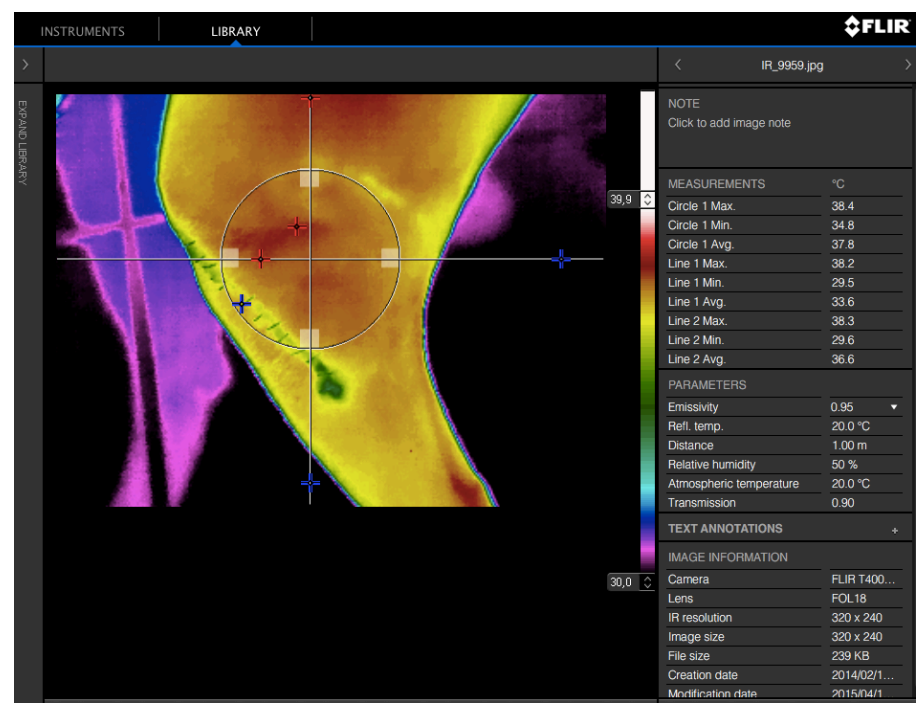

Fonte: Formenton, M. R. (2015)

Figura 8 - Foto termográfica com guias (horizontal, vertical e círculo) para análise feita do Software FLIR Tools (versão 2.1, Flyr Systems, 2014), coletada durante uma avaliação inicial do animal F1, vista latero-lateral. Foto registrada no ADCP, FMVZ-USP - São Paulo - 2014

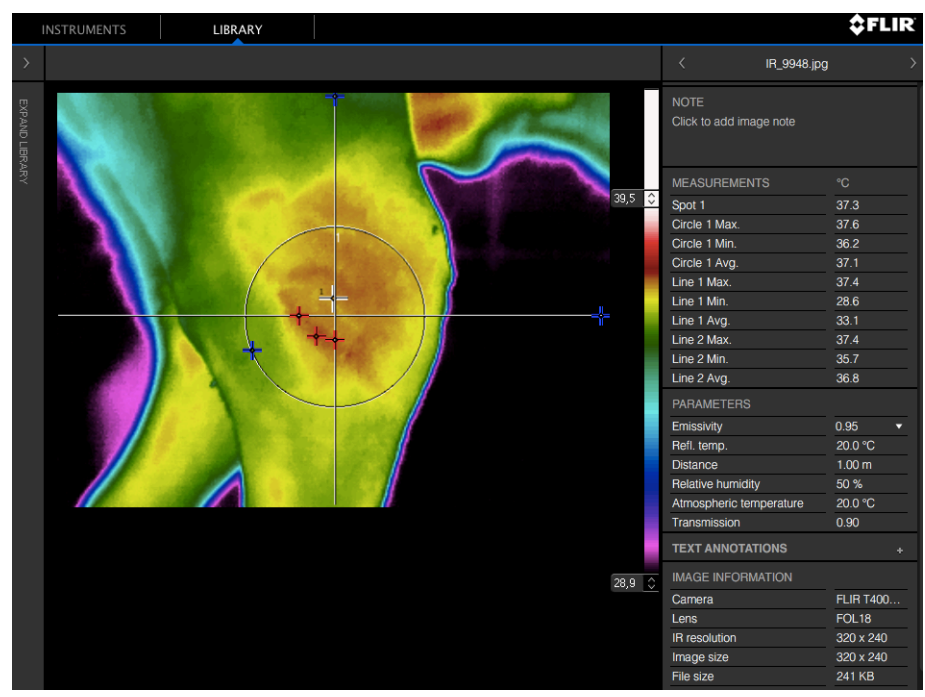

Fonte: Formenton, M. R. (2015) 
Figura 9 - Relatório emitido pelo Software FLIR Tools (versão 2.1, Flyr Systems, 2014) no qual obtém-se o dado da média de temperatura na região do círculo (Circle Average). No caso do animal F1, na vista médio lateral da avaliação inicial, a medida é de $37,80 \mathrm{C}$

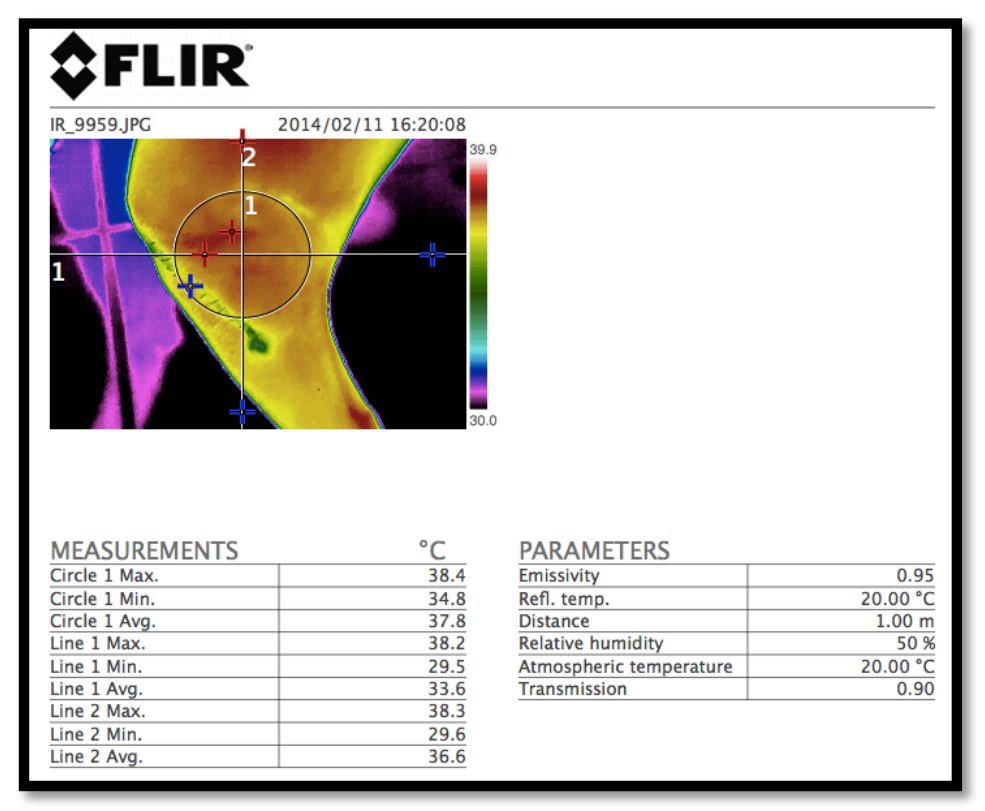

Fonte: Formenton, M. R. (2015)

\subsubsection{Momentos de coleta dos dados}

Durante o estudo, foram estabelecidas as coletas dos dados nas avaliações TPRE, T0 e TF, nos quais os métodos anteriormente citados foram utilizados:

Na Avaliação Pré-Operatória (TPRE), foram realizadas a perimetria do joelho, a termografia e a análise cinética baropodométrica .

No T0, foram analisados o grau de dor, segundo cuidador do animal e avaliador, grau de edema (perimetria do joelho) e grau de claudicação. Nesta, também foi repetida a avaliação termográfica latero-lateral e médio lateral, do joelho operado.

No TF, foram coletados os mesmos dados da avaliação T0 (grau de dor, segundo cuidador e avaliador, perimetria do joelho, grau de claudicação e termografia). Nesta, porém, foi coletada novamente a análise cinética. O cuidador do animal, o cirurgião e o avaliador não tinham conhecimento a qual dos grupos o animal pertencia. 
Um resumo dos momentos do estudo e análises feitas estão demonstrados na quadro 1:

Quadro 1 - Resumo das avaliações nos diferentes momentos do estudo

\begin{tabular}{|c|c|c|c|}
\hline Grupos & $\begin{array}{l}\text { Avaliação Pré } \\
\text { Operatória } \\
\text { (TPRE) }\end{array}$ & $\begin{array}{l}\text { Avaliação inicial } \\
\text { (TO) } 3 \text { a } 5 \text { dias } \\
\text { PO }\end{array}$ & $\begin{array}{l}\text { Avaliação final } \\
\text { (TF) } \\
17 \text { a } 20 \text { dias } P O\end{array}$ \\
\hline $\begin{array}{l}\text { Placebo } \\
\text { (P) }\end{array}$ & $\begin{array}{l}\text {-Termografia } \\
\text {-Grau de } \\
\text { edema(perimetria) } \\
\text {-Baropodometria }\end{array}$ & $\begin{array}{l}\text {-Avaliação de dor } \\
\text { (ENV e Glasgow) } \\
\text {-Edema } \\
\text { (perimetria) } \\
\text {-Claudicação } \\
\text { (escalas) } \\
\text {-Termografia } \\
\text { Encaminhado } \\
\text { para sessões } \\
\text { placebo. }\end{array}$ & $\begin{array}{l}\text {-Avaliação de dor } \\
\text { (ENV e Glasgow) } \\
\text {-Edema } \\
\text { (perimetria) } \\
\text {-Claudicação } \\
\text { (escalas) } \\
\text {-Termografia } \\
\text {-Baropodometria }\end{array}$ \\
\hline $\begin{array}{l}\text { Fisioterapia } \\
\text { (F) }\end{array}$ & $\begin{array}{l}\text {-Avaliação } \\
\text { termográfica } \\
\text {-Grau de } \\
\text { edema(perimetria) } \\
\text {-Baropodometria }\end{array}$ & $\begin{array}{l}\text {-Avaliação de dor } \\
\text { (ENV e Glasgow) } \\
\text {-Edema } \\
\text { (perimetria) } \\
\text {-Claudicação } \\
\text { (escalas) } \\
\text {-Termografia } \\
\text { Encaminhado } \\
\text { para sessões } \\
\text { reais. }\end{array}$ & $\begin{array}{l}\text {-Avaliação de dor } \\
\text { (ENV e Glasgow) } \\
\text {-Edema } \\
\text { (perimetria) } \\
\text {-Claudicação } \\
\text { (escalas) } \\
\text {-Termografia } \\
\text {-Baropodometria }\end{array}$ \\
\hline
\end{tabular}

Fonte: Formenton, M. R. (2015)

\subsubsection{Protocolo fisioterapêutico}

Nos animais do grupo Fisioterapia $(F)$, foram associadas duas técnicas de fisioterapia, a laserterapia e a eletroterapia, realizadas em sequência e nesta ordem:

A primeira técnica aplicada foi a laserterapia, a qual foi realizada empregando-se o modo contínuo e puntual, por meio de uma caneta de $830 \mathrm{~nm}$ de comprimento de onda. A potência da caneta de LASER utilizada foi de $40 \mathrm{~mW}$, 
sendo a área do feixe na ponta da caneta de $0,1075 \mathrm{~cm}^{2}$, fornecidos pelo fabricante no anexo D. Seguindo as recomendações da literatura para afecções agudas e, considerando as dosificações indicadas para se obter o efeito anti-inflamatório, a densidade de energia estabelecida por ponto foi de $3 \mathrm{~J} / \mathrm{cm}^{2}$. No momento da aplicação, o cabeçote da caneta foi posicionado perpendicular à superfície de contato.

Como o total de pontos aplicados no joelho depende do tamanho da área de aplicação, a dose total aplicada em cada animal foi relacionada ao tamanho do indivíduo. Ou seja, o número de pontos foi maior quanto maior fosse a área a ser tratada, sendo esta área proporcional ao tamanho do animal.

Desta forma, o joelho de cada animal foi mapeado a cada $1 \mathrm{~cm}$ de distância por pontos de aplicação da laserterapia. Para a determinação dos pontos de aplicação, foram delimitadas as seguintes áreas (Figura 10):

- Área ao redor da patela;

- Área do terço proximal da tíbia, desviando-se do implante metálico na região medial;

- Área do terço distal do fêmur e linha interarticular, bilateralmente. 
Figura 10 - Exemplo dos pontos de aplicação da laserterapia na articulação fêmoro-tíbio-patelar de um animal SRD na vista lateral. Evidencia-se a distância de um centímetro entre cada ponto. Em amarelo estão destacados os pontos interarticulares, em vermelho os pontos ao redor da patela. Em roxo encontram-se os pontos no terço proximal da tíbia e em verde os pontos no terço distal do joelho. Foto registrada no ADCP, FMVZ-USP - São Paulo - 2015

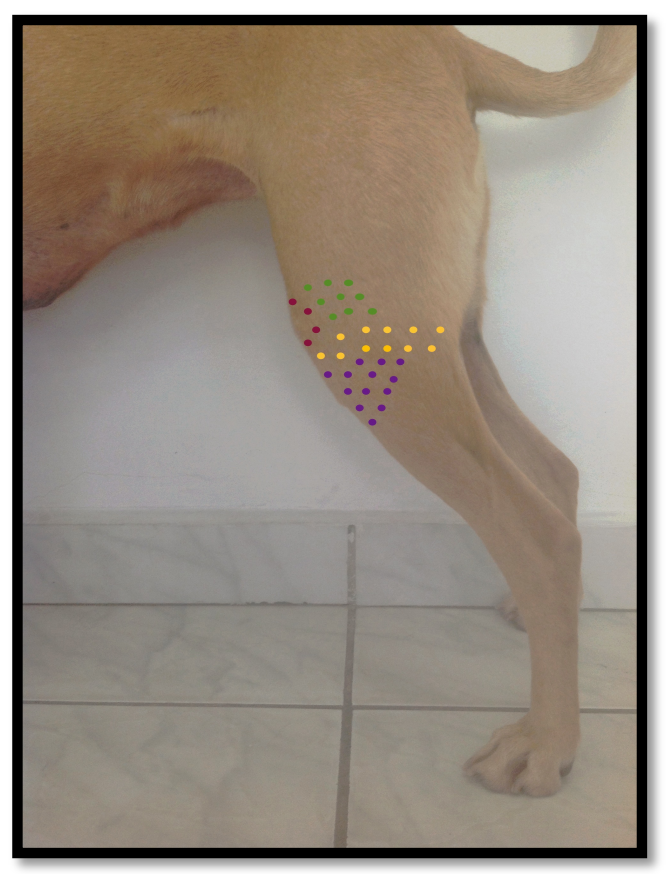

Fonte: Formenton, M. R. (2015)

Em seguida à aplicação da laserterapia foi realizada a sessão de eletroterapia por meio da modalidade de estimulação elétrica nervosa transcutânea (TENS), seguindo os conceitos de aplicação da referida técnica:

a) Um canal local no joelho, por meio de técnica local, não envolvendo a região dos implantes e posicionando os eletrodos próximos aos côndilos femorais, sendo um eletrodo lateral, o outro medial. Uma faixa elástica foi utilizada quando necessário para manter os eletrodos no local.

b) Dois canais, por técnica segmental, em região paravertebral de coluna lombar (um eletrodo paravertebral à vértebra lombar L4 e outro paravertebral à L7, bilateralmente).

A aplicação de TENS foi utilizada em modo burst $(2 \mathrm{~Hz})$, a uma estabelecida frequência base de $100 \mathrm{~Hz}$, com comprimento de onda $250 \mathrm{~nm}$, e por um tempo de 30 minutos nos locais designados anteriormente. A intensidade foi determinada pela 
sensibilidade individual, sendo o nível de eletroestimulação considerado do sensitório ao início do nível motor. Foram utilizados eletrodos de silicone e gel para fisioterapia como meio de condução. Os pelos do animal foram afastados no local de aplicação dos eletrodos dispostos nos seguimentos da coluna, quando necessário. No joelho, não foi necessária a remoção dos pelos devido ao fato de terem sido removidos pelo procedimento cirúrgico (Figuras 11 e 12). A cada 10 minutos aumentava-se em 1 a $2 \%$ a intensidade, a fim de diminuir o grau de acomodação do sistema nervoso à eletroestimulação.

Figura 11 - Aplicação de eletroterapia com o aparelho Bioset ${ }^{\circledR}$ Physiotonus Four, São Paulo, Brasil. Nota-se a aplicação segmental de eletrodos na região lombar (bilateral), e aplicação local no joelho acometido. Imagem coletada durante a sessão do animal F9 no ADCP, FMVZ-USP - São Paulo - 2015

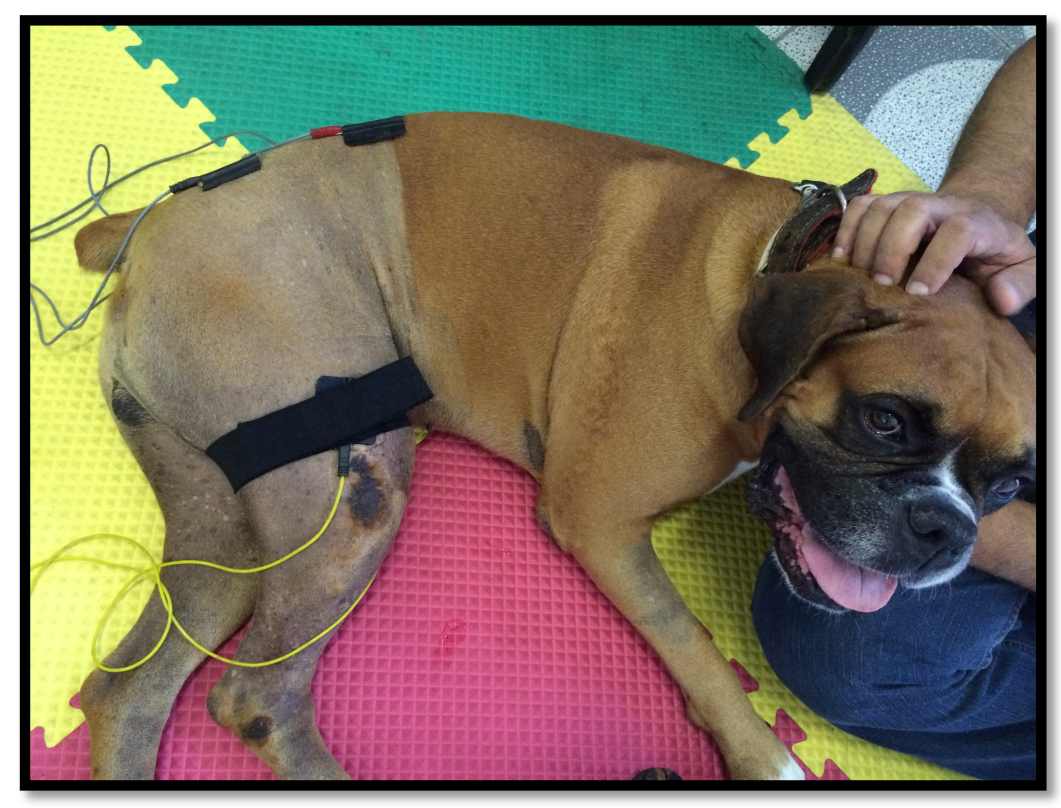

Fonte: Formenton, M. R. (2015) 
Figura 12 - Aplicação de eletroterapia com o aparelho Bioset@ Physiotonus Four, São Paulo, Brasil. Detalhe da aplicação local no joelho acometido. Ressalta-se que a aplicação não deve ser feita na região do implante metálico, por isso, o uso nas proximidades do côndilos femorais. Imagem coletada durante a sessão do animal F9 no ADCP, FMVZ-USP - São Paulo - 2015

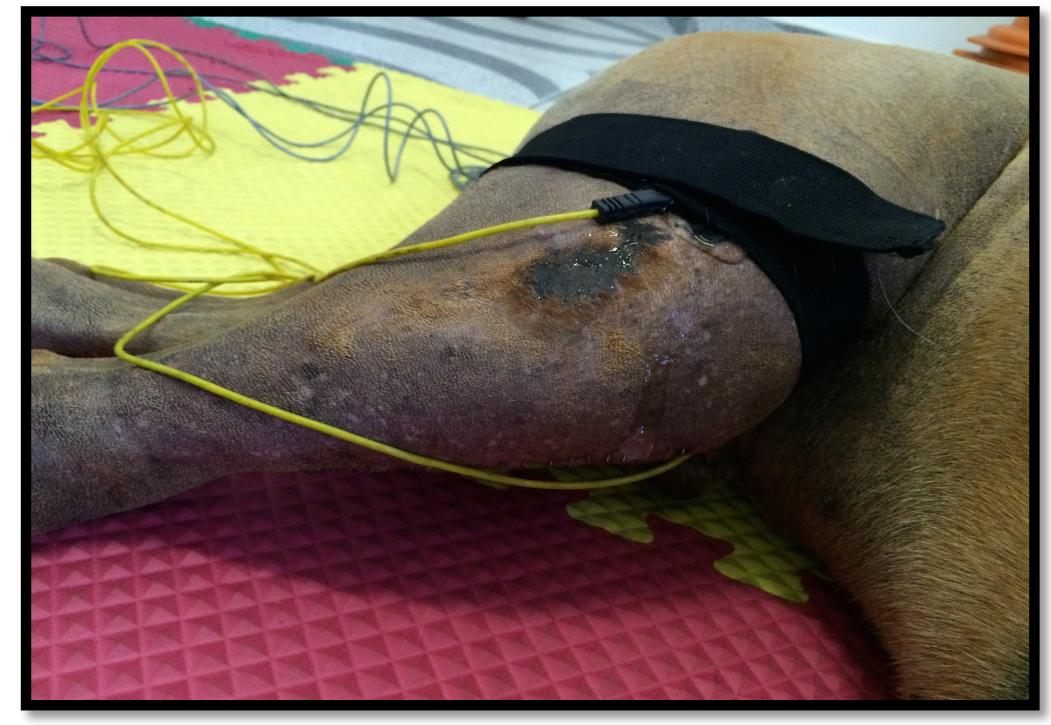

Fonte: Formenton, M. R. (2015)

\subsubsection{Resgate analgésico}

Foi instituído resgate analgésico quando identificada piora no quadro álgico do animal durante o tratamento. $O$ resgate foi realizado a critério do cirurgião e, pelo mesmo, sem a presença do pesquisador. Ressalta-se que o cirurgião não tinha conhecimento do grupo ao qual o animal pertencia.

Segundo esta avaliação feita pelo cirurgião, quando era identificado um grau de dor ou desconforto leve, era prescrito dipirona $25 \mathrm{mg} / \mathrm{kg} / \mathrm{TID}$. Quando encontrado um grau moderado de dor, foi prescrito cloridrato de tramadol $2 \mathrm{mg} / \mathrm{kg} / \mathrm{TID}$, e para o grau intenso foi realizada na prescrição da associação de cloridrato de tramadol e dipirona nas mesmas doses e frequências descritas anteriormente.

A figura 13 mostra a metodologia desenvolvida para este estudo. 
Figura 13 - Fluxograma com a metodologia detalhada empregada no estudo

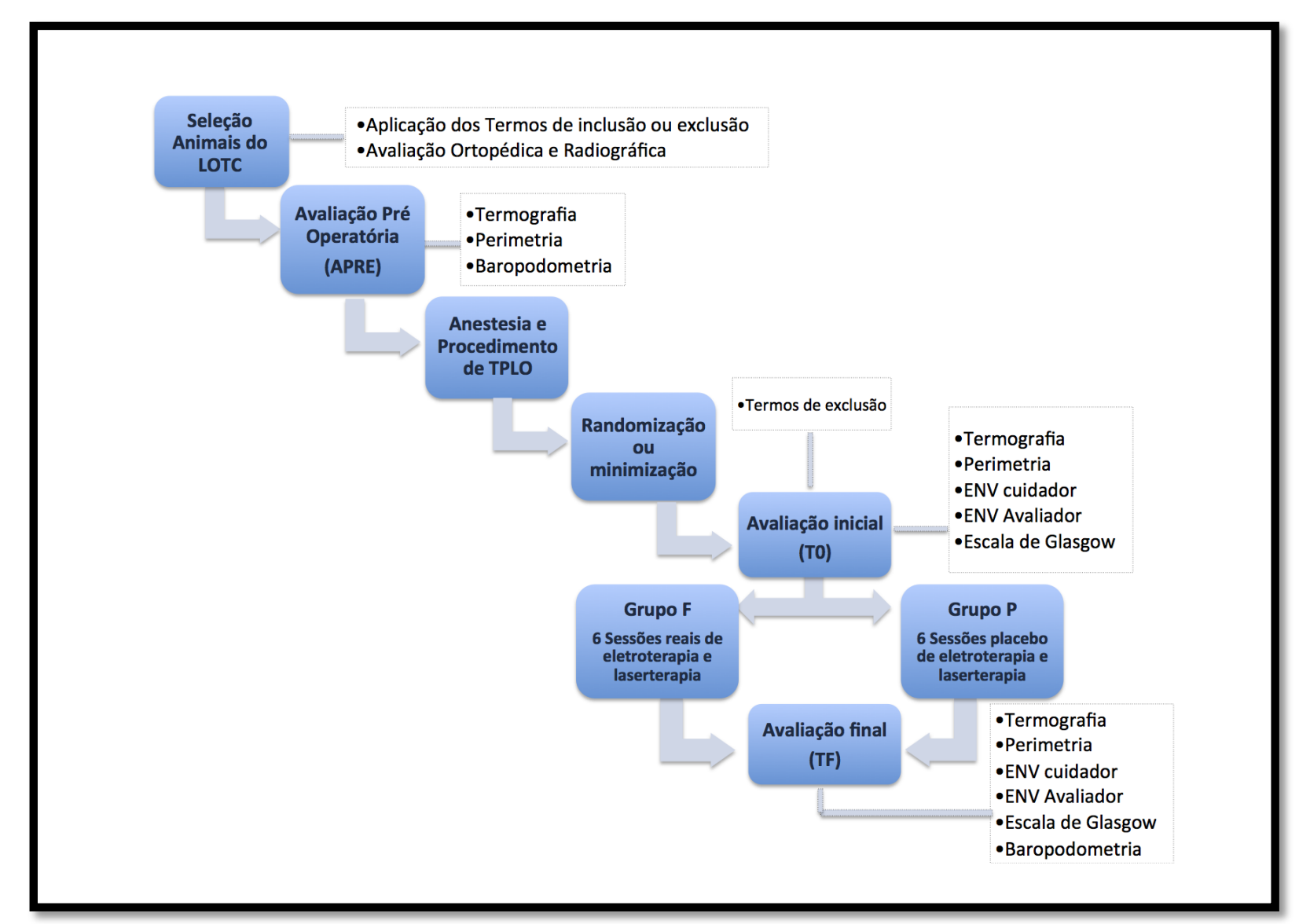

Fonte: Formenton, M. R. (2015)

\subsubsection{Estatística}

Para análise estatística foi utilizado o software GraphPad Instat versão 3.06. Os gráficos foram feitos no software GraphPad Prism 6 (Versão 6.0f) para MAC OSX. Primeiramente, foi aplicado nos dados o teste de normalidade Kolmogorov-Smirnov, considerando que, quando obtida a distribuição normal, foram em seguida submetidos ao teste $T$ pareado e não pareado, de acordo com as dependências das amostras. Para os dados que não se mostraram com distribuição gaussiana, foram utilizados os testes não paramétricos de Mann-Whitney para as amostras não pareadas e o teste de Wilcoxon para medidas pareadas.

Para avaliação de dados obtidos em três momentos (termografia e perimetria), usou-se o teste de ANOVA para medidas repetidas seguido de pós teste 
de Tukey para dados paramétricos. Para amostras não paramétricas foi utilizado o teste de Kruskal Wallis seguido pós teste de Dunn. Para amostras com mensuração repetida, foi utilizado o teste de Fridmann, seguido do pós teste de Dunn.

Foi considerado para este estudo o nível de significância de 95\% $(p<0,05)$ para os testes realizados. 


\section{RESULTADOS}

\subsection{CARACTERÍSTICAS DEMOGRÁFICAS}

Foram selecionados 24 animais no período pré-operatório que se enquadravam nos termos de inclusão e exclusão do estudo. Destes, 6 não foram randomizados e foram excluídos (motivos listados no Quadro 2). Apenas 1 (um) animal foi excluído após a randomização por infecção no local dos implantes.

Quadro 2 - Animais selecionados, porém, não incluídos e animais excluídos do projeto - FMVZ-USP - São Paulo - 2015

\begin{tabular}{|l|c|c|}
\hline Motivo da não inclusão & $\begin{array}{c}\text { Número de } \\
\text { animais (N) }\end{array}$ & $\begin{array}{c}\text { Randomizado } \\
\text { Sim / Não }\end{array}$ \\
\hline Piodermite pré-operatória & 3 & Não \\
\hline Cio & 1 & Não \\
\hline Suspeita tumor trans-operatório & 1 & Não \\
\hline Insuficiência Renal & 1 & Sim - Excluído \\
\hline Contaminação cirúrgica & 1 & \\
\hline
\end{tabular}

Dos animais randomizados, foram distribuídos 8 no grupo Fisioterapia e 6 no grupo Placebo. Foi minimizado um animal no grupo $F$ (Quadros 3 e 4). 
Quadro 3 - Distribuição entre Randomização e Minimização do grupo Fisioterapia (F) - FMVZUSP - São Paulo - 2015

\begin{tabular}{|c|c|c|}
\hline Animal & Randomizado & Minimizado \\
\hline $\mathbf{1}$ (Unilateral) & $\mathrm{x}$ & \\
\hline $\mathbf{2}$ (Unilateral) & $\mathrm{x}$ & \\
\hline $\mathbf{3}$ (Unilateral) & $\mathrm{x}$ \\
\hline $\mathbf{4}$ (Bilateral) & $\mathrm{x}$ & \\
\hline $\mathbf{5}$ (Unilateral) & $\mathrm{x}$ & \\
\hline $\mathbf{6}$ (Unilateral) & $\mathrm{x}$ & \\
\hline $\mathbf{7}$ (Unilateral) & $\mathrm{x}$ & \\
\hline $\mathbf{8}$ (Unilateral) & & \\
\hline & & \\
\hline
\end{tabular}

Quadro 4 - Distribuição entre Randomização e Minimização do grupo Placebo (P) - FMVZUSP - São Paulo - 2015

\begin{tabular}{|c|c|c|}
\hline Animal & Randomizado & Minimizado \\
\hline $\mathbf{1}$ (Unilateral) & $\mathrm{x}$ & \\
\hline $\mathbf{2}$ (Unilateral) & $\mathrm{x}$ & \\
\hline $\mathbf{3}$ (Unilateral) & $\mathrm{x}$ & \\
\hline $\mathbf{4}$ (Bilateral) & $\mathrm{x}$ & \\
\hline $\mathbf{5}$ (Unilateral) & $\mathrm{x}$ & \\
\hline $\mathbf{6 ( U n i l a t e r a l )}$ & $\mathrm{x}$ & \\
\hline $\mathbf{7 ( U n i l a t e r a l )}$ & $\mathrm{x}$ & \\
\hline
\end{tabular}


Dos 16 animais incluídos no estudo, não houve diferença estatística entre os grupos $(p<0,05)$ com relação ao peso (Tabela 1$)$ e às idades dos animais.

Tabela 1 - Média e desvio-padrão dos pesos dos animais $(n=16)$ nos diferentes grupos do estudo FMVZ-USP - São Paulo - 2015

\begin{tabular}{lccc}
\hline Grupo & $\mathbf{N}$ & Media $\mathbf{( K g )}$ & Desvio-padrão \\
\hline Fisioterapia & 9 & 31,8 & 13,3 \\
Placebo & 7 & 28,5 & 7,4 \\
\hline
\end{tabular}

Dentro dos grupos ocorreu uma maior incidência de fêmeas, em um total de 9 animais (56\%), sendo observado um número significativamente maior de fêmeas no grupo P. O número de machos totalizou 7 animais (44\%), como mostra a tabela 2.

Tabela 2 - Proporção entre fêmeas e machos $(n=16)$ nos diferentes grupos do estudo - FMVZ-USP - São Paulo - 2015

\begin{tabular}{lccc}
\hline Grupo & N & Fêmeas & Machos \\
\hline Fisioterapia & 9 & $4(44 \%)$ & $5(56 \%)$ \\
Placebo & 7 & $5(71 \%)$ & $2(29 \%)$ \\
Total & 16 & $9(56 \%)$ & $5(44 \%)$ \\
\hline
\end{tabular}

Entre as raças, houve uma maior frequência de animais sem raça definida (SRD), com uma porcentagem equivalente a $25 \%$, seguida pelas raças Bulldogue inglês, Labrador e Boxer, que apresentaram uma porcentagem de 12,5\%. As raças Golden Retriever, Rottweiller, Fila Brasileiro, Doguo Argentino, Chow-chow e Pit Bull tiveram a incidência de 6,5\% cada (Tabela 3). 
Tabela 3 - Raças dos animais incluídos no estudo e a incidência no estudo (\%)FMVZ-USP - São Paulo - 2015

\begin{tabular}{lcccc}
\hline \multicolumn{1}{c}{ Raça } & Fisioterapia & Placebo & Total & $\%$ \\
\hline SRD & 3 & 1 & 4 & $25 \%$ \\
Bulldogue Inglês & 2 & 0 & 2 & $12,5 \%$ \\
Labrador & 2 & 0 & 2 & $12,5 \%$ \\
Boxer & 0 & 2 & 2 & $12,5 \%$ \\
Golden Retriever & 0 & 1 & 1 & $6,25 \%$ \\
Rottweiller & 0 & 1 & 1 & $6,25 \%$ \\
Fila Brasileiro & 1 & 0 & 1 & $6,25 \%$ \\
Doguo Argentino & 1 & 0 & 1 & $6,25 \%$ \\
Chow Chow & 0 & 1 & 1 & $6,25 \%$ \\
Pit Bull & 0 & 1 & 1 & $6,25 \%$ \\
Total & 9 & 7 & 16 & $100 \%$ \\
\hline
\end{tabular}

\subsection{NECESSIDADE DE RESGATE ANALGÉSICO}

Entre os grupos do estudo, nenhum animal do grupo fisioterapia precisou de resgate analgésico durante o período de avaliação. Em contrapartida, no grupo Placebo, 3 animais (42\%) necessitaram do resgate, sendo dois (28\%) dos animais resgatados com cloridrato de tramadol, e um (14\%) resgatado com dipirona (Tabela 4). 
Tabela 4 - Necessidade de resgate analgésico entre os grupos F e P - FMVZ-USP - São Paulo - 2015

\begin{tabular}{lccc}
\hline Grupo & $\begin{array}{c}\text { Número total } \\
\text { de animais }\end{array}$ & $\begin{array}{c}\text { Número de } \\
\text { Resgates }\end{array}$ & Fármaco \\
\hline Fisioterapia & 9 & 0 & - \\
Placebo & 7 & $3(42 \%)$ & $2(28 \%)$ Tramadol \\
& & & $1(14 \%)$ Dipirona \\
\hline
\end{tabular}

\subsection{ESCALAS DE DOR}

\subsubsection{Escala Numérica Verbal}

Quando analisados de forma seriada, os escores de ENV obtidos pelo avaliador, mostram que o grupo Fisioterapia apresentou uma melhora do momento T0 para TF $(P=0,0156)$. O grupo Placebo não apresentou melhora relevante à estatística , comparando-se os momentos inicial e final, sendo o valor de $\mathrm{P}=0,4375$. Os valores obtidos estão evidenciados no apêndice $A$.

Da mesma forma que os resultados dos escores de ENV realizada pelo avaliador, na análise dos escores relatados pelo Cuidador, o grupo Fisioterapia apresentou uma melhora na análise seriada $(P=0,011)$ entre os momentos T0 e TF. No grupo Placebo, os resultados dos escores de ENV, avaliados pelo cuidador, igualmente mostram que não houve uma melhora estatisticamente significativa $(P=0,4375)$ entre os momentos T0 e TF (Tabela 5 e Gráfico 1). 
Tabela 5 - Médias e Desvios Padrão dos escores de ENV do cuidador e do avaliador nos momentos de T0 e TF- FMVZ-USP - São Paulo - 2015

\section{Avaliação T0 Avaliação TF}

\begin{tabular}{lllll}
\hline & \multicolumn{3}{c}{ Avaliação T0 } & \multicolumn{3}{c}{ Avaliação TF } \\
Grupo & ENV & ENV & ENV & ENV \\
& Avaliador & Cuidador & Avaliador & Cuidador \\
\hline Fisioterapia & $3,4 \pm 1,4$ & $4,0 \pm 1,8$ & $1,6 \pm 1,1$ & $1,4 \pm 1,2$ \\
Placebo & $2,2 \pm 2,0$ & $1,4 \pm 1,7$ & $2,7 \pm 2,1$ & $1,7 \pm 1,8$ \\
\hline
\end{tabular}

Gráfico 1 - Escores de ENV do Avaliador (Av.) e do Cuidador nas respectivas avaliações inicial(T0) e final (TF) - FMVZ-USP - São Paulo - 2015

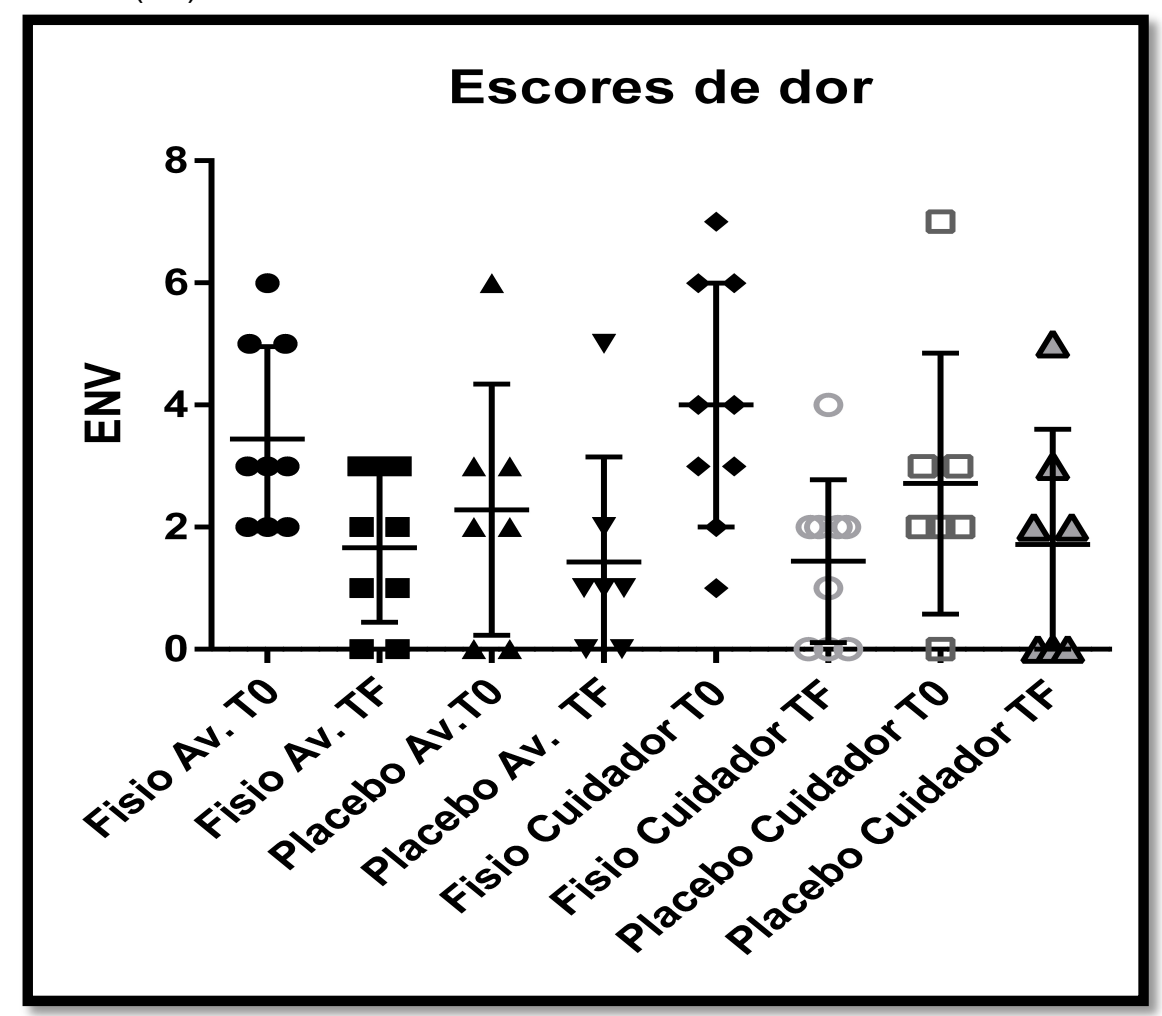

Quando comparados os grupos entre si, não houve diferença em relação aos escores de ENV tanto nas avaliações do avaliador quanto do cuidador $(P>0,05)$, em ambos os momentos de avaliação.

Ao serem confrontadas as mensurações do avaliador com as do cuidador em um mesmo momento, não houve diferença estatística entre as avaliações 
$(P>0,05)$ tanto do grupo Fisioterapia quanto do grupo Placebo.

Nas análises referentes ao grau de decaimento da dor, houve significativa diferença entre os grupos nos escores do avaliador. O grupo fisioterapia teve um grau de decaimento de $50 \%$ e $36 \%$ na média dos escores do avaliador e do cuidador, respectivamente, ao passo que no grupo $\mathrm{P}$ a melhora foi de $13 \%$ na média da avaliação do avaliador e $33 \%$ na do cuidador.

\subsubsection{Escala de Dor Composta de Glasgow Modificada:}

Em comparação seriada entre os momento T0 e TF, os escores de Glasgow do grupo Fisioterapia mostraram diminuição do valor entre as avaliações T0 $(3,6 \pm 2,1)$ e TF $(2,1 \pm 0,7)(P=0.0272)$. No grupo Placebo, a comparação seriada não mostrou diferença entre os momentos T0 $(1,95 \pm 1,8)$ e TF $(1,7 \pm 1,7) \quad(P=0.4375)$. Quando realizada a comparação entre os grupos nos diferentes momentos T0 $(P=0,2151)$ e TF $(P=0,8309)$, não houve diferença estatística significante (Gráfico 2).

Gráfico 2 - Resultados dos escores segundo a Escala de Glasgow aferidos pelo avaliador nos momentos T0 e TF - FMVZ-USP - São Paulo - 2015

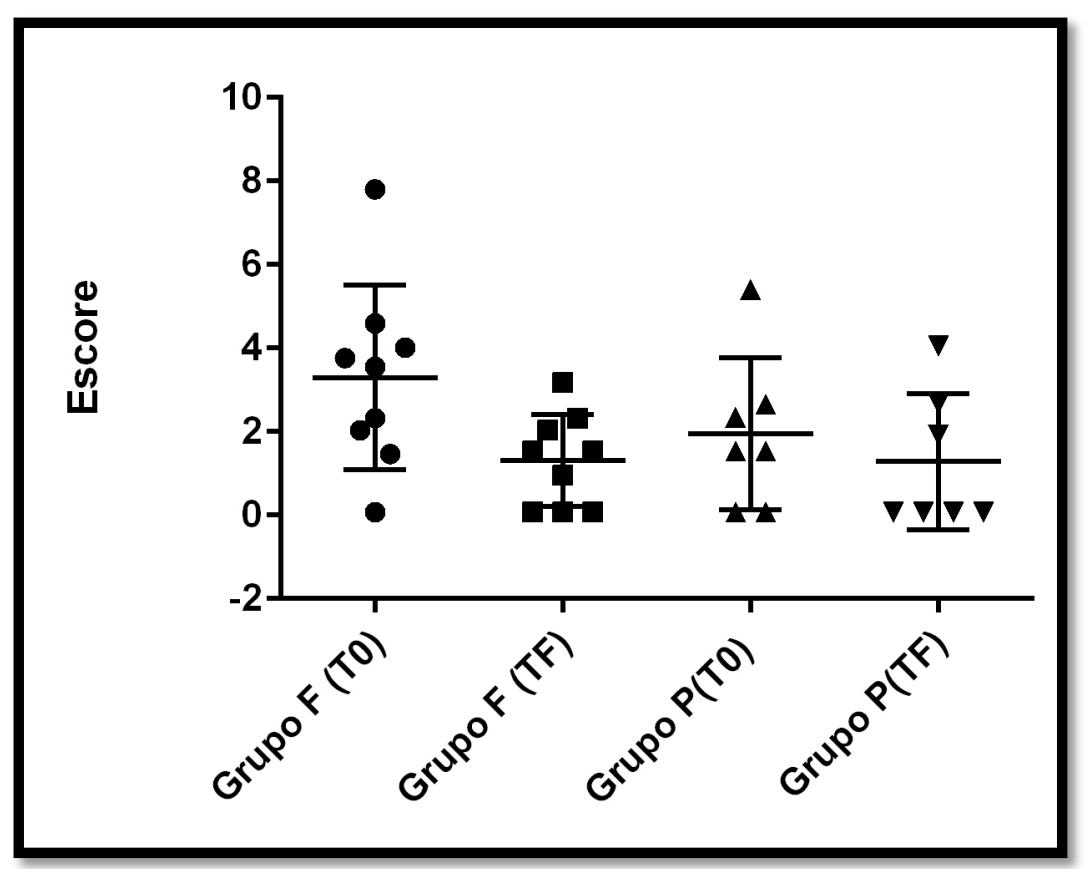




\subsection{ANÁLISE PERIMÉTRICA}

Quando considerados os valores obtidos de perimetria da articulação fêmoro-tíbio-patelar acometida (Apêndice $C$ ), o grupo Fisioterapia apresentou

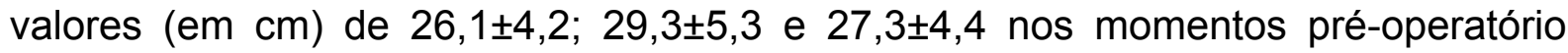
(APRE), T0 e TF respectivamente. No grupo Placebo, os respectivos valores foram de $26,0 \pm 1,5 ; 26,9 \pm 3,0$ e $25,6 \pm 2,6$.

$\mathrm{Na}$ análise seriada houve diferença entre os momentos APRE, T0 e TF em ambos os grupos $(P<0,05)$. Em ambos os grupos houve aumento nos valeres de perimetria no pós-operatório, e, este, ainda, foi significativo ao momento da avaliação final.

Para comparação entre os dois grupos, foi calculada a diferença entre as medidas inicial e final, divididos pela medida inicial. Obteve-se nesta comparação outras duas médias e desvios padrão (para o grupo $F$ de $-0,06 \pm 0,1$ e $-0,04 \pm 0,03$ para o grupo $M$ ) que se refere à diferença da perimetria entre os momentos do estudo. Os números referem-se à valores negativos pois houve uma redução do edema entre as análises T0 e TF, considerando, assim, que não houve diferença entre os grupos em relação à medida de diferença de perimetria (Gráfico 3).

Gráfico 3 - Valores de média e desvio padrão da medida de perimetria da articulação fêmoro-tíbiopatelar nos momentos TPRE, T0 e TF - FMVZ-USP - São Paulo - 2015

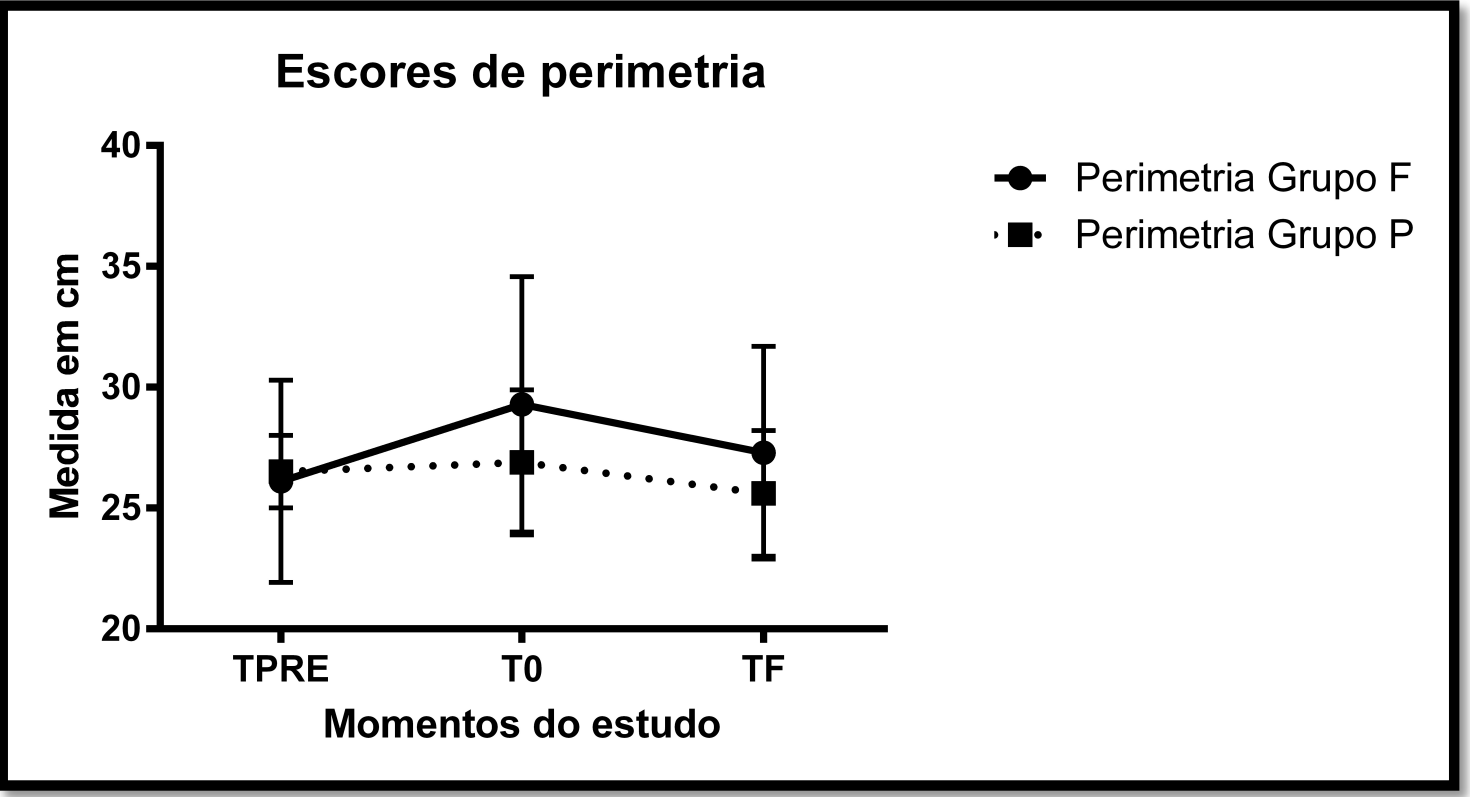




\subsection{AVALIAÇÃO DAS ESCALAS DE CLAUDICAÇÃO}

Nas avaliações das escalas de claudicação 1 e 2 não houve significância estatística $(P<0,05)$ entre os grupos nos diferentes momentos do estudo. Também não foi significante a comparação seriada nos grupos tanto na escala 1 , quanto na escala 2 (Tabela 6). Os escores obtidos dos animais em cada escala estão demostrados no apêndice $B$.

Tabela 6 - Média e desvio padrão dos escores de claudicação das escalas 1 e 2, nos diferentes grupos nos momentos T0 e TF - FMVZ-USP - São Paulo - 2015

\section{Avaliação T0 Avaliação TF}

$\begin{array}{llll}\text { Grupo } & \text { Escala } 1 & \text { Escala } 2 & \text { Escala } 1\end{array}$

\begin{tabular}{lllll}
\hline Fisioterapia & $3,4 \pm 1,0$ & $2,3 \pm 1,1$ & $2,8 \pm 0,7$ & $1,6 \pm 1,2$ \\
Placebo & $3,1 \pm 0,8$ & $2,2 \pm 1,1$ & $2,7 \pm 1,1$ & $1,7 \pm 1,1$ \\
\hline
\end{tabular}

\subsection{ANÁLISE CINÉTICA POR BAROPODOMETRIA}

A análise cinética pela baropodometria foi realizada no membro acometido nos momentos PPRE e TF. Foram analisados o Pico de Força Vertical e o Impulso Vertical, transformados nas medidas de PFV (\%PC) e IV (\%PC*s). Os resultados da medida de $\mathrm{PFV}(\% \mathrm{PC})$ (Apêndice $\mathrm{E})$, em média e desvio padrão, dos grupos nos diferentes momentos, estão representados na tabela 7 e os valores no gráfico 4: 
Tabela 7- Média e desvio padrão dos valores de baropodometria de PFV(\%DA), nos diferentes grupos e momento TPRE e TF - FMVZ-USP - São Paulo - 2015

\section{Avaliação TPRE Avaliação TF}

$\begin{array}{lll}\text { Grupo } & (\% \mathrm{PC}) & (\% \mathrm{PC})\end{array}$

\begin{tabular}{lll}
\hline Fisioterapia & $17,7 \pm 5,6$ & $16,0 \pm 4,4$ \\
Placebo & $15,9 \pm 6,5$ & $13,7 \pm 5,9$ \\
\hline
\end{tabular}

Gráfico 4 - Valores de baropodometria do parâmetro de PFV(\%DA) expressos em Newtons (N) FMVZ-USP - São Paulo - 2015

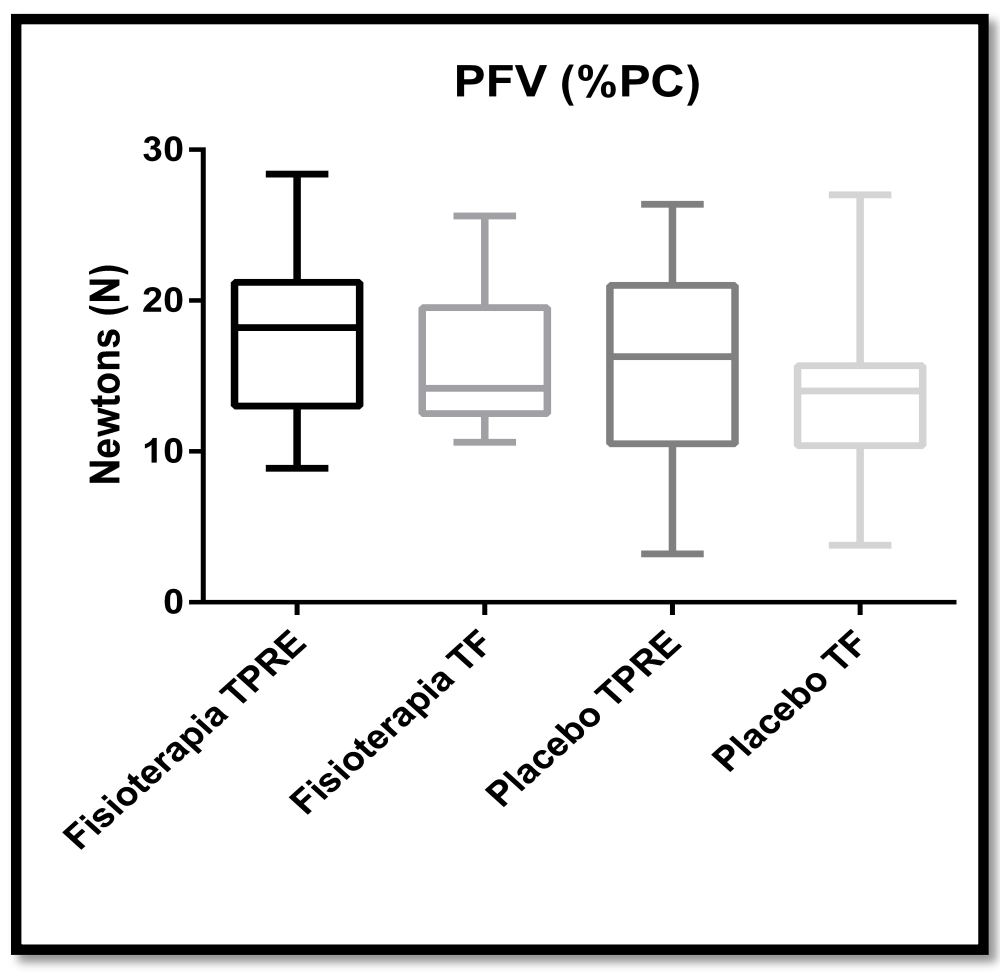

Em análise seriada, em ambos os grupos, houve uma redução do valor de $\mathrm{PFV}(\% \mathrm{PC})$ na análise final, mostrando uma redução esperada do apoio no pósoperatório tardio. Os valores obtidos para o grupo $\mathrm{F}$ geraram um valor de $\mathrm{P}=0,0067$ e $\mathrm{P}=0,0052$ no grupo $M$. Comparando-se os valores entre os grupos, não houve diferença entre os grupos no TPRE $(P=0,185)$ e nem no TF $(P=0,102)$.

Os resultados da medida de IV(\%PC*s) estão apresentados no apêndice $\mathrm{E}$, e os valores média e desvio padrão dos grupos nos diferentes momentos, representados na tabela 8 e no gráfico 5 . 
Tabela 8 - Valores de média e desvio padrão da baropodometria considerando o IV(\%PC*s) nos momento TPRE e TF dos grupos Fisioterapia e Placebo - FMVZ-USP - São Paulo 2015

\section{Avaliação TPRE $\quad$ Avaliação TF}

Grupo

$\left(\% P C^{*} s\right)$

$\left(\% \mathrm{PC}^{*} \mathrm{~s}\right)$

Fisioterapia

Placebo
$5,6 \pm 2,1$

$3,8 \pm 1,5$
$5,0 \pm 2,2$

$3,35 \pm 1,5$

Gráfico 5 - Valores obtidos pela baropodometria considerando o IV(\%PC*s) expressos em N*s FMVZ-USP - São Paulo - 2015

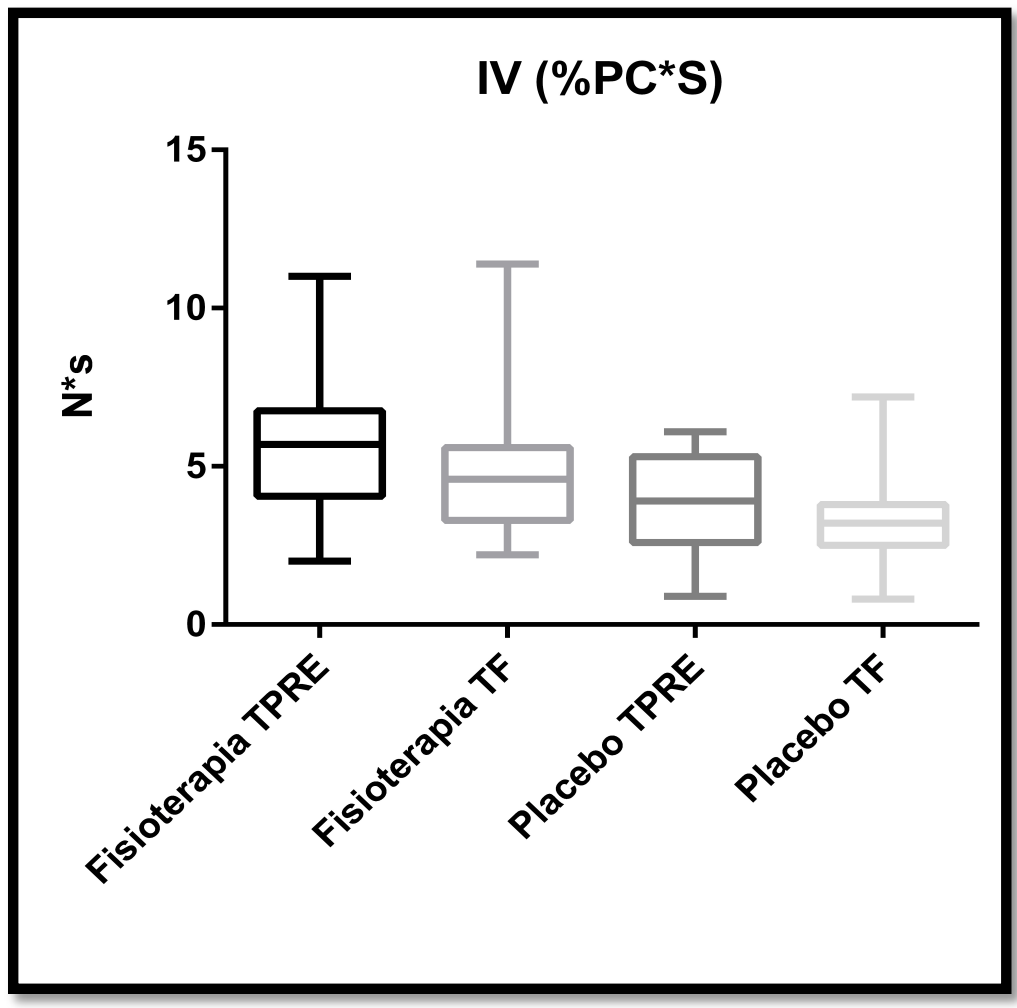

Nas análises seriadas, mostrou-se uma diminuição nas médias de IV(\%PC*s) em ambos os grupos, similar ao que ocorreu com PFV(\%PC), sendo esta diminuição significativa, com valores de $\mathrm{P}=0,03$ para ambos os grupos nesta análise seriada.

Já na análise comparativa entre os grupos, diferentemente do que ocorreu com o PFV(\%PC), houve uma diferença significante entre os grupos nos momentos. 
No momento TPRE a comparação entre os grupos nos fornece um valor de $P<0,05$. No momento TF, também apresentou-se uma diferença significativa com $P<0,05$, tendendo à melhora do grupo $\mathrm{F}$ em relação ao grupo $\mathrm{M}$.

\subsection{ANÁLISE TERMOGRÁFICA}

$\mathrm{Na}$ análise termográfica do joelho acometido, foram comparados os animais do mesmo grupo em diferentes momentos (análise seriada) e entre os grupos nos diferentes momentos.

A análise termográfica no grupo Fisioterapia nos momentos TPRE, T0 e TF (Apêndice D) resultaram em valores de média e desvio padrão respectivamente $34 \pm 1,9 ; 35,4 \pm 1,4 ; 35 \pm 1,9$. No grupo Placebo, os resultados obtidos foram respectivamente $35,1 \pm 1 ; 35,6 \pm 1,3 ; 35,8 \pm 0,9$ (Gráfico 6):

Gráfico 6 - Resultado das análises termográficas entre os grupos F e P nos momentos TPRE, T0 e TF- FMVZ-USP - São Paulo - 2015

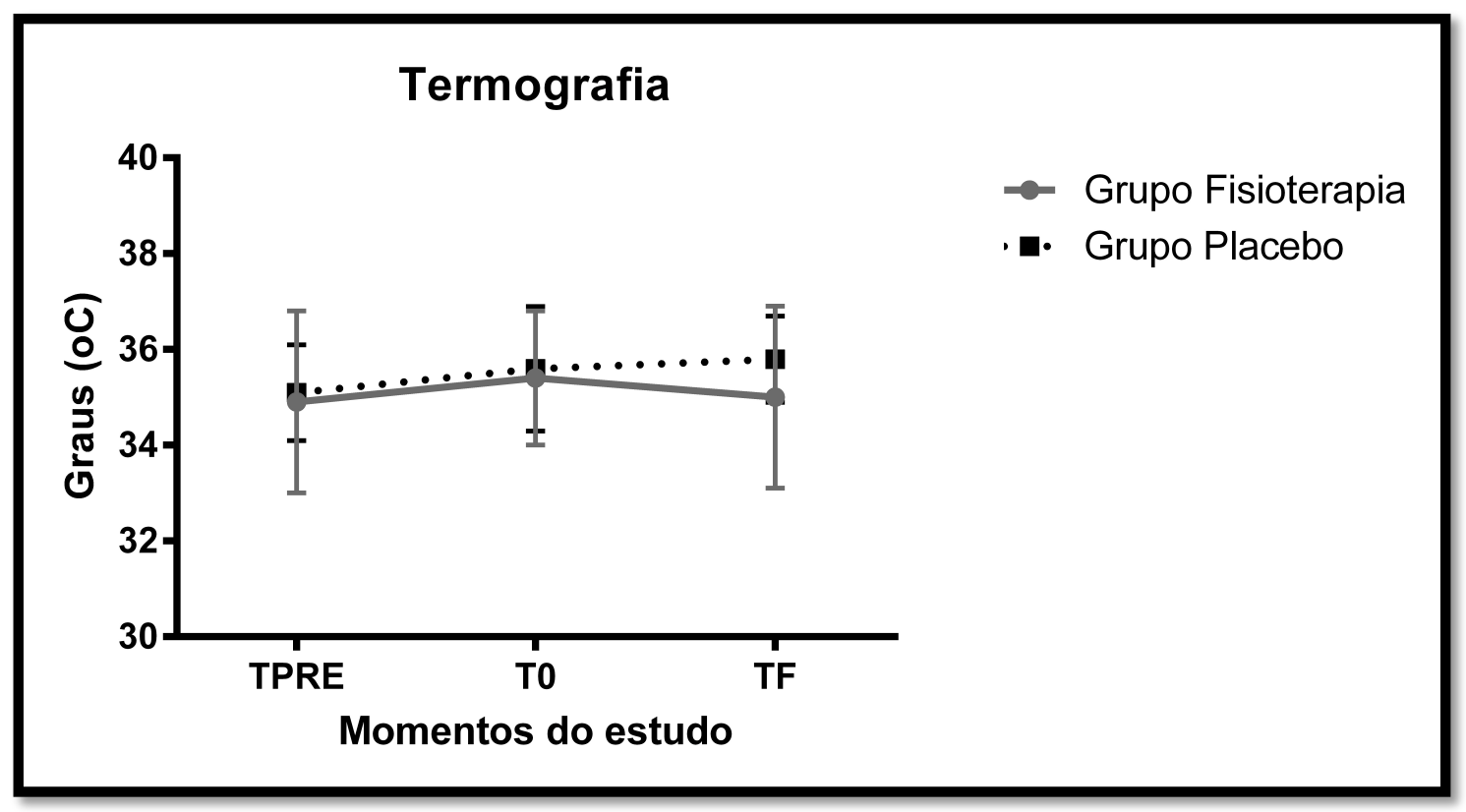

Pela análise seriada de cada grupo, houve diferença estatística do TPRE para o momento T0, seguido também de diferença significativo para o TF, com um aumento dos valores da termografia, evidenciando a inflamação no joelho do animal após o procedimento cirúrgico. Nos dois grupos, no momento da avaliação final, ainda apresentavam uma alteração na termografia com aumento da temperatura 
média, mostrando que, aos 17-20 dias, ainda não houve completa resolução da injúria. Não houve diferença quando comparados os grupos entre si, nos diferentes momentos, com valores de $\mathrm{P}$ maiores do que 0,05 em todas as análises feitas intergrupos. 


\section{DISCUSSÃO}

As evidências científicas sobre a eficácia das técnicas de fisioterapia e reabilitação que são aplicadas em cães é pequena, o que gera a necessidade de estudos bem conduzidos e de qualidade, envolvendo procedimentos já consagrados na reabilitação em humanos. Considerando que o cão tem sido empregado como modelo para o estudo da dor, bem como das técnicas de reabilitação em humanos (MILLIS; CIUPERCA, 2015), e, até mesmo da eletroacupuntura (GROPPETTI et al., 2011), o presente estudo demonstrou que as técnicas preconizadas para o homem podem ser adaptadas e utilizadas com sucesso em cães. De fato, os animais submetidos à fisioterapia apresentaram benefícios em relação ao controle da dor pós-operatória, sem apresentar efeitos colaterais, mostrando através de uma metodologia precisa, a importância das técnicas de reabilitação na medicina veterinária.

A técnica escolhida para o alívio da dor foi o TENS, por sua ampla utilização na área de reabilitação humana (SLUKA; WALSH, 2003). Considerando o período pós-operatório em que foi realizado o estudo, ou seja, dos 3-5 dias até os 17-20 dias de PO, a dor tinha as características crônicas, segundo os conceitos da eletroterapia estabelecidos por Agne (2009, 2013): animal permitia o toque e a movimentação, porém claudicava ao andar e ao se movimentar. A eletroterapia foi de fácil aplicação e aceitação por parte dos animais, e a transposição de técnicas de eletroterapia humanas denominadas como aplicação referida, o uso de dermatômeros e a aplicação local (BERGER, 1999), foram transpostas sem dificuldades. Da mesma forma que ocorreu com a eletroterapia, a laserterapia teve grande aceitação por parte dos animais, sem nenhuma dificuldade em sua aplicação.

Os resultados do presente estudo demonstram que os animais do grupo submetido a sessões de fisioterapia reais tiveram uma melhora nos escores de dor ao longo do tempo, sendo que, nenhum animal precisou de resgate analgésico, ao contrário do grupo controle, onde três animais precisaram de resgate. A despeito do pequeno número de animais, evidenciou-se que o grupo controle não apresentou melhora significativa da dor. Comparando-se o grau de decaimento da dor entre os dois grupos, nos escores de dor de ENV, houve uma diferença significativa de 
melhora do grupo fisioterapia nos escores do avaliador, o que reafirma que este grupo teve ganhos no controle álgico com a terapia, em comparação ao grupo placebo.

Não há estudos similares em cães sobre o uso do TENS em pósoperatório de cirurgia de joelho. Em humanos, porém, um trabalho analisou os efeitos do uso do TENS após artroplastia total de joelho (BREIT; WALL; VAN DER, 2004). Neste estudo foram estabelecidos três grupos de tratamento: um grupo controle, onde era realizada somente a medicação pós-operatória, um grupo com medicação somado à aplicação de TENS, e um terceiro grupo onde foi realizada a aplicação de TENS placebo e medicação. Para aplicação do TENS, foi utilizada a técnica local no joelho nas primeiras 24 horas após a cirurgia, sendo avaliados o grau de sedação, requerimento de analgesia epidural ou o uso de analgésicos pelo paciente. Os resultados não mostraram diferença significativa entre os grupos nos três parâmetros citados anteriormente, sendo que não houve ganho na analgesia pós operatória com o uso do TENS no período de 24 horas. Considerando apenas um estudo e referente à na área humana, onde fatores psicológicos apresentam significativa influência na recuperação do paciente (MEDOFF; COLLOCA, 2015) não se pode afirmar que a técnica de TENS não trará resultados no pós-operatório imediato também em cães, sugere-se desta forma um estudo similar na medicina veterinária.

Se considerarmos o uso da eletroacupuntura, a literatura é vasta, porém esta modalidade não deve ser usada como uma transposição direta para o TENS. $\mathrm{Na}$ analgesia pela eletroacupuntura são utilizadas agulhas e estimulação em pontos específicos, além de configurações da corrente elétrica diferentes do TENS. Acredita-se, porém, que haveria alguma resposta fisiológica similar aos estímulos por diferentes tipos de eletroanalgesia. Um estudo mostrou evidências do uso da eletroanalgesia em cães, na modalidade da eletroacupuntura (GROPPETTI et al., 2011). Foi comparada a eletroanalgesia em pontos de acupuntura ao grupo controle tratado com butorfanol, sendo os animais randomizados entre os grupos e avaliados por escores de dor. Os animais do grupo tratado com eletroacupuntura obtiveram uma analgesia prolongada, sem necessidade de resgate, enquanto seis animais do grupo controle necessitaram de resgate analgésico.

Foi encontrado um único estudo em cães sobre o uso de TENS na articulação fêmoro-tíbio-patelar, onde avaliou-se a dor e o grau de apoio dos cães 
que apresentavam osteoartrose de joelho (JOHNSTON et al., 2002). Cinco animais foram tratados com TENS localmente com uma frequência pré-estabelecida de 70 $\mathrm{Hz}$, em sequência submetidos à avaliação por baropodometria, imediatamente após o tratamento e a cada 30 minutos, por até 4 horas. Houve melhora nas medidas de força de reação ao solo imediatamente após o tratamento, e esta melhora persistiu significativamente por 210 minutos. O estudo indica um provável efeito benéfico do TENS em cães com osteoartrite de joelho, porém a ausência de um grupo controle requer que mais estudos como o presente sejam realizados.

Quando comparadas diferentes correntes elétricas para eletroanalgesia em cães, há apenas um único estudo na literatura (KRSTIC et al., 2010) envolvendo a comparação entre TENS, corrente interferencial e micro-ondas no alívio de dor crônica secundária à espondilose anquilosante. Os animais eram tratados pelas diferentes formas de eletroterapia, anteriormente citadas, por 15 minutos durante 10 dias consecutivos. Todos os grupos obtiveram resultados positivos, porém o grupo submetido à aplicação de TENS apresentou a maior diferença nos quesitos de dor. Novamente a ausência de um grupo controle prejudica a interpretação dos dados, o que torna o presente estudo importante na comparação dos efeitos de analgesia com eletroterapia.

Assim como nos estudos-supra citados, não foi observado nenhum efeito colateral da aplicação da eletroanalgesia, o que mostra ser uma técnica segura quando utilizada corretamente, como afirmam também Hanks, Levine e Bockstahler (2015).

Houve similaridade das avaliações entre as escalas de dor utilizadas, porém todas mostraram subjetividade na avaliação, o que corrobora com alguns autores que afirmam que a avaliação fisiátrica do paciente deve ser multimodal (MORTON et al., 2005; HYYTIÄINEN et al., 2013), além de ser essencial a associação entre escalas unidimensionais com multidimensionais como também afirmaram Hawker et al. (2011) e Epstein et al. (2015).

Não houve diferença entre a percepção de dor entre o avaliador e o cuidador do animal, o que também foi citado por outros estudos os quais asseguram que o proprietário pode ser um bom parâmetro para a avaliação do animal (INNES, 1998; BUFALARI et al., 2007), porém não deve ser o único.

Em relação à formação de edema, não houve diferença neste estudo quando os grupos foram comparados entre si. O principal parâmetro para esta 
avaliação foi a perimetria da articulação acometida, sendo que se mostrou uma medida viável e de fácil mensuração, de acordo com o que é referido por Baker et al. (2010). Ressalta-se a importância na padronização da mensuração para obter-se uma medida confiável, assim como referido em Millis e Ciuperca (2015). Mesmo em análise da diferença da perimetria, houve a similaridade entre os grupos. Desta forma, não foi possível evidenciar o efeito anti-edematoso da laserterapia relatado amplamente na literatura científica (BJORDAL et al., 2006; BORATO et al., 2008; FARIVAR; MALEKSHAHABI; SHIARI, 2014). Doses diárias de laserterapia foram utilizadas em um estudo em ratos, no qual se induziu a inflamação aguda do joelho por infiltração articular, sendo que a laserterapia foi aplicada por 5 dias (parâmetros de caneta de $810 \mathrm{~nm}$, dosificação de 3 a $30 \mathrm{~J} / \mathrm{cm}^{2}$ ) (CASTANO et al., 2007). No referido estudo, o efeito anti-edematoso e anti-inflamatório da laserterapia foi tão eficiente quando no grupo controle, onde utilizou-se a dexametasona como medicação anti-inflamatória.

Não é possível afirmar o porquê não houve a redução do edema no grupo que recebeu as sessões reais de laserterapia. Em primeiro lugar, pode haver influência do número pequeno da amostra, mas também pode estar relacionado com o intervalo de aplicação, pois em estudos como o de Castano et al. (2007), as aplicações eram diárias, e, neste presente estudo, foram possíveis apenas 6 aplicações em um período de 2 semanas.

Uma revisão sistemática (BJORDAL et al., 2006) evidencia o efeito positivo do laser sobre a inflamação aguda, modulando a resposta inflamatória pela redução de marcadores biocelulares como PGE2, mRNA Cox 2, modulação do estresse oxidativo ou ainda de forma sugestiva na modulação de IL-1 e TNF. Esta revisão afirma que estes resultados são dose-dependentes, em um intervalo de 0.3$19 \mathrm{~J} / \mathrm{cm}^{2}$. Ressalta-se que também não houve efeitos negativos ou piora no edema nos animais do grupo fisioterapia, que receberam as 6 aplicações de laserterapia.

A análise da claudicação pelas escalas mostrou-se pouco sensível, e apesar de não evidenciada diferença entre os grupos fisioterapia e medicação, a subjetividade destas análises deve ser levada em conta como também referem Waxman et al. (2008). Por este fato, optou-se, no trabalho, acrescentar a análise baropodométrica, como uma medida objetiva de avaliação dos animais submetidos à cirurgia de ligamento cruzado cranial.

A baropodometria mostrou-se um importante método para avaliação da 
claudicação nos animais do estudo, por ser uma medida precisa e não subjetiva. Esta metodologia é amplamente utilizada para aferir o resultado de intervenções ou tratamentos na ortopedia veterinária, entre elas, lesões de ligamento cruzado cranial (SOUZA; TATARUNAS; MATERA, 2014). Na fisioterapia veterinária, a análise cinética também tem sido amplamente utilizada como forma de avaliar os resultados decorrentes da reabilitação do paciente (HENDERSON; LATIMER; MILLIS, 2015), porém deve ser associada à avaliação outros métodos para a avaliação da dor (SHARKEY, 2013).

No presente estudo compararam-se os dados dos animais antes da cirurgia e aos 17-20 dias de pós-operatório, na avaliação final. Nesta fase do tratamento é esperada uma piora no apoio, como referido por diversos autores (MARSOLAIS; DVORAK; CONZEMIUS, 2002; BALLAGAS et al., 2004; LEE et al., 2007; AU et al., 2010), o que foi também mostrado pelos valores de IV e PFV em nosso estudo.

Os valores de PFV(\%PC) não mostraram diferença entre os animais que foram submetidos às sessões reais comparados ao grupo placebo. Porém ressaltamos que esta análise do grupo controle pode ser influenciada pelo resgate analgésico e baixo número de indivíduos nesta amostra. No estudo do parâmetro de Impulso Vertical (\%PC*s), apresentou-se uma diferença significativa entre os grupos entre todos os momentos, tendendo a melhores resultados de apoio do grupo submetido à fisioterapia. Porém, deve-se considerar que o valor de IV tem $70 \%$ de acurácia quando analisado ao passo (KROTSCHECK et al., 2014), e portanto mostra-se mais confiável a análise anterior de PFV, onde não houve diferença entre os grupos.

Em relação à fisioterapia, nenhum trabalho avaliou isoladamente o uso de eletroanalgesia ou da laserterapia no pós-operatório em cães. Marsolais, Dvorak e Conzemius (2002) estudaram os efeitos da fisioterapia no pós-operatório recente de cirurgia de sutura fabelo-tibial em cães, utilizando em seu protocolo massoterapia, cinesioterapia e hidroterapia, sendo que, a partir da $4^{a}$ semana até a $16^{a}$, foram orientados exercícios domiciliares. O grupo controle recebeu a orientação de restrição de exercícios até a $4^{\mathrm{a}}$ semana. A análise cinética mostrou que os animais submetidos ao programa de reabilitação obtiveram um resultado de PFV 15,5\% maior que os animais onde o exercício foi restrito, e 13,9\% maior na medida de Impulso Vertical. Esta análise foi realizada 6 meses após a cirurgia, ou seja, distante 
da intervenção realizada pela fisioterapia que foi até a $4^{a}$ semana de pós cirúrgico, e, mesmo assim, manteve-se um benefício do grupo tratado.

Um outro estudo de Au et al. (2010) avaliou as cirurgias de TPLO e sutura fabelo-tibial, em relação à análise cinética. Ambos os grupos foram submetidos ao tratamento com protocolos de fisioterapia que envolviam cinesioterapia e hidroterapia em esteira aquática. O grupo que foi submetido à TPLO apresentou uma piora na análise cinética em relação aos parâmetros de forças de reação ao solo, nas três semanas de pós-operatório, da mesma forma que no presente estudo. A melhora no apoio somente foi considerada significante pela análise cinética às 7 semanas de pós-operatório.

Um último estudo avaliou o efeito da fisioterapia no pós-operatório recente em cães submetidos à TPLO, comparando-se a fisioterapia realizada 3 vezes por semana em um centro de reabilitação a exercícios passados para o cuidador realizar em domicílio. Os animais foram avaliados aos dias $1^{\circ}, 10^{\circ}$, às 3 semanas e às 6 semanas após a cirurgia. Da mesma forma, foram utilizados recursos da cinesioterapia e hidroterapia em esteira aquática para o protocolo fisioterapêutico sendo que o grupo que recebeu fisioterapia obteve melhores escores de amplitude de movimento e de perimetria do membro acometido.

Destacamos e concordamos com os autores anteriormente citados sobre a importância dos exercícios e da hidroterapia no processo de reabilitação de animais submetidos à cirurgia de ligamento cruzado cranial. Como o objetivo do presente estudo foi especificamente o estudo da dor e dos efeitos da eletroterapia e da laserterapia, como medida de padronização, os animais foram mantidos em restrição de exercícios durante o projeto. Aos animais do grupo Fisioterapia, ficou a critério do cirurgião, após o término das 6 sessões do projeto, o encaminhamento à realização de mais sessões de fisioterapia nas quais incluíssem a cinesioterapia e hidroterapia necessárias. Ao grupo placebo, como foram oferecidas mais 6 sessões de tratamento após as sessões do projeto, nas quais incluíram-se as técnicas necessárias aos animais individualmente.

A termografia mostrou-se um método sensível para avaliação da inflamação do joelho. Em ambos os grupos a termografia evidenciou um aumento estatisticamente significante da temperatura nos momentos de avaliação inicial comparados à avaliação pré-operatória. Este aumento ainda estava presente após 3 semanas do procedimento cirúrgico no momento da avaliação final, o que sugere a 
presença de inflamação residual na articulação. Não foi possível evidenciar o efeitos anti-inflamatórios da laserterapia neste estudo, pois não apresentaram diferenças significativas entre os grupos na temperatura ao momento da avaliação final, porém concordamos com Pryor e Millis (2015), que a laserterapia deve ser um tratamento indicado no período pós-operatório, quando mais estudos clínicos são necessários para evidenciar os resultados observados na rotina da fisioterapia veterinária.

Em um estudo realizado em humanos, com metodologia duplo-cego, randomizado com grupo placebo, mostrou-se a melhora nos grupos tratados com a laserterapia (HEGEDUS et al., 2009). No estudo foi utilizado um laser com configurações similares ao que utilizamos, ou seja, uma caneta de $830 \mathrm{~nm}$, contínua, potência de $50 \mathrm{~mW}$ na dosificação de $6 \mathrm{~J} /$ ponto, para tratamento de osteoartrose moderada. Foram estabelecidos dois grupos, em que um recebeu a aplicação do laser duas vezes na semana por quatro semanas, o outro recebeu aplicações placebo, com uma caneta de potência inexpressiva $(0,5 \mathrm{mV})$. O grupo tratado com a laserterapia real obteve uma melhora significativa nos quesitos dor, amplitude de movimento, sensibilidade à pressão e na escala de dor empregada (Escala Numérica Visual). Neste estudo citado, o grupo tratado obteve um aumento da temperatura de $0,58{ }^{\circ} \mathrm{C}$, fato que os autores referem como um achado positivo $\mathrm{e}$ considerado como um incremento na circulação sanguínea na articulação acometida pela artrose. Como não há padronização nas dosificações da laserterapia na literatura científica, tanto na área humana quanto na veterinária, não podemos afirmar se a não resposta de nosso estudo está relacionada à uma dosificação não adequada. Mais estudos são necessários a fim de aprofundar sobre os efeitos da laserterapia na inflamação, principalmente por meio de estudos clínicos com metodologia adequada, além da padronização dos parâmetros.

Concordamos que a termografia foi um método de fácil coleta e uma forma válida de diagnóstico complementar como citado por Harper (2000) e também referido por Marino e Loughin (2010). A análise termográfica apresenta a ressalva de não diferenciar as possíveis causas do aumento de temperatura, como, por exemplo, infecções, inflamações ou, até mesmo, neovascularização, reafirmando que não deve ser a única forma de avaliação.

$\mathrm{Na}$ área de reabilitação, a termografia tem ganho espaço pelas vantagens acima citadas. Em equinos (WESTERMANN et al., 2013) e na área humana, diversos artigos referem o uso da termografia como um exame complementar 
(RING; AMMER, 2012; MEIRA et al., 2014). Em cães, é citado por Marino e Loughin (2010) como um dos métodos válidos para a avaliação do joelho em cães. Na área de reabilitação, Um et al. (2005) verificou o efeito da acupuntura em artrite induzida em cães. Foi aplicada uma sessão semanal, por quatro semanas, sendo que após 3 semanas evidenciou-se uma diferença significativa, com melhora na avaliação termográfica entre o grupo tratado e o não tratado com acupuntura.

As limitações deste estudo devem ser consideradas, destacando o número limitado de pacientes em cada grupo e a presença de resgate analgésico. $O$ resgate pode ter alterado alguns dados na análise final dos pacientes do grupo medicação, porém, por questões éticas, é imprescindível assumir estas alterações. A presença de animais com lesão bilateral de ligamento cruzado cranial foi minimizada entre os grupos, diminuindo o impacto deste item nas análises.

A inclusão de diversas raças no estudo também foi necessária para possibilitar o estudo, porém ressaltamos que este item reflete a população de cães que são submetidos à cirurgia para correção de RLCCr, relevante na proposta de um estudo clínico como este.

Os critérios de inclusão e exclusão foram adequados, além da metodologia ter contribuído de forma inédita às pesquisas na área de reabilitação veterinária. A metodologia proposta neste estudo atingiu seu objetivo, fazer uma avaliação multimodal do paciente, gerando uma fidedigna avaliação dos quesitos dor e inflamação no pós-operatório. 


\section{CONCLUSÕES}

Concluímos que as técnicas de eletroterapia através de TENS associado à laserterapia são eficazes como método adjuvante no controle álgico, e devem ser indicadas no pós-operatório recente de TPLO, diminuindo a necessidade de resgate analgésico durante este período. As técnicas de fisioterapia utilizadas no estudo mostraram-se seguras e sem efeitos colaterais.

A termografia é uma técnica adequada e segura para a avaliação da inflamação na articulação fêmoro-tíbio-patelar dos cães, com grande sensibilidade a pequenas variações de temperatura, porém deve ser usada como método complementar à avaliação clínica. 


\section{REFERÊNCIAS}

AGNE, J. E. Eu sei eletroterapia. 2. ed. Santa Maria: Palloti, 2009. 400 p.

AGNE, J.E. Eletrotermofototerapia. Santa Maria: O Autor, 2013. 448 p.

ALMEIDA, R. M.; ESCOBAR, A.; MAGUILNIK, S. Comparison of analgesia provided by lidocaine, lidocaine-morphine or lidocaine-tramadol delivery epidurally in dogs following orchiectomy. Veterinary Anesthesia and Analgesia, v. 37, n. 6, p. 542549, 2010.

ABERGEL, R: Biochemical mechanisms of wound and tissue healing with lasers. In: CANADIAN LOW POWER MADICAL LASER CONFERENCE, 1987, Ontario, Canadá. Proceedings.., Ontario, Canadá,1987.

ANBAR, M. Clinical thermal imaging today: shifting from phenomenological Thermography to pathophysiolocally based thermal imaging. Engineering in Medicine and Biology, v. 17, n. 4, p. 25-33, 1998.

ANNEROTH, G.; HALL, G.; RYDEN, H.; ZETTERQUIST, L. The effect of low energy infra-red laser radiation on wound healing in rats. British Journal of Oral and Maxillofacial Surgery, v. 26, p.12-7, 1988.

AU, K. K.; GORDON-EVANS, W. J.; DUNNING, D.; O'DELL-ANDERSON, K. J.; KNAP, K. E.; GRIFFON, D.; JOHNSON, A. L. Comparison of short- and long-term function and radiographic osteoarthrosis in dogs after postoperative physical rehabilitation and tibial plateau leveling osteotomy or lateral fabellar suture stabilization. Veterinary Surgery, v. 39, p. 173-180, 2010.

BAKER, S. G.; ROUSH, J. K.; UNIS, M. D.; WODISKE, T. Comparison of four commercial devices to measure limb circumference in dogs. Veterinary Comparative Orthophaedics Traumatology, v. 23, p. 406-10, 2010.

BALLAGAS, A. J.; MONTGOMERY, R. D.; HENDERSON, R. A.; GILLETTE, R. Preand postoperative force plate analysis of dogs with experimentally transected cranial cruciate ligaments treated using tibial plateau leveling osteotomy. Veterinary Surgery, v. 33, n. 2, p. 187-90, 2004.

BARLETTA, M.;YOUNG, C. N.; QUANDT, J. E.; HOFMEISTER, E. H. Agreement between veterinary students and anesthesiologists regarding postoperative pain assessment in dogs. Veterinary Anaesthesia and Analgesia, v. 12269, p. 1-8, 2015.

BERGER, P. The role of the physiotherapist in the treatment of complex peripheral pain syndromes. Pain Reviews, v. 6, p. 211-232, 1999. 
BERGH, M. S.; SULLIVAN, C.; FERREL, C. L.; TROY, J.; BUDSBERG, S. C. Systematic review of surgical treatments for cranial cruciate ligament disease in dogs. Journal American Animal Hospital Association, v. 50, p. 315-321, 2014.

BJORDAL, J. M.; JOHNSON, M. I.; IVERSEN, V.; AIMBIRE, F.; LOPES-MARTINS, R. A. B. Low-level laser therapy in acute pain: a systematic review of possible mechanisms of action and clinical effects in randomized placebo-controlled trials.

Photomedicine and Laser Surgery, v. 24, n. 2, p. 158-68, 2006.

BORATO, E.; OLIVEIRA, J. J. J.; CIENA, A. P.; BERTOLINI, G. R. F. Avaliação imediata da dor e edema em lesão muscular induzida por formalina e tratada com laser 808 nm. Revista Brasileira de Medicina do Esporte, v. 14, n. 5, p. 446-449, 2008.

BOWSHER, D. Termination of the central pain pathway in man: the concious appreciation of pain. Brain, v. 80, p. 606-22, 1957.

BOURGUIGNON, A. M. F.; FEITOSA, R. C. A.; BELTRÃO, G. C.; PAGNONCELLI, M. R. Utilização do laser de baixa intensidade no processo de cicatrização tecidual. Revisão de literatura. Revista Portuguesa Estomatologia e Cirurgia Maxilofacial, v. 46, p. 37-43, 2005.

BRADLEY, P. F. Pain relief in laser therapy. In: CONGRESS OF THE INTERNATIONAL SOCIETY FOR LASERS IN DENTRISTRY, 1996, Jerusalem. Proccedings... Bologna: Monduzzi, 1996. p.1-6.

BREIT, R.; VAN DER WALL, H. Transcutaneous electrical nerve stimulation for postoperative pain relief after total knee arthroplasty. The Journal of Arthroplasty, v. 19, n. 1, p. $45-48,2004$.

BROWN, D.; CURRY, C.; RUTERBORIES, L.; AVERY, F.; ANSON, P. Evaluation of pain after arthroscopically assisted anterior cruciate ligament reconstruction.

American Journal Sports Medicine, v. 25, n. 2, p. 182-6, 1997.

BUFALARI, A.; ADAMI, C.; ANGELI, G.; SHORT, C. E. Pain assessment in animals. Veterinary Research Communications, Amsterdam, v. 31, n. 1, p. 55-58, 2007.

CAMELO, F. P. Avaliação clínica do efeito da irradiação pós-operatória do laser de baixa intensidade na cicatrização de gengivoplastias em humanos. 2007. 83 p. Dissertação (Mestrado) - Universidade Federal do Rio Grande do Norte, Natal, 2007.

CASTANO, A. P. DAI, T.; YAROSLAVSKY, I.; COHEN, R.; APRUZZESE, W. A.; SMOTRICH, M. H.; HAMBLIN, M. R. Low-level laser therapy for zymosan-induced arthritis in rats: importance of illumination time. Lasers in Surgery and Medicine, $v$. 39, n. 6, p. 543-50, 2007.

CHATERED SOCIETY OF PHISIOTHERAPY (SAFETY OF ELECTROTHERAPY EQUIPAMENT WORKING GROUP). Guidelines for the safe use of lasers in physiotherapy, Physiotherapy, v. 77, n. 3, p. 169- 170, 1991.

CHENG, R. Combination laser/ eletrotherapy in pain management. In: CANADIAN 
LOW LASER CONFERENCE, 2.,1987, Ontário, Canada. Proceedings... Ontário, Canadá, 1987.

CHRISTIANSEN, J.; GEROW, G. Electronic thermography. In: CHRISTIANSEN, J.; GEROW, G. Thermography. Baltimore: Williams \& Wilkins, p.19-30, 1990.

COMERFORD, E. J.; SMITH, K.; HAYASHI, K. Update on the aetiopathogenesis of canine cranial cruciate ligament disease. Veterinary Companion Orthopedics and Traumatology, v. 24, n. 2, p. 91-98, 2011.

DECAMP, C. E. Kinetic and kinematic gait analysis and the assessment of lameness in the dog. Veterinary Clinics North American Small Animal Practice, v. 27, n. 4, p. 825-841, 1997.

DIAKIDES, N. A. Advances in medical infrared imaging. Engineering in Medicine and Biology, v. 21, n. 6, p. 32-33, 2002.

EPSTEIN, M. E.; RODANM, I.; GRIFFENHAGEN, G.; KADRLIK, J.; PETTY M. C.; ROBERTSON, S. A.; SIMPSON, W. 2015 AAHA/AAFP pain management guidelines for dogs and cats. Journal Feline Medicine Surgery, v.17, n.3, p.251-72, 2015.

FANCHON, L.; GRANDJEAN, D. Accuracy of asymmetry indices of ground reaction forces for diagnosis of hind limb lameness in dogs. American Journal Veterinary, v. 68, n. 10, p. 1089-1094, 2007.

FARIVAR, S.; MALEKSHAHABI, T.; SHIARI, R. Biological effects of low level laser therapy. Journal of Lasers in Medical Sciences, v. 5, n. 2, p. 58-62, 2014.

FARRIS, H.W. Clinical sensitivity and thermographic accuracy. In: CHRISTIANSEN, J.; GEROW, G. Thermography. Baltimore: Williams \& Wilkins, 1990. p.121-125.

GAYNOR, J. S. Control of cancer pain in veterinary patients. Veterinary Clinics of North America: small animal practice, v.38, n. 6, p, 1429-1448, 2008.

GILLETTE, R. L.; ANGLE, T. C. Recent developments in canine locomotor analysis: a review. Veterinary Journal, v. 178, n. 2, p. 165-76, 2008.

GROPPETTI, D.; PECILE, A. M.; SACERDOTE, P.; BRONXO, V.; RAVASIO, G. Effectiveness of electroacupuncture analgesia compared with opioid administration in a dog model: a pilot study. British Journal of Anaesthesia, v. 107, n. 4, p. 612-618, , 2011.

HANKS, J.; LEVINE, D.; BOCKSTAHLER, B. Physical agent modalities in physical therapy and rehabilitation of small animals. The Veterinary Clinics of North America: small animal practice, v. 45, n. 1, p. 29-44, 2015.

HARPER D.L. The value of infrared thermography in the diagnosis and prognosis of injuries in animals. In: PROPCEEDINGS OF INFRAMATION, 2000. Orlando.

Proceedings... Orlando, USA, 2000.

HARWAY, R. A. Reflex symphathetic dystrophy and pain dysfunction in the lower extremity. Journal Bone Joint Surgery American, v. 79, n. 12, p. 1894-1895, 1997. 
HAWKER, G. A.; MIAN, S.; KENDZERSKA, T.; FRENCH, M. Measures of adult pain. Arthritis Care \& Research, v. 63, n. 11, p. 240-252, 2011.

HEGEDÜS, B.; VIHAROS, L.; GERVAIN. M.; GÁLFI, M. The effect of low-level laser in knee osteoarthritis: a double-blind, randomized, placebo-controlled trial.

Photomedicine and Laser Surgery, v. 27, n. 4, p. 577-584, 2009.

HELLYER, P.; RODAN, L.; BRUNT, J.; DOWNING, R.; HAGEDORN, J. E.;

ROBERTSON, S. A. AAHA/AAFP Pain management guidelines for dogs and cats. Journal of Feline Medicine and Surgery, v. 9, n. 6, p. 466-480, 2007.

HELLYER, P. W.; ROBERSON, S. A.; FAILS, A. D. Pain and its management. Lumb \& Jones' veterinary anesthesia and analgesia. $4^{\text {th }}$ ed. Oxford: Blackwell Publishing, 2007. p. 31.

HENDERSON, A. L.; LATIMER, C.; MILLIS, D. L. Rehabilitation and physical therapy for selected orthopedic conditions in veterinary patients. The Veterinary Clinics of North America Small Animal Practice, v. 45, n. 1, p. 91-121, 2015.

HOLZLER, M. G.; HARVEY, R. C.; LIDBETTER, D. A.; MILLIS, D. L. Comparisin of perioperative analgesic protocols for dogs undergoing tibial plateau leveling osteotomy. Veterinary Surgery, v. 5, n. 34, p. 337-344, 2005.

HOMSI, C.; FERREIRA, J.; BELEZA, A. C. S. Abordagem fisioterapêutica na dor pós - operatória : a eletroestimulação nervosa transcutânea. Revista do Colégio Brasileiro de Cirurgiões, v. 34, p. 127-130, 2007.

HUDSON, J.; SLATER, M. R.; TAYLOR, L.; SCOTT, H. M.; KERWIN S.C. Assessing repeatability and validity of a visual analogue scale questionnaire for use in assessing pain and lameness in dogs. Americal Journal Veterinary Research, v.65, n. 2, p. 1634-1643, 2004.

HYYTIÄINEN, H. K.; MÖLSÄ, S. H.; JUNNILA, J.T.; LAITINEN-VAPAAVUORI, O. M.; HIELM-BJÖRKMAN A.K. Ranking of physiotherapeutic evaluation methods as outcome measures of stifle functionality in dogs. Acta Veterinaria Scandinavica, v. 55, p. 29, 2013.

INNES, J. F.; BARR, A. R. Can owners assess outcome followinf tretmebt of canine cruciate ligament deficiency? Journal of Small Animal Practice, v. 39, 1998.

JETTE, D. U. Effect of different forms of TENS on experimental pain. Physical Therapy, v. 66, p. 187-192, 1986.

JOHNSON, J.M.; JOHNSON, A. L. Cranial cruciate ligament rupture. Pathogenesis, diagnosis and postoperative rehabilitation. Veterinary Clinics of Noth America: small animal practice, Philadelphia, v. 23, n. 12, p. 717-733, 1993.

KRAMER, J. F.; SANDRIN, M. Effect of low power laser and White light on sensory conduction rate of the superficial radial nerve. Physiotherapy, v. 3, p. 165-170, 1993. 
KREISLER, M.; CHRISTOFFERS, A. B.; WILLERSHAUSEN, B.; D'HOEDT, B. Effect of low-level GaAIAs laser irradiation on the proliferation rate of human periodontal ligament fibroblasts: an in vitro study. Journal Clinic Periodontology, v. 30, p. 353358, 2003.

JOHNSTON, K. D.; LEVINE, D.; PRICE, M. N.; SCHNEIDER N. H.; MILLIS, D. L. The effect of TENS on Osteoarthritic pain in the stifle of dogs. In: Second INTERNATIONAL SYMPOSIUM ON PHYSICAL THERAPY AND REHABILITATION IN VETERINARY MEDICINE, 2., 2002, Knoxville, Tennessee. Proceedings... Knoxville, Tennessee, 2002.

KROTSCHECK, U.; TODHUNTER, R. J.; NELSON, S. A.; SUTTER, N. B.; MOHAMMED, H. O. Precision and accuracy of ground reaction force normalization in a heterogeneous population of dogs. Veterinary Surgery, v. 43, n. 4, p. 437-45, 2014.

KRSTIC, N.; LAZAREVIC-MACANOVIC, M.; PROKIC, B.; MUSTUR, D.; TANISAVLJEVIC, D. Testing the effect of different electrotherapeutic procedures in the treatment of canine ankylosing spondylitis. Acta Veterinaria (Bergard), v. 60, n. 5-6, p. 585-595, 2010.

LEE, J. Y.; KIM, G.; KIM, J.H.; CHOI, S. H. Kinematic gait analysis of the hind limb after tibial plateau levelling osteotomy and cranial tibial wedge osteotomy in ten dogs. Journal of Veterinary Medicine Series A, v. 54, n. 10, p. 579-584, 2007.

MARINO, D. J.; LOUGHIN, C. A. Diagnostic imaging of the canine stifle: a review. Veterinary Surgery, v. 39, n. 3, p. 284-295, 2010.

MARSOLAIS, G. S.; DVORAK, G.; CONZEMIUS, M. G. Effects of postoperative rehabilitation on limb function after cranial cruciate ligament repair in dogs. Journal of the American Veterinary Medical Association, v. 220, n. 9, p.1325-1350, 2002.

MARSOLAIS, G. S.; MCLEAN, S.; DERRICK, T.; CONZEMIUS, M. G. Kinematic analysis of the hind limb during swimming and walking in healthy dogs and dogs with surgically corrected cranial cruciate ligament rupture. Journal American Veterinary Medical Association, v. 222, p. 739-743, 2003.

MEDOFF, Z. M.; COLLOCA, L. Placebo analgesia: understanding the mechanisms. Pain Management, v. 5, n. 2, p. 89-96, 2015.

MEIRA, L. F. K.; NEVES E.; NEVES, E. B.; NOHAMA, P.; SOUZA, M. A. Termografia na área biomédica. Pan American Journal of Medical Thermology, $v$. 1, n. 1, p. 31-41, 2014.

MELZACK, R.; WALL, P. D. Pain mechanisms: a new theory. Science, v. 150, p. 971-979, 1965.

MENSE, S. Referral of muscle pain: new aspects. Amerincan Pain Society, v. 3, p. $1-9,1994$.

MENSE, S. Pathophysiologic basis of muscle pain syndromes. Physical Medicine and Rehabilitation Clinics of North America, v. 8, p. 23- 53, 1997. 
MENSE, S.; SCHIMIDT, R. F. Muscle pain: which receptors are responsible for the transmission of noxious stimuli? In: CLIFFORD, R. F. Physiological aspects of clinical neurology. Oxford: Blackwell, 1977. p. 265-78.

MIKAIL, S. Laser terapêutico, in PEDRO, C. R., MIKAIL, S. Fisioterapia veterinária. 2. ed. Barueri: Manole, 2009. p. 93.

MICH, P. M.; HELLYER, P. W. Objective, categoric methods for assessing and analgesia. Handbook of veterinary pain management. 2. ed. St Louis: Elsevier, 2008. p. 78.

MILLIS, D. L. Getting the dog moving after surgery darryl. Journal of the American Animal Hospital Association Postoperative, v. 40, p. 429-436, 2004.

MILLIS, D. L.; CIUPERCA, I. A. Evidence for canine rehabilitation and physical therapy. The Veterinary clinics of North America: small animal practice, v. 45, $\mathrm{n}$. 1, p. 1-27, 2015.

MILLIS, D. L.; SAUNDERS, D. G. Laser therapy in canine rehabilitation. In: MILLIS, D. L.; LEVINE, D. Canine rehabilitation and physical therapy. 2. ed. Philadelphia: Elsevier, 2014. p.760.

MOREAU, M.; LUSSIER, B.; BALLAZ, L.; TRONCY, E. Kinetic measurements of gait for osteoarthritis research in dogs and cats. Canadian Veterinary Journal, v. 55, n.1, p. 1057-1065, 2014.

MONK, M. L.; PRESTON, C. A.; McGOWAN, C. M. Effects of early intensive postoperative physiotherapy on limb function after tibial plateau leveling osteotomy in dogs with deficiency of cranial cruciate ligament. American Journal Veterinary Research, v. 67, n. 3, p. 529-536, 2006.

MORTON, C.; REID, J.; SCOTT, E.; NOLAN, A. Application of a scaling model to establish and validate an interval level pain scale for assessment of acute pain in dogs. American Journal Veterinary Research, v. 66, n.12, p. 2154-66, 2005.

OLIVEIRA, S. P.; RAHAL S. C.; PEREIRA, J. P.;BERSANO, P. R. O. B.; VIEIRA, F. A.; PADOVAN, C. R. Laser terapêutico de baixa potência na placa de crescimento de ratos. Acta Cirúrgica Brasileira, v. 27, n. 2, p. 117-122, 2012.

POSTEN, W.; WRONE, D. A.; DOVER, J. S.; ARNDT, K. A.; SILAPUNT, S.; ALAM, M. Low-level laser therapy for wound healing: mechanism and efficacy.

Dermatology Surgery, v. 31, p. 334-339, 2005.

PRYOR, B.; MILLIS, D. L. Therapeutic laser in veterinary medicine. The Veterinary clinics of North America: small animal practice, v. 45, n. 1, p. 45-56, 2015.

RESENDE, M. A.; GONÇALVES, H. H.; SABINO, G. S.; PEREIRA, L. S. M.; FRANCISCHI, J. M. Redução do efeito analgésico da estimulação elétrica nervosa transcutânea de baixa frequência em ratos tolerantes à morfina. Revista Brasileira Fisioterapia, v. 10, n. 3, p. 291-296, 2006.

RING, E. F. J. Progress in the measurement of human body temperature. 
Engineering in Medicine and Biology Magazine, v. 17, n. 4, p.19-24, 1998.

RING, E.; AMMER, K. Infrared thermal imaging in medicine. Physiological Measurement, v. 33, p 33-46, 2012.

RUSCH, D.; FOLLMANN, M.; BOSS, B.; NEECK G. Dynamic Thermography of the knee joints in rheumatoid arthritis in the course of the first therapy of the patient with methylpredinisolone. Zeitschrift für Rheumatologie, v. 59, p. II/131-II/135, 2000. Supplement, 2.

SHARKEY, M. The challenges of assessing osteoarthritis and postoperative pain in dogs. The American Association Pharmaceitical Scientists Journal, v. 15, n. 2, p. $598-607,2013$

SHARP, B. Physiotherapy in small animal practice. Practice, v. 30, p.190-199, 2008.

SILVA, E. C.; FILHO, A. H.; MUSSKOPF, D. E. Radiação Laser. In: RODRIGUES, E. M.; GUIMARÃES, C. S. Manual de recursos fisioterapêuticos. São Paulo: Revinter, 1998.

SILVA, E. M.; GOMES, S. P.; ULBRICH, L. M.; GIOVANNI, A. F. Avaliação histológica da laserterapia de baixa intensidade na cicatrização de tecidos epitelial, conjuntivo e ósseo: estudo experimental em ratos. Revista Sul-Brasileira Odontologia, v. 4, n. 2, p. 29-35, 2007.

SLOCUM, B.; SLOCUM, T. D. Tibial plateau leveling osteotomy for repair of cranial cruciate ligament rupture in the canine. Veterinary Clinics of North America: small animal pratice, Philadelphia, v. 23, n. 4, p. 777-95, 1993.

SLUKA, K. A.; WALSH, D. Trancutaneous electrical nerve stimulation: basic science mechanisms and clinical effectiveness. Journal Pain, v. 4, n. 3, p. 109-121, 2003.

SOUZA, A. N. A.; TATARUNAS, A. C.; MATERA, J. M. Evaluation of vertical forces in the pads of Pitbulls with cranial cruciate ligament rupture. BMC Veterinary Research, v. 10, n. 1, p. 51, 2014.

SOUZA, A. N. A.; PINTO, A. C. B. C. F.; MARVULLE, V.; MATERA, J. M. Vertical forces assessment according to radiographic hip grade in German shepherd dogs.

The Journal of Small Animal Practice, v. 56, n. 2, p.108-11, 2015.

PIERMATTEI, D. L.; FLO, G. L.; DeCAMP, C. E. The stiffle joint. In: PIERMATTEI, D. L.; FLO, G. L.; DeCAMP, C. E. Handbook of small animal orthopedics and fracture repair. 4. ed. Philadelphia: Saunders, 2006. p. 562-632.

ROLA, P.; DOROSZKO, A.; DERKACZ, A. The use of low-level energy laser radiation in basic and clinical research. Advances in Clinical and Experimental Medicine, v. 23, n. 5, p. 835-842, 2014.

TEIXEIRA, M. J. Fisiopatologia da nocicepção e da supressão da dor. Jornal Brasileiro de Oclusão, ATM e Dor Orofacial, v.1, n. 4, p. 329-334, 2001.

TEIXEIRA, M. J. Fisiopatologia da dor neuropática. Revista Medicina, v. 78, p. 53- 
84, 1999.

TEIXEIRA, M. J.; FIGUEIRÓ, J. A. B. Dor: epidemiologia, fisiopatologia, avaliação, síndromes dolorosas e tratamento. 4. ed. São Paulo: Moreira Júnior, 2001. p. 41-47.

UM, SE-WOOK; KIM, MIN-SU; LIM, JI-HEY; KIM, SUN-YOUNG; SEO, KANGMOON; NAM, TCHI-CHOU Thermographic evaluation for the efficacy of acupuncture on induced chronic arthritis in the dog. Journal of Veterinary Medical Science, v. 67, n. 12, p. 1283-1284, 2005.

VARJÚ, G.; PIEPER, C. F.; RENNER, J. B.; KRAUS, V. B. Assesment of hand osteoarthritis: correlation between thermographic and radiographic methods. Rheumatology, v. 43, n. 7, p. 915-9, 2004.

VASCONCELOS, W.; SANTOS, C.; FERRACINI, A. M.; DEJOUR, D. Influência da dor anterior nos resultados das reconstruções do ligamento cruzado anterior.

Revista Brasileira de Ortopedia, v. 46, n.1, p. 40-44, 2011

VASSEUR, P. B. Stifle joint. In : SLATTER, D. Textbook of small animal surgery. 3. ed. Philadelphia: Elsevier Science, 2003. p. 2090-2133.

VENANCIO, R. A.; CAMPARIS, C. M.; LIZARELLI, R. F. Z. Laser no tratamento de desordens temporomandibulares. Jornal Brasileiro de Oclusão, ATM e Dor Orofacial, v. 2, n. 7, p. 229-234, 2002.

VINK,E. M.; CAGNIE, B. J.; CORNELISSEN, M. J.; DECLEREQ, H. A.; CAMBIER, D. C. Increased fibroblast proliferation induced by light emitting diode and low power laser irradiation. Lasers Medicine Science, v.18, p. 95-99, 2003.

WALL, P. D.; GUTNICK, M. Properties of afferent nerve impulses originating from neuroma. Nature, v. 248, p. 740-743, 1974.

WARZEE, C. C.; DEJARDIN, L. M.; ARNOCZKY, S. P.; PERRY, R. L. Effect os tibial plateau leveling on cranial and caudal tibial thrusts in canine cranial cruciate deficient stifles: an in vitro experimental study. Veterinary Surgery, v. 30, n. 3, p. 278-286, 2001.

WEISS, A. P. C. Thermal regulatory testing for pain dysfunction syndromes (commentary). The Lancet, v. 344, p. 209-210, 1994.

WAXMAN, A. S. ROBINSON, D. A.; EVANS, R. B.; HULSE, D. A.; INNES, J. F.; CONZEMIUS, M. G. Relationship between objective and subjective assessment of limb function in normal dogs with an experimentally induced lameness. Veterinary Surgery, v. 37, n. 3, p. 241-246, 2008.

WESTERMANN, S.; SCHRAMEL, J. P.; TICHY, A.; STANEK, C. Effects of infrared camera angle and distance on measurement and reproducibility of thermographically determined temperatures of the distolateral aspects of the forelimbs in horses.

Journal of the American Veterinary Medical Association, v. 242, n. 3, p. 1-8, 2013.

YAKSH, T. L.; AIMONE, L. D. The central pharmacology of pain transmission. In: 
WALL, P. D.; MELZACK, R. Textbook of pain. Edinburgh: Churchill Livingstone, 1989. p.181-205.

ZIMMERMANN, M. Physiological mechanisms of pain in the musculo-skeletal system. In: EMRE, M.; MATHIES, H. Muscle spasms and pain. Caarnforth: Pathernon Publishing, 1988. p. 7-17. 
APÊNDICES 


\section{APÊNDICE A}

\section{RESULTADOS DOS ESCORES DE DOR}

\begin{tabular}{llllllllll}
\hline ANIMAIS & $\begin{array}{l}\text { ENV } \\
\text { Av. } \\
\text { inicial }\end{array}$ & $\begin{array}{l}\text { ENV } \\
\text { Av. } \\
\text { final }\end{array}$ & $\begin{array}{l}\text { Grau } \\
\text { decaimento } \\
\text { da dor }\end{array}$ & $\begin{array}{l}\text { ENV } \\
\text { Cuidador } \\
\text { Inicial }\end{array}$ & $\begin{array}{l}\text { ENV } \\
\text { Cuidador } \\
\text { Final }\end{array}$ & $\begin{array}{l}\text { Grau } \\
\text { Decaimento } \\
\text { da dor }\end{array}$ & $\begin{array}{l}\text { Escore } \\
\text { Glasgow } \\
\text { Inicial }\end{array}$ & $\begin{array}{l}\text { Escore } \\
\text { Glasgow } \\
\text { Final }\end{array}$ \\
\hline F1 & & & & & & & \\
\end{tabular}


APÊNDICE B

RESULTADOS DOS ESCORES DE CLAUDICAÇÃO

\begin{tabular}{lllll}
\hline Animais & $\begin{array}{l}\text { Escala 1 } \\
\text { Inicial }\end{array}$ & $\begin{array}{l}\text { Escala 1 } \\
\text { Final }\end{array}$ & $\begin{array}{l}\text { Escala 2 } \\
\text { Inicial }\end{array}$ & $\begin{array}{l}\text { Escala 2 } \\
\text { Final }\end{array}$ \\
\hline F1 & 3 & 2 & 2 & 1 \\
F2 & 5 & 3 & 4 & 2 \\
F3 & 3 & 3 & 2 & 2 \\
F4 & 4 & 4 & 2 & 3 \\
F5 & 3 & 4 & 3 & 3 \\
F6 & 4 & 3 & 2 & 1 \\
F7 & 5 & 3 & 4 & 3 \\
F8 & 2 & 2 & 1 & 0 \\
F9 & 2 & 2 & 1 & 0 \\
\hline
\end{tabular}

\begin{tabular}{lllll} 
Animais & $\begin{array}{l}\text { Escala 1 } \\
\text { Inicial }\end{array}$ & $\begin{array}{l}\text { Escala 1 } \\
\text { Final }\end{array}$ & $\begin{array}{l}\text { Escala 2 } \\
\text { Inicial }\end{array}$ & $\begin{array}{l}\text { Escala 2 } \\
\text { Final }\end{array}$ \\
P1 & 4 & 3 & 4 & 2 \\
P2 & 3 & 2 & 2 & 1 \\
\hline P3 & 2 & 3 & 1 & 2 \\
P4 & 4 & 2 & 3 & 1 \\
P5 & 3 & 1 & 2 & 0 \\
P6 & 2 & 4 & 1 & 3 \\
P7 & 4 & 4 & 3 & 3 \\
\hline
\end{tabular}




\section{APÊNDICE C}

\section{ESCORES DE PERIMETRIA}

\begin{tabular}{lrrrr}
\hline ANIMAIS & $\begin{array}{l}\text { Perimetria } \\
\text { Pré-op. }\end{array}$ & $\begin{array}{l}\text { Perimetria } \\
\text { Inicial }\end{array}$ & $\begin{array}{l}\text { Perimetria } \\
\text { Final }\end{array}$ & $\begin{array}{l}\text { Diferença de } \\
\text { Perimetria }\end{array}$ \\
\hline F1 & 24 & 25,1 & 24 & $-0,043824701$ \\
\hline F2 & 33,2 & 42 & 36,1 & $-0,14047619$ \\
\hline F3 & 34 & 34,5 & 34,2 & $-0,008695652$ \\
F4 & 27 & 30,5 & 27,8 & $-0,08852459$ \\
\hline F5 & 25,5 & 28 & 26,6 & $-0,05$ \\
F6 & 24 & 27,6 & 25,4 & $-0,079710145$ \\
\hline F7 & 21,6 & 25 & 22,6 & $-0,096$ \\
F8 & 22,3 & 24,6 & 23,3 & $-0,052845528$ \\
\hline F9 & 24,1 & 26,5 & 25,7 & $-0,030188679$ \\
\hline
\end{tabular}

\begin{tabular}{lrrrl} 
ANIMAIS & $\begin{array}{l}\text { Perimetria } \\
\text { Pré-Op. }\end{array}$ & $\begin{array}{l}\text { Perimetria } \\
\text { Inicial }\end{array}$ & $\begin{array}{l}\text { Perimetria } \\
\text { Final }\end{array}$ & $\begin{array}{l}\text { Diferença de } \\
\text { Perimetria }\end{array}$ \\
\hline P1 & 28 & 30 & 27,5 & $-0,083333333$ \\
\hline P2 & 24 & 25,5 & 24,3 & $-0,047058824$ \\
\hline P3 & 26,3 & 28,3 & 27,5 & $-0,028268551$ \\
P4 & 26,5 & 27,5 & 27,4 & $-0,003636364$ \\
\hline P5 & 17.5 & 21 & 20,5 & $-0,023809524$ \\
P6 & 24,5 & 27 & 25 & $-0,074074074$ \\
\hline P7 & 27 & 29,5 & 27,1 & $-0,081355932$ \\
\hline
\end{tabular}




\section{APÊNDICE D}

\section{RESULTADOS TERMOGRAFIA EM ${ }^{\circ} \mathrm{C}$}

\begin{tabular}{clrrrrrrr}
\hline Animais & Posição & $\begin{array}{c}\text { Grupo } \\
\text { F TPRE }\end{array}$ & $\begin{array}{l}\text { Grupo } \\
\text { F TO }\end{array}$ & $\begin{array}{l}\text { Grupo } \\
\text { F TF }\end{array}$ & $\begin{array}{l}\text { Grupo } \\
\text { P TPRE }\end{array}$ & $\begin{array}{l}\text { Grupo } \\
\text { P TO }\end{array}$ & $\begin{array}{l}\text { Grupo } \\
\text { P TF }\end{array}$ & Animais \\
\hline \multirow{2}{*}{ F1 } & latero-lateral & 36,6 & 37,1 & 35,9 & 34 & 36,7 & 35,5 & P1 \\
& médio-lateral & 37,1 & 37,8 & 37,9 & 35,1 & 35,8 & 37 & \\
F2 & latero-lateral & 33,1 & 35,7 & 35,7 & 34,5 & 34 & 34,8 & P2 \\
& médio-lateral & 34,3 & 35,7 & 37,9 & 34,8 & 33,6 & 35 & \\
\multirow{2}{*}{ F3 } & latero-lateral & 33,1 & 36 & 36,9 & 33,4 & 35,7 & 36,9 & P3 \\
& médio-lateral & 37,5 & 36,9 & 36 & 35,8 & 34,6 & 36,9 & \\
\multirow{2}{*}{ F4 } & latero-lateral & 34,7 & 36,1 & 36,5 & 35,1 & 36 & 34,2 & P4 \\
& médio-lateral & 36 & 36,1 & 37,3 & 34,9 & 36,8 & 35,8 & \\
\multirow{2}{*}{ F5 } & latero-lateral & 32,4 & 34,7 & 33,2 & 35,4 & 36,9 & 35,8 & P5 \\
& médio-lateral & 34,8 & 35,7 & 35,6 & 37,1 & 37,4 & 36,7 & \\
\multirow{2}{*}{ F6 } & latero-lateral & 30,5 & 31,9 & 31,1 & 35,4 & 36,2 & 35,6 & P6 \\
& médio-lateral & 32,5 & 34,4 & 33,4 & 36,9 & 37,6 & 37,2 & \\
\multirow{2}{*}{ F7 } & latero-lateral & 32 & 33,1 & 33,2 & 34,4 & 33,8 & 34,5 & P7 \\
& médio-lateral & 34,7 & 34,1 & 34,5 & 34,6 & 34,4 & 36,3 & \\
\multirow{2}{*}{ F8 } & latero-lateral & 33,7 & 35,2 & 34,7 & & & & \\
& médio-lateral & 35 & 36 & 35,6 & & & & \\
\multirow{2}{*}{ F9 } & latero-lateral & 31 & 34,5 & 33,9 & & & & \\
& médio-lateral & 34,7 & 36,5 & 32,4 & & & & \\
\hline
\end{tabular}




\section{APÊNDICE E}

ESCORES DE BAROPODOMETRIA

PARAMETRO DE PFV EXPRESSOS EM \%PC

\begin{tabular}{|c|c|c|c|c|c|}
\hline $\begin{array}{l}\text { Animais } \\
\text { Grupo F }\end{array}$ & $\begin{array}{l}\text { Grupo F } \\
\text { TPRE }\end{array}$ & $\begin{array}{l}\text { Grupo F } \\
\text { TF }\end{array}$ & $\begin{array}{l}\text { Grupo P } \\
\text { TPRE }\end{array}$ & $\begin{array}{l}\text { Grupo P } \\
\text { TF }\end{array}$ & $\begin{array}{l}\text { Animais } \\
\text { Grupo P }\end{array}$ \\
\hline \multirow[t]{5}{*}{$F 1$} & 28,2 & 20,3 & 13,2 & 13,0 & \multirow[t]{5}{*}{$\mathrm{P} 1$} \\
\hline & 25,0 & 20,7 & 12,0 & 11,6 & \\
\hline & 24,9 & 21,4 & 12,4 & 13,7 & \\
\hline & 28,4 & 20,4 & 14,3 & 10,8 & \\
\hline & 27,8 & 22,1 & 12,8 & 14,0 & \\
\hline \multirow[t]{5}{*}{ F2 } & 24,9 & 19,1 & 9,7 & 14,7 & \multirow[t]{5}{*}{ P2 } \\
\hline & 18,5 & 24,5 & 9,4 & 9,8 & \\
\hline & 19,1 & 23,1 & 10,1 & 15,4 & \\
\hline & 21,4 & 18,7 & 10,5 & 12,6 & \\
\hline & 22,2 & 15,3 & 11,5 & 16,7 & \\
\hline \multirow[t]{5}{*}{ F3 } & 21,3 & 19,2 & 4,6 & 5,6 & \multirow[t]{5}{*}{ P3 } \\
\hline & 20,4 & 24,4 & 8,6 & 3,8 & \\
\hline & 19,1 & 25,6 & 3,2 & 4,0 & \\
\hline & 23,4 & 19,9 & 5,2 & 4,9 & \\
\hline & 20,6 & 25,5 & 6,6 & 4,1 & \\
\hline \multirow[t]{5}{*}{ F4 } & 19,4 & 17,8 & 26,4 & 23,5 & \multirow[t]{5}{*}{ P4 } \\
\hline & 15,2 & 13,3 & 24,7 & 27,0 & \\
\hline & 21,1 & 18,1 & 19,8 & 24,1 & \\
\hline & 19,2 & 16,1 & 26,3 & 23,1 & \\
\hline & 22,7 & 17,1 & 23,6 & 24,9 & \\
\hline \multirow[t]{5}{*}{ F5 } & 17,8 & 12,3 & 20,1 & 14,3 & \multirow[t]{5}{*}{ P5 } \\
\hline & 19,1 & 16,4 & 20,2 & 15,6 & \\
\hline & 19,0 & 16,3 & 18,8 & 14,8 & \\
\hline & 15,1 & 12,7 & 21,0 & 19,4 & \\
\hline & 17,4 & 14,9 & 25,0 & 15,7 & \\
\hline \multirow[t]{5}{*}{ F6 } & 18,2 & 11,6 & 20,0 & 18,2 & \multirow[t]{5}{*}{ P6 } \\
\hline & 14,6 & 11,1 & 18,5 & 14,3 & \\
\hline & 17,5 & 12,5 & 25,7 & 13,7 & \\
\hline & 19,5 & 12,5 & 22,9 & 14,8 & \\
\hline & 17,1 & 12,6 & 21,0 & 14,3 & \\
\hline \multirow[t]{5}{*}{ F7 } & 10,2 & 11,2 & 15,6 & 9,8 & \multirow[t]{5}{*}{ P7 } \\
\hline & 11,8 & 12,4 & 15,5 & 10,4 & \\
\hline & 11,0 & 11,7 & 17,3 & 11,0 & \\
\hline & 10,4 & 10,6 & 16,3 & 8,7 & \\
\hline & 11,1 & 11,3 & 16,4 & 10,5 & \\
\hline F8 & 17,3 & 14,0 & & & \\
\hline
\end{tabular}




\begin{tabular}{|c|c|c|c|c|c|}
\hline & 12,7 & 13,1 & & & \\
\hline & 13,3 & 12,7 & & & \\
\hline & 16,0 & 14,2 & & & \\
\hline & 15,1 & 13,2 & & & \\
\hline Animais & Grupo F & Grupo F TF & Grupo P & Grupo P & Animais \\
\hline Grupo F & TPRE & & TPRE & TF & Grupo P \\
\hline \multirow[t]{5}{*}{ F9 } & 11,4 & 12,5 & & & \\
\hline & 10,5 & 11,4 & & & \\
\hline & 10,5 & 13,6 & & & \\
\hline & 8,9 & 12,6 & & & \\
\hline & 10,2 & 12,4 & & & \\
\hline
\end{tabular}

ESCORES DE BAROPODOMETRIA

PARAMETRO DE IV EXPRESSOS EM \%PC*S

\begin{tabular}{|c|c|c|c|c|c|}
\hline Animais & $\begin{array}{l}\text { Grupo F } \\
\text { TPRE }\end{array}$ & $\begin{array}{l}\text { Grupo F } \\
\text { TF }\end{array}$ & $\begin{array}{l}\text { Grupo P } \\
\text { TPRE }\end{array}$ & $\begin{array}{l}\text { Grupo P } \\
\text { TF }\end{array}$ & Animais \\
\hline \multirow[t]{5}{*}{ F1 } & 5,5 & 4,9 & 3,6 & 4,0 & P1 \\
\hline & 6,2 & 5,5 & 2,8 & 2,8 & \\
\hline & 5,0 & 4,7 & 3,4 & 3,7 & \\
\hline & 6,5 & 4,9 & 3,3 & 2,2 & \\
\hline & 5,4 & 3,5 & 3,3 & 3,4 & \\
\hline \multirow[t]{5}{*}{ F2 } & 10,1 & 9,0 & 2,4 & 4,5 & P2 \\
\hline & 8,1 & 11,4 & 2,4 & 2,2 & \\
\hline & 6,5 & 9,2 & 2,3 & 3,3 & \\
\hline & 9,7 & 8,7 & 2,6 & 2,9 & \\
\hline & 11,0 & 6,4 & 2,7 & 3,8 & \\
\hline \multirow[t]{5}{*}{ F3 } & 6,9 & 7,6 & 1,3 & 1,4 & P3 \\
\hline & 7,1 & 9,2 & 1,8 & 0,9 & \\
\hline & 6,6 & 9,1 & 0,9 & 0,8 & \\
\hline & 9,0 & 7,3 & 1,6 & 1,1 & \\
\hline & 7,5 & 9,7 & 1,9 & 1,0 & \\
\hline \multirow[t]{5}{*}{ F4 } & 6,6 & 4,6 & 5,6 & 6,3 & P4 \\
\hline & 3,9 & 3,8 & 5,4 & 6,3 & \\
\hline & 6,6 & 5,6 & 3,8 & 7,2 & \\
\hline & 5,2 & 5,3 & 6,1 & 6,2 & \\
\hline & 5,2 & 5,0 & 5,0 & 6,3 & \\
\hline \multirow[t]{5}{*}{ F5 } & 5,7 & 3,3 & 4,0 & 2,5 & P5 \\
\hline & 7,3 & 4,9 & 3,9 & 2,8 & \\
\hline & 5,3 & 4,6 & 3,6 & 2,6 & \\
\hline & 4,1 & 3,3 & 4,0 & 3,0 & \\
\hline & 5,7 & 4,3 & 4,4 & 2,3 & \\
\hline
\end{tabular}




\begin{tabular}{|c|c|c|c|c|c|}
\hline \multirow[t]{5}{*}{ F6 } & 6,0 & 3,6 & 4,4 & 4,4 & \multirow[t]{5}{*}{ P6 } \\
\hline & 4,6 & 3,2 & 4,7 & 3,0 & \\
\hline & 6,5 & 3,1 & 5,9 & 3,6 & \\
\hline & 6,5 & 3,3 & 5,6 & 3,5 & \\
\hline & 6,0 & 3,3 & 5,0 & 2,8 & \\
\hline Animais & Grupo F & Grupo F TF & Grupo P & Grupo P TF & Animais \\
\hline Grupo F & TPRE & & TPRE & & Grupo P \\
\hline \multirow[t]{5}{*}{ F7 } & 2,0 & 2,9 & 6,0 & 3,3 & \multirow[t]{5}{*}{ P7 } \\
\hline & 2,2 & 2,5 & 5,2 & 3,2 & \\
\hline & 2,0 & 2,8 & 5,9 & 3,5 & \\
\hline & 2,2 & 2,2 & 5,3 & 3,3 & \\
\hline & 2,4 & 2,7 & 5,7 & 3,2 & \\
\hline \multirow[t]{5}{*}{ F8 } & 4,6 & 4,4 & & & \\
\hline & 2,7 & 3,7 & & & \\
\hline & 3,4 & 3,1 & & & \\
\hline & 5,0 & 4,0 & & & \\
\hline & 4,0 & 4,3 & & & \\
\hline \multirow[t]{5}{*}{ F9 } & 2,8 & 4,6 & & & \\
\hline & 7,7 & 4,0 & & & \\
\hline & 3,2 & 5,6 & & & \\
\hline & 7,9 & 4,8 & & & \\
\hline & 5,4 & 4,6 & & & \\
\hline
\end{tabular}


ANEXOS 


\begin{abstract}
ANEXO A
TERMO DE CONSENTIMENTO LIVRE E ESCLARECIDO
\end{abstract}

DADOS DE IDENTIFICAÇÃO DO PROPRIETÁRIO OU RESPONSÁVEL

1. NOME.

DOCUMENTO DE IDENTIDADE No :

SEXO : $M \square F \square$

DATA NASCIMENTO: .......................

ENDEREÇO

No

APTO:

BAIRRO: CIDADE

CEP:

TELEFONE: DDD

$(\ldots \ldots \ldots . . .$.

DADOS DE IDENTIFICAÇÃO DO ANIMAL

1. NOME DO ANIMAL E/OU NÚMERO DE REGISTRO

ESPÉCIE:

RAÇA:

PELAGEM:

SEXO:

DATA DE NASCIMENTO:

\title{
DADOS SOBRE A PESQUISA
}

1. TÍTULO DO PROTOCOLO DE PESQUISA

Eletroterapia e Laserterapia no controle da dor e da inflamação no pósoperatório de TPLO.

PESQUISADOR: Maira Rezende Formenton

CARGO/FUNÇÃO: Mestrando 
INSCRIÇÃO CONSELHO REGIONAL Nº -SP 24.842

1. Departamento: $\mathrm{VCI}$ Serviço: Ambulatório de dor e Cuidados Paliativos

2. AVALIAÇÃO DO RISCO DA PESQUISA:

$\begin{aligned} \text { RISCO MÍNIMO } X & \text { RISCO MÉDIO } \square \\ \text { RISCO BAIXO } \square & \text { RISCO MAIOR } \square\end{aligned}$

1. DURAÇÃO DA PESQUISA : 2 anos

\section{FACULDADE DE MEDICINA VETERINÁRIA E ZOOTECNIA DA UNIVERSIDADE DE SÃO PAULO}

Essas informações estão sendo fornecidas para sua participação voluntária neste estudo, que visa a avaliação da eletroterapia e da laserterapia no controle da dor pós operatória de TPLO. Estas técnicas são utilizadas rotineiramente na fisioterapia e reabilitação de pequenos animais.

O animal passará por sessões de eletroterapia associadas a laserterapia por um período de 2 semanas, sendo três sessões semanais totalizando 6 sessões. Além disso passará por avaliações (pré operatória, com 3 dias e com 15 dias de pós-operatório ) com um avaliador cego. As sessões terão a duração em média de 40 minutos e serão realizadas no Hospital Veterinário FMVZ USP. Os equipamentos não oferecem riscos nem desconfortos ao animal. O animal será distribuído aleatoriamente no grupo Fisioterapia $(F)$ ou Placebo $(P)$.

O animal do grupo Fisioterapia (F), além da medicação usual, se beneficiará das sessões e dos efeitos da aplicação dos aparelhos sem custos ao proprietário. Os animais do grupo Placebo $(P)$ passarão por sessões placebo, porém sem nenhum efeito deletério ao animal.

Em qualquer etapa do estudo, você terá acesso aos profissionais responsáveis pela pesquisa para esclarecimento de eventuais dúvidas. $O$ principal investigador é a Dr. Maira Rezende Formenton que pode ser encontrado no endereço Av. Prof. Dr. Orlando Marques de Paiva, 87 - Cidade Universitária São Paulo/SP - Brasil e pelo telefone (011) 98567-5756 ou email 
maira.formenton@usp.br,dfantoni@usp.br.

É garantida a liberdade da retirada de consentimento a qualquer momento e deixar de participar do estudo, sem qualquer prejuízo à continuidade de tratamento do animal na Instituição;

As informações obtidas (relativas tanto ao proprietário quanto ao animal) serão analisadas em conjunto com outros pacientes, não sendo divulgado a identificação de nenhum animal ou proprietário.

O pesquisador se compromete utilizar os dados e o material coletado somente para esta pesquisa ou após a aprovação da CEUAVET.

Acredito ter sido suficientemente informado a respeito das informações que li ou que foram lidas para mim, descrevendo o estudo "Eletroterapia e Laserterapia no controle da dor e da inflamação no pós-operatório de TPLO"

Eu discuti com a Dra Maira Rezende Formenton sobre a minha decisão em incluir meu(s) animal(is) nesse estudo. Ficaram claros para mim quais são os propósitos do estudo, os procedimentos a serem realizados em meu(s) animal(is), seus desconfortos e riscos, as garantias de confidencialidade e de esclarecimentos permanentes.

Concordo voluntariamente que meu(s) animal(is) participe $(\mathrm{m})$ deste estudo e poderei retirar o meu consentimento a qualquer momento, antes ou durante $o$ mesmo, sem penalidades ou prejuízo ou perda de qualquer benefício que eu ou meu(s) animal(is) possa(m) ter adquirido, ou no meu atendimento neste Serviço.

Nome e assinatura do proprietário ou responsável

(caso seja o responsável, descrever o vínculo)

Data 11

Nome e assinatura da testemunha

Data 11 
para casos de proprietários analfabetos, semi-analfabetos ou portadores de deficiência auditiva ou visual

(Somente para o responsável do projeto)

Declaro que obtive de forma apropriada e voluntária o Consentimento Livre e Esclarecido deste proprietário para a participação de seu(s) animal(is) neste estudo.

Maira Rezende Formenton

Profa. Denise Tabacchi Fantoni

Data

11




\begin{abstract}
ANEXO B
Características técnicas do aparelho de Bioset® Physiotonus Four, São Paulo, Brasil
\end{abstract}

Fabricante: BIOSET

Modelo do equipamento: PHYSIOTONUS FOUR

Função e aplicação: Equipamento de Eletroestimulação

Tensão de alimentação: 127 V / 220 - 230 V

Seleção da tensão de alimentação: Automática

Freqüência da rede de alimentação: $60 \mathrm{~Hz}$

Potência de entrada: 16 VA

Temporizador: de 01 a 30 minutos

Função: TENS BURST

Forma de onda: Quadrada bifásica assimétrica

Faixa de amplitude (carga de 1000 Ohm): de 0 a $60 \mathrm{~mA}$

Faixa de freqüência: variável de 7 a $255 \mathrm{~Hz}$

Modulação em trens de pulso: 7 pulsos com freqüência de $175 \mathrm{~Hz}$ modulado em $2 \mathrm{~Hz}$ Largura do pulso: variável de 20 a $300 \mu s$

- Canais de saída: 04 canais

- Componentes C.C. Ausente

Dimensões (cm): 22,5 x 18,5 x 8,5 (L x P x A)

Peso (aproximado s/ acessórios): 1,3 kg

Fusíveis: 250mA x 250 V / Tipo 20AGT (ação retardada)

Nota: 1) Os dados técnicos aqui apresentados poderão apresentar alteração de até $+/-10 \%$ segundo o fabricante. 


\section{ANEXO C}

Certificado de calibração do aparelho de eletroterapia Bioset ${ }^{\circledR}$ Physiotonus Four, São Paulo, Brasil

\section{三BIOSET}

BIOSET Indústria de Tecnologia Eletrônica Ltda.

Tabela de Calibração do Physiotonus Four- n.o 1101010

\begin{tabular}{|c|c|c|}
\hline Indicação do Aparelho N.3050 (1) & $\begin{array}{c}\text { Valor Mensurado pelo } \\
\text { EIME (I) }\end{array}$ & Desvio (\%) \\
\hline Intensidade canal 1 & $70 \mathrm{~mA}$ & $\mathbf{0 , 0}$ \\
\hline Intensidade canal 2 & $70 \mathrm{~mA}$ & $\mathbf{0 , 0}$ \\
\hline Intensidade canal 3 & $70 \mathrm{~mA}$ & $\mathbf{0 , 0}$ \\
\hline Intensidade canal 4 & $70 \mathrm{~mA}$ & $\mathbf{0 , 0}$ \\
\hline Freqüências programadas (2) & Aprovado & -- \\
\hline Modos programados (2) & Aprovado & -- \\
\hline Parâmetros programados (2) & Aprovado & - \\
\hline Tempo programado(2) & Aprovado & - \\
\hline
\end{tabular}

(1): Notas:
Conforme a característica de medição.

(2): Conforme caracteristicas gravada no micro processador do aparelho, de acordo com as características River

Robson Matoseordeiro

Técrico Responsável especificados no manual de instrução do mesmo.

Data:31/03/2014. 


\section{ANEXO D \\ Características do aparelho de laserterapia Bioset ${ }^{\circledR}$, caneta de $830 \mathrm{~nm}$, São Paulo, Brasil}

Fabricante: BIOSET

Modelo do equipamento: PHYSIOLUX DUAL

Função e aplicação: equipamento de LASER

Modo de operação: Contínuo

Tensão de alimentação: 127 V - 230 V

Seleção da tensão de alimentação:

Automática Frequência da rede de alimentação: 50 / 60Hz Potência de entrada: 18VA

Controle de energia aplicada: 0 a $20 \mathrm{~J}( \pm 20 \%)$

Dimensões (cm): $28 \times 28 \times 11(\mathrm{~L} \times \mathrm{P} \times \mathrm{A})$

Peso (aproximado s/ acessórios): 1,7kg

Fusíveis: 250 mA / Tipo 20AGT (ação retardada) / 250V

Caneta 830nm especificações:

Divergência do feixe:12o

Área do feixe na ponta da caneta: $10,75 \mathrm{~mm}^{2} / 0,1075 \mathrm{~cm}^{2}$

Distância de Risco Ocular Nominal (DRON) com 830nm: 1,9m

Modo de Aplicação: Contínuo / Pulsado

Frequência de Pulsação: 5, 10, 20, 30, 40, 50, 60, 70, 80, 90, 100, 200, 300, 400, 500, 1000, 2000 e $4000 \mathrm{~Hz}$

Divisão dos Pulsos (duty cicle):50\% Índice de modulação: 100\% Potência: 40mW 
ANEXO E

Certificado de calibração do aparelho de laserterapia Bioset $₫$, caneta de 830nm, São Paulo, Brasil

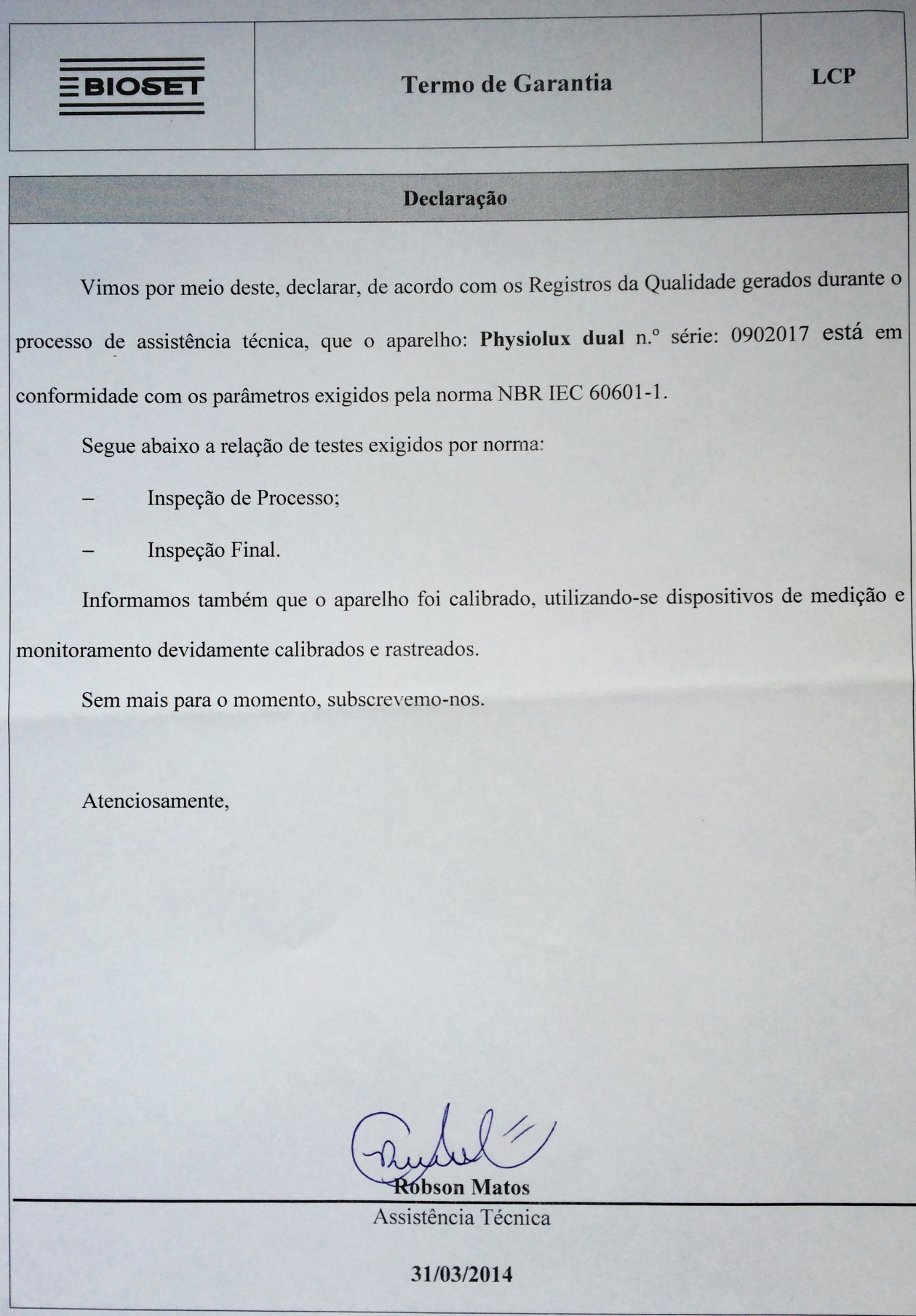




\section{ANEXO F}

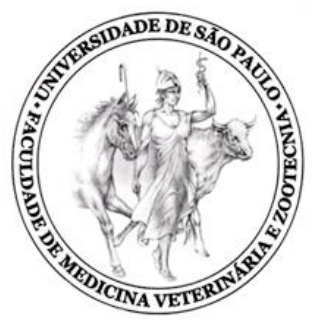

FICHA DE AVALIAÇÃO INICIAL

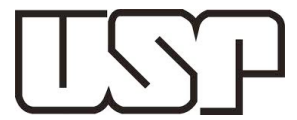
DATA:

ANIMAL:

SEXO:

RAÇA:

CASTRADO:
IDADE:

PRONTUÁRIO:

CUIDADOR:

NOME:

ENDEREÇO:

TELEFONE:

EMAIL:

AMAMNESE:

DATA TPLO:

PERIMETRIA JOELHO ANTES TPLO:

ESCALA AVALIAÇÃO DOR - CUIDADOR

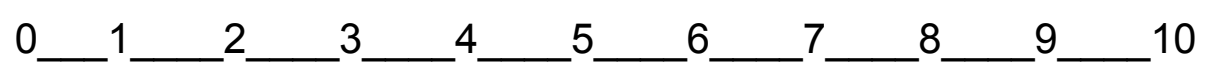

ESCALA AVALIAÇÃO DOR - AVALIADOR CEGO

$0+1 \_2-3 \quad 4 \quad 5 \quad 6 \quad 7 \quad 8 \quad 9 \quad 9-10$


AVALIAÇÃO PELA ESCALA GLASGOW:

PERIMETRIA DO JOELHO ( INICIAL):

\section{ANEXO G}

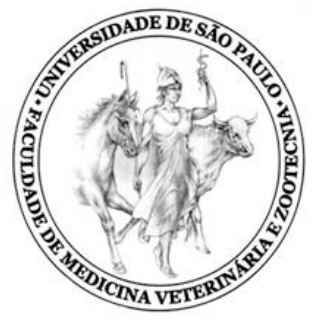

FICHA DE AVALIAÇÃO FINAL- 15 dias

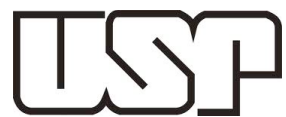

DATA:

ANIMAL:

PRONTUÁRIO:

CUIDADOR:

ANIMAL COMPARECEU ÀS SESSÕES? SIM NÃO

FOI SEGUIDO O P/O INDICADO? SIM NÃO

ESCALA AVALIAÇÃO DOR - CUIDADOR

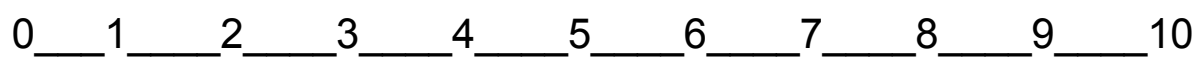

ESCALA AVALIAÇÃO DOR - AVALIADOR CEGO

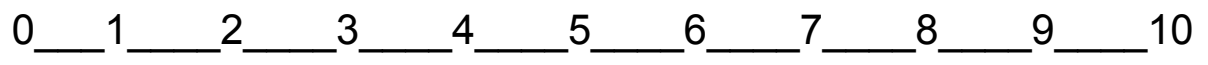

GRAU CLAUDICAÇÃO - AVALIADOR CEGO:

AVALIAÇÃO PELA ESCALA GLASGOW:

PERIMETRIA DO JOELHO: 
ANEXO H

ESCALA MODIFICADA COMPOSTA DE GLASGOW

\begin{tabular}{|c|c|c|c|}
\hline & Parâmetros & Critério & $\mathbf{P}$ \\
\hline \multirow{10}{*}{ 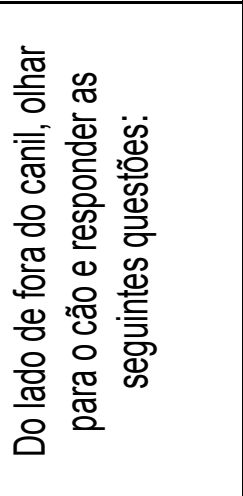 } & \multirow{3}{*}{ Postura } & Rígido & 1.20 \\
\hline & & Corcunda & 1.13 \\
\hline & & Normal & 0.00 \\
\hline & \multirow{4}{*}{ Vocalização } & Chora & 0.83 \\
\hline & & Geme & 0.92 \\
\hline & & Grita & 1.75 \\
\hline & & Não vocaliza & 0.00 \\
\hline & \multirow{3}{*}{$\begin{array}{l}\text { Atenção à } \\
\text { ferida } \\
\text { cirúrgica }\end{array}$} & Mordendo & 1.40 \\
\hline & & $\begin{array}{l}\text { Lambendo/ } \\
\text { olhando/ } \\
\text { esfregando }\end{array}$ & 0.94 \\
\hline & & Ignorando & 0.00 \\
\hline \multirow{5}{*}{ 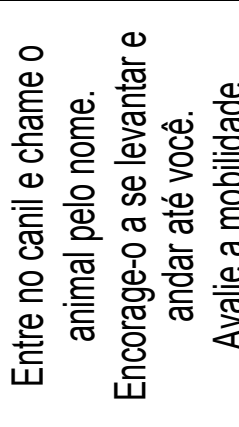 } & \multirow{5}{*}{ Mobilidade } & $\begin{array}{l}\text { Recusa-se a se } \\
\text { mover }\end{array}$ & 1,56 \\
\hline & & $\begin{array}{l}\text { Rígido, duro, } \\
\text { inflexível }\end{array}$ & 1.17 \\
\hline & & $\begin{array}{l}\text { Lento ou } \\
\text { relutante para } \\
\text { levantar e sentar }\end{array}$ & 0.87 \\
\hline & & Claudicando & 1.46 \\
\hline & & Normal & 0 \\
\hline \multirow{5}{*}{ 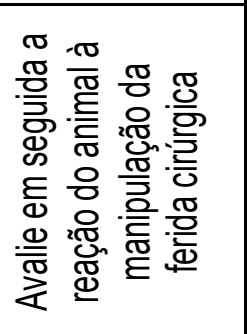 } & \multirow{5}{*}{$\underset{\text { toque }}{\text { Resposta ao }}$} & Chora & 1.37 \\
\hline & & $\begin{array}{l}\text { Foge/tira } 0 \\
\text { corpo fora } \\
\text { antes/ao toque }\end{array}$ & 0.81 \\
\hline & & $\begin{array}{l}\text { Tenta morder } \\
\text { antes/ao toque }\end{array}$ & 1.38 \\
\hline & & $\begin{array}{l}\text { Rosna/guarda } \\
\text { antes/ao toque }\end{array}$ & 1.12 \\
\hline & & Não reage & 0 \\
\hline \multirow{7}{*}{ 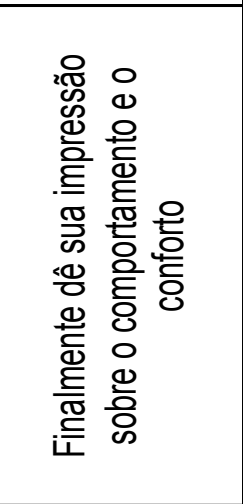 } & \multirow{5}{*}{ Comporta/o } & $\begin{array}{l}\text { Agressivo/ } \\
\text { Deprimido }\end{array}$ & 1.22 \\
\hline & & Desinteressado & 1.56 \\
\hline & & $\begin{array}{l}\text { Nervoso, } \\
\text { ansioso, } \\
\text { medroso }\end{array}$ & 1.13 \\
\hline & & $\begin{array}{l}\text { Quieto } \\
\text { Indiferente }\end{array}$ & 0.87 \\
\hline & & $\begin{array}{l}\text { Contente/ } \\
\text { Saltitante }\end{array}$ & 0.08 \\
\hline & \multirow{2}{*}{ Conforto } & Desconfortável & 1.17 \\
\hline & & Confortável & 0.00 \\
\hline
\end{tabular}




\section{ANEXO I}

\section{ESCALA PARA AVALIAÇÃO DE CLAUDICAÇÃO}

(MONK ET AL; 2006)

\begin{tabular}{|c|c|}
\hline 1 & Nenhuma claudicação é detectada. \\
\hline 3 & $\begin{array}{c}\text { Claudicação intermitente em alguns passos, com descarga de peso } \\
\text { completa. }\end{array}$ \\
\hline 4 & $\begin{array}{l}\text { Sempre usa o membro afetado para caminhar com uma } \\
\text { claudicação leve detectada. }\end{array}$ \\
\hline 5 & $\begin{array}{l}\text { Sempre usa o membro afetado porém com descarga de peso } \\
\text { parcial e claudicação evidente. }\end{array}$ \\
\hline 6 & Apoio intermitente ao andar \\
\hline & Não apoia o membro ao andar \\
\hline
\end{tabular}

ESCALA PARA AVALIAÇÃO DE CLAUDICAÇÃO / MARCHA (HUDSON ET AL; 2004)

\begin{tabular}{l|c|}
\hline $\mathbf{0}$ & Ausente \\
\cline { 2 - 3 } 2 & Intermitente \\
\cline { 2 - 3 } 3 & Contínua e discreta \\
\cline { 2 - 3 } 4 & Contínua e moderada \\
\cline { 2 - 3 } & Intensa \\
\hline
\end{tabular}

